\title{
PATRÍCIA ZAMBERLAN
}

O uso de indicadores antropométricos na

$$
\text { avaliação nutricional seqüencial de crianças e }
$$

adolescentes gravemente doentes internados em

\section{uma Unidade de Terapia Intensiva}

Dissertação apresentada à Faculdade de Medicina da Universidade de São Paulo para obtenção do título de Mestre em Ciências

Área de concentração: Pediatria

Orientador: Prof ${ }^{\mathrm{a}}$. Dr ${ }^{\mathrm{a}}$. Thelma Suely Okay

SÃO PAULO

2009 
Dados Internacionais de Catalogação na Publicação (CIP)

Preparada pela Biblioteca da

Faculdade de Medicina da Universidade de São Paulo

reprodução autorizada pelo autor

\section{Zamberlan, Patrícia}

O uso de indicadores antropométricos na avaliação nutricional sequencial de crianças e adolescentes gravemente doentes internados em uma Unidade de Terapia Intensiva / Patrícia Zamberlan. -- São Paulo, 2009.

Dissertação(mestrado)--Faculdade de Medicina da Universidade de São Paulo. Departamento de Pediatria.

Área de concentração: Pediatria.

Orientadora: Thelma Suely Okay.

Descritores: 1.Unidades de terapia intensiva pediátrica 2.Avaliação nutricional 3.Antropometria 4.Criança 5.Adolescente

USP/FM/SBD-201/09 
Se, a princípio, a idéia não é absurda, então não há esperança para ela.

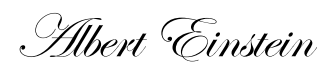




\section{Dedicatória}

Aos meus pais, Paulo (in memorian) e Tereza, por todo sacrifício para que eu pudesse estudar, e pelo exemplo de vida baseado na ética, honestidade e preocupação com o próximo.

À minha família, que está comigo em todos os momentos, nas alegrias e nas dificuldades.

À minha irmã Renata pela amizade e cumplicidade durante toda a vida.

À minha querida amiga Joice De Martino Benedini por tudo... 


\section{AGRADECIMENTOS}

À Prof ${ }^{\mathrm{a}}$. Dr ${ }^{\mathrm{a}}$. Thelma Suely Okay, pela confiança, pelo admirável exemplo de competência e pelo privilégio de tê-la como orientadora.

Ao Prof. Dr. Rubens Feferbaum, idealizador deste estudo e responsável pelas grandes oportunidades profissionais da minha vida.

Ao Dr. Artur Figueiredo Delgado, meu grande orientador, pelo constante apoio científico e incentivo em todos estes anos de trabalho em conjunto na Unidade de Terapia Intensiva Pediátrica e na Equipe Multidisciplinar de Terapia Nutricional do Instituto da Criança.

Ao incansável Prof. Dr. Cláudio Leone, por sua valiosa orientação na análise estatística, pelos ensinamentos e por seus, sempre, providenciais e úteis conselhos.

À Prof ${ }^{\mathrm{a}}$. Dr ${ }^{\mathrm{a}}$. Vera Hermina Kalika Koch, pelo exemplo de entusiasmo profissional e pela oportunidade de trabalho em conjunto.

A toda equipe multidisciplinar da UCINE do Instituto da Criança, com quem tenho aprendido muito durante todos estes anos de trabalho em conjunto; e à Prof ${ }^{a}$. Dr ${ }^{a}$. Maria Esther Jurfest Rivero Ceccon, pelo exemplo maior de competência, dedicação, humildade e generosidade.

Ao Dr. Mário Cícero Falcão pelo incentivo. 
Às nutricionistas do Instituto da Criança, e em especial à minha grande amiga Dinorá Gal Silva, pela inestimável ajuda durante todo o estudo.

À equipe de enfermagem e fisioterapia da Unidade de Terapia Intensiva Pediátrica, pelo grande auxílio para a precisa coleta dos dados.

À bibliotecária Mariza Umetsu, por todo o apoio na estruturação da bibliografia e pela amizade.

Aos meus queridos amigos Milene Ribeiro Rocha e Nivaldo Lira Rocha, por todo o auxílio na obtenção da bibliografia.

À minha jovem amiga Viviane Garcia Pinheiro, pelos momentos inesquecíveis de convivência.

Às crianças que compuseram esta casuística. 
Esta tese está de acordo com as seguintes normas, em vigor no momento desta publicação:

Referências: adaptado de International Committee of Medical Journals Editors (Vancouver)

Universidade de São Paulo. Faculdade de Medicina. Serviço de Biblioteca e Documentação. Guia de apresentação de dissertações, teses e monografias. Elaborado por Anneliese Carneiro da Cunha, Maria Julia de A. L. Freddi, Maria F. Crestana, Marinalva de Souza Aragão, Suely Campos Cardoso, Valéria Vilhena. $2^{\mathrm{a}}$ ed. São Paulo: Serviço de Biblioteca e Documentação; 2005.

Abreviaturas dos títulos dos periódicos de acordo com List of Journals Indexed in Index Medicus. 


\section{SUMÁRIO}

Lista de abreviaturas e siglas

Lista de figuras

Lista de quadros

Lista de tabelas

Lista de gráficos

Resumo

Summary

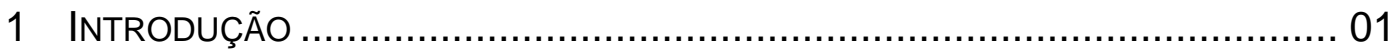

1.1 Desnutrição Hospitalar.............................................................. 02

1.2 Resposta Metabólica no Paciente Gravemente Doente ................... 10

1.2.1 Metabolismo de carboidratos .............................................. 14

1.2.2 Metabolismo de gorduras ...................................................... 16

1.2.3 Metabolismo de proteínas .................................................... 17

1.3 Avaliação nutricional .......................................................... 18

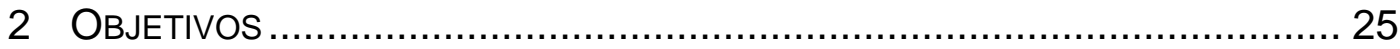

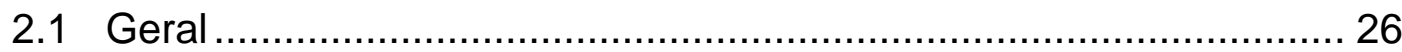

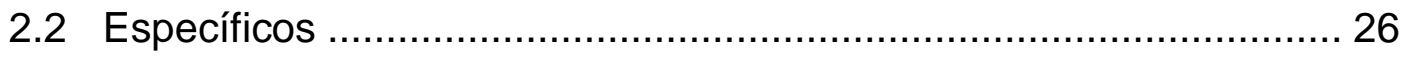

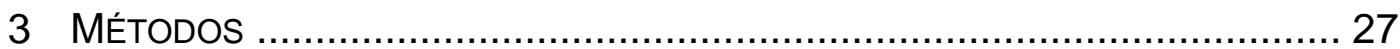

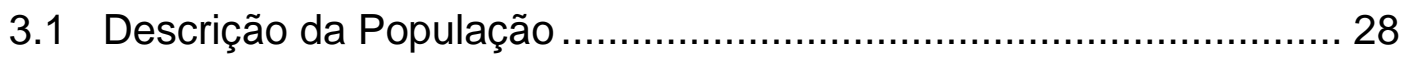

3.1.1 Critérios de inclusão .......................................................... 29

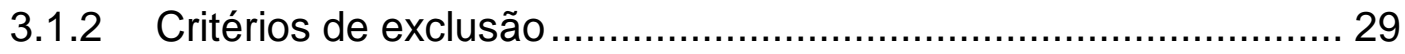

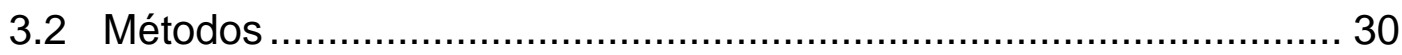

3.2.1 Avaliação geral ................................................................. 30

3.2.2 Avaliação nutricional antropométrica....................................... 30

3.2.3 Avaliação de risco e gravidade ................................................ 33

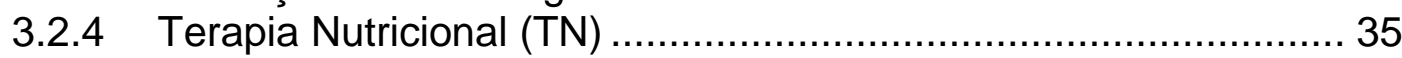

3.2.5 Análise estatística ........................................................... 39

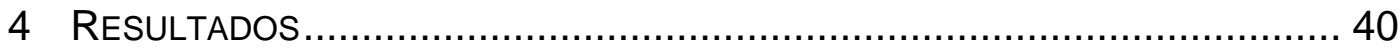

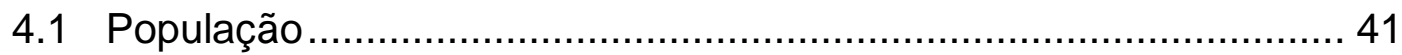

4.2 Avaliação da Gravidade ....................................................... 43

4.3 Avaliação Nutricional Antropométrica ........................................ 44

4.3.1 Avaliação nutricional antropométrica inicial ............................ 44

4.3.2 Avaliação nutricional antropométrica evolutiva........................ 52

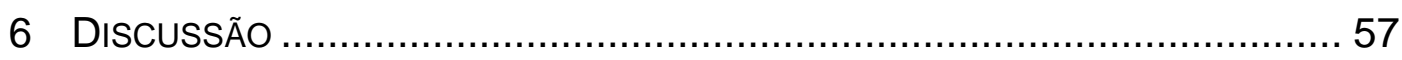

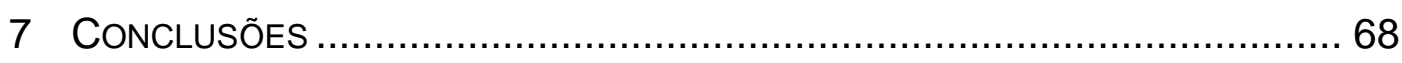

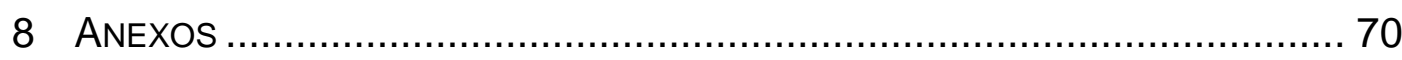

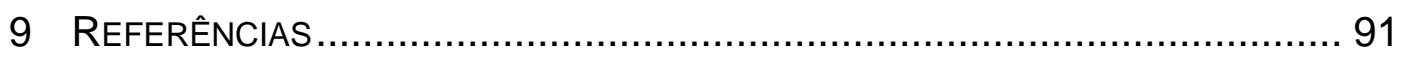




\section{LISTA DE ABREVIATURAS E SIGLAS}

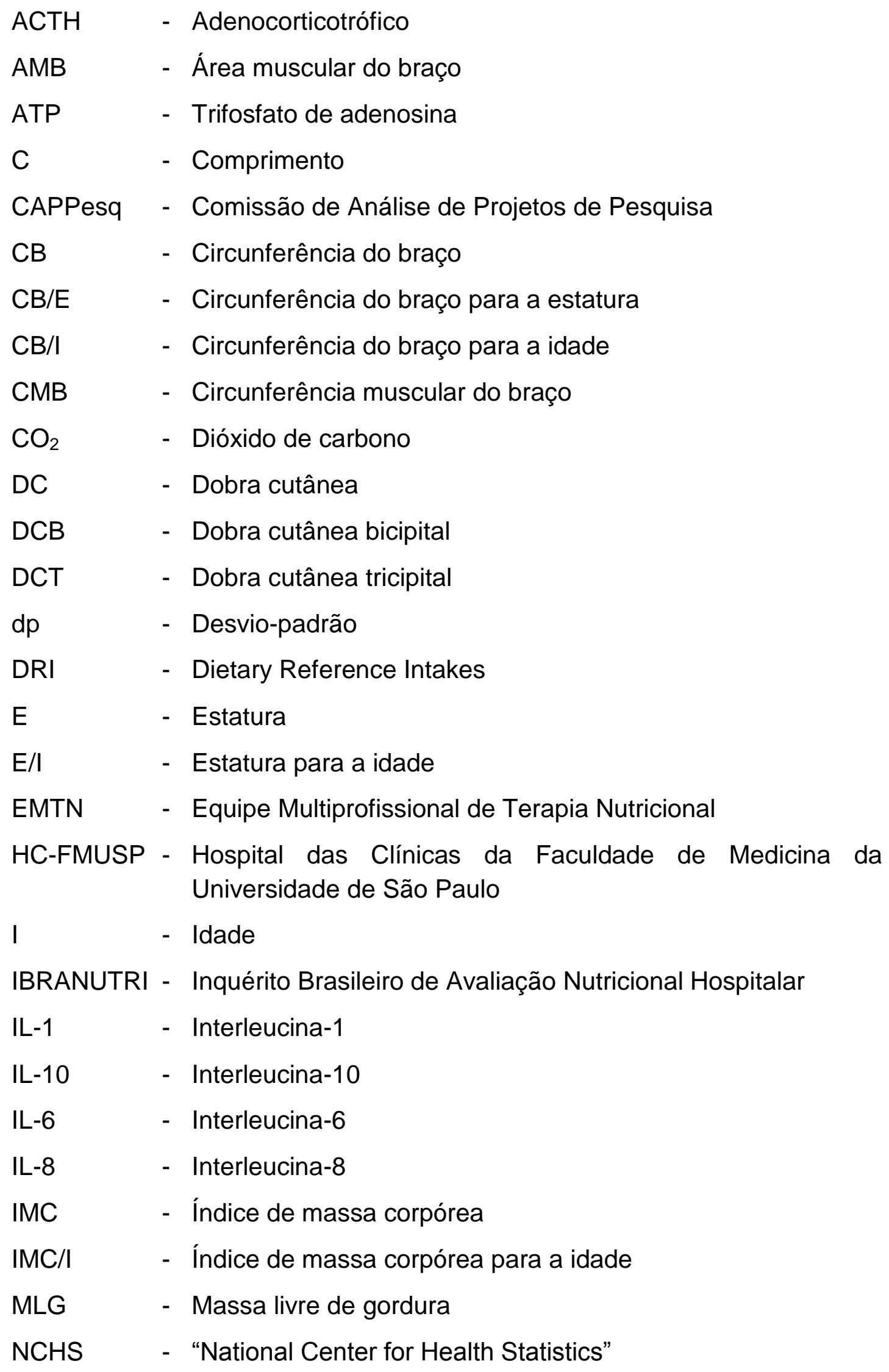




$\begin{array}{ll}\text { OMS } & \text { - Organização Mundial da Saúde } \\ p & - \text { Nível de significância } \\ p & \text { - Percentil } \\ P & \text { - Peso } \\ \text { P/E } & \text { - Peso para a estatura } \\ \text { P/I } & \text { - Peso para a idade } \\ \text { PIM } & \text { - "Paediatric Index of Mortality" } \\ \text { PNDS } & \text { - Pesquisa Nacional de Demografia e Saúde } \\ \text { SBNPE } & \text { - Sociedade Brasileira de Nutrição Parenteral e Enteral } \\ \text { SNG } & \text { - Sonda nasogástrica } \\ \text { SRIS } & \text { - Síndrome da resposta inflamatória sistêmica } \\ \text { TCL } & \text { - Triacilglicerol de cadeia longa } \\ \text { TMB } & - \text { Taxa metabólica basal } \\ \text { TN } & - \text { Terapia nutricional } \\ \text { TNE } & - \text { Terapia nutricional enteral } \\ \text { TNF- } \alpha & - \text { Fator de necrose tumoral alfa } \\ \text { TNP } & - \text { Terapia nutricional parenteral } \\ \text { UTI } & - \text { Unidade de Terapia Intensiva } \\ \text { UTIP } & - \text { Unidade de Terapia Intensiva Pediátrica } \\ \text { Z } & - \text { Z escore }\end{array}$




\section{LISTA DE FIGURAS}

Figura 1 - Alterações no metabolismo basal no decorrer do tempo e de acordo com o tipo de estresse

Figura 2 - Fluxograma de TN do Instituto da Criança do HCFMUSP.... 36

Figura 3 - Metodologia do estudo 38 


\section{LISTA DE QUADROS}

Quadro 1 - Fases de fluxo e refluxo de Cuthbertson ............................. 13

Quadro 2 - Variáveis clínicas do PIM ................................................... 34 


\section{LISTA DE TABELAS}

Tabela 1 - Distribuição das doenças de base (em porcentagem) dos pacientes internados na UTI do Instituto da

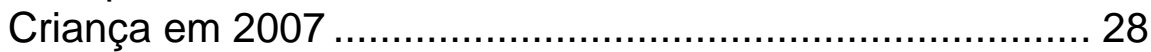

Tabela 2 - Causas de internação na UTIP durante o estudo ................. 43

Tabela 3 - Média ( $\pm d p)$ e mediana dos indicadores antropométricos das crianças avaliadas na UTIP à admissão

Tabela 4 - Freqüência de desnutrição à admissão na UTIP, de acordo com indicadores antropométricos

Tabela 5 - Média ( $\pm d p)$ e mediana dos valores de DCT, AMB e CMB das crianças avaliadas na UTIP à admissão. 45

Tabela 6 - Comparação da mediana de escore $Z$ dos indicadores antropométricos entre 0 grupo de pacientes que evoluiu a óbito e os que receberam alta da UTIP 


\section{LISTA DE GRÁFICOS}

Gráfico 1 - Distribuição por faixa etária das crianças avaliadas na UTIP

Gráfico 2 - Distribuição por sexo das crianças avaliadas na UTIP 42

Gráfico 3 - Evolução das crianças avaliadas na UTIP 42

Gráfico 4 - Correlação entre o escore de gravidade (PIM) e o escore Z de E/l à admissão. 45

Gráfico 5 - Correlação entre o escore de gravidade (PIM) e o escore $Z$ de $P / l$ à admissão.

Gráfico 6 - Correlação entre o escore de gravidade (PIM) e o escore $Z$ de $P / E$ à admissão

Gráfico 7 - Correlação entre o escore de gravidade (PIM) e o escore Z de IMC/I à admissão

Gráfico 8 - Correlação entre o escore de gravidade (PIM) e o escore $Z$ de $C B / E$ à admissão...

Gráfico 9 - Correlação entre o escore Z de E/l e o tempo de internação na UTIP

Gráfico 10 -Correlação entre o escore $Z$ de $P / l$ e o tempo de internação na UTIP

Gráfico 11 -Correlação entre o escore $Z$ de P/E e o tempo de internação na UTIP

Gráfico 12 -Correlação entre o escore $Z$ de $\mathrm{IMC} / \mathrm{I}$ e o tempo de internação na UTIP

Gráfico 13 -Correlação entre o escore $Z$ de CB/E e o tempo de internação na UTIP

Gráfico 14 -Comparação da mediana de escore Z CB/E entre o grupo de pacientes que evoluiu a óbito e os que receberam alta da UTIP.

Gráfico 15 -Comparação dos valores de escore Z E/l obtidos à admissão e no sétimo dia de internação das crianças avaliadas na UTIP 
Gráfico 16 -Comparação dos valores de escore Z P/l obtidos à admissão e no sétimo dia de internação das crianças avaliadas na UTIP.

Gráfico 17 -Comparação dos valores de escore Z IMC/I obtidos à admissão e no sétimo dia de internação das crianças avaliadas na UTIP

Gráfico 18 -Comparação dos valores de escore Z CB/E obtidos à admissão e no sétimo dia de internação das crianças avaliadas na UTIP

Gráfico 19 -Comparação dos valores absolutos de DCT obtidos à admissão e no sétimo dia de internação das crianças avaliadas na UTIP

Gráfico 20 -Comparação dos valores absolutos de CMB obtidos à admissão e no sétimo dia de internação das crianças avaliadas na UTIP

Gráfico 21 -Comparação dos valores absolutos de AMB obtidos à admissão e no sétimo dia de internação das crianças avaliadas na UTIP 


\section{RESUMO}

Zamberlan, P. O uso de indicadores antropométricos na avaliação nutricional seqüencial de crianças e adolescentes gravemente doentes internados em uma Unidade de Terapia Intensiva [dissertação]. São Paulo: Faculdade de Medicina, Universidade de São Paulo; 2009.

Apesar dos avanços tecnológicos, a subnutrição ainda permanece muito prevalente nas unidades de terapia intensiva pediátrica (UTIP). Crianças gravemente doentes apresentam maior risco nutricional devido às modificações no metabolismo intermediário, ocasionadas pelo estresse, e que se caracterizam por aumento da taxa metabólica basal e intenso catabolismo protéico. Estudos mostram que uma intervenção precoce, indicada com base em avaliação nutricional, pode prevenir a subnutrição, bem como, minimizar suas complicações. A avaliação nutricional antropométrica (ANA) de crianças e adolescentes em estado grave é particularmente difícil, e a discussão sobre a sua efetividade torna importante um estudo sobre a utilização de indicadores antropométricos nestes pacientes. Foi realizado um estudo prospectivo para classificar lactentes, pré-escolares, escolares e adolescentes segundo o seu estado nutricional à admissão e durante a internação em UTIP de nível de atendimento terciário, por intermédio de indicadores antropométricos. Foram avaliados 256 pacientes no período de janeiro de 2005 a janeiro de 2006, admitidos na UTIP do Instituto da Criança do Hospital das Clínicas da Faculdade de Medicina da Universidade de São Paulo. A ANA foi realizada nas primeiras 24 horas de admissão e repetida semanalmente até a alta da UTIP e contemplou peso (P), estatura/comprimento (E), circunferência do braço (CB), dobra cutânea tricipital (DCT), circunferência muscular do braço (CMB) e área muscular do braço (AMB). A classificação nutricional foi realizada com o escore $Z$ nas relações peso/idade $(P / I)$, estatura/idade $(E / I)$, peso/estatura (P/E), índice de massa corpórea/idade (IMC/I), circunferência do braço/idade (CB/I) e circunferência do braço/estatura (CB/E), tomando como referencial os valores do National Center for Health Statistics (NCHS, 2000) para crianças maiores de cinco anos, e os da OMS/2006 para as crianças com idade inferior. O grau de gravidade dos pacientes foi determinado pelo escore "Paediatric Index of Mortality" (PIM). As médias, medianas e os desvios-padrão do escore $Z$ foram obtidos em todos os indicadores. Nas crianças avaliadas seqüencialmente, foi realizada análise comparativa entre os resultados obtidos à admissão e o sétimo dia de internação com o teste $\mathrm{t}$ de Student emparelhado, visando identificar modificações dos indicadores antropométricos ao longo do tempo. $O$ estado 
nutricional e suas relações com a gravidade, mortalidade e tempo de internação foram analisados por métodos de correlação e regressão linear, com cálculo do coeficiente de Pearson e da tendência de evolução. A mediana de idade foi de 58 meses e as faixas etárias predominantes foram as de escolares e menores de dois anos, sendo que $84,76 \%$ dos pacientes apresentavam doença de base. A mediana do tempo de internação foi de quatro dias e a do PIM 10,7. Durante a evolução ocorreram 38 óbitos (15\% dos casos). Houve subnutrição à admissão em $37 \%$ dos pacientes pelo indicador Z E/I; $23 \%$ por Z P/l; $12,7 \%$ por Z P/E; $15,6 \%$ por Z IMC/I; 43,2\% por Z CB/l; $23,8 \%$ por Z CB/E; $28,5 \%$ por DCT; $43 \%$ por $\mathrm{CMB}$ e $43 \%$ por AMB. Não houve alteração estatisticamente significante nos indicadores antropométricos durante o período de internação, bem como não houve correlação entre o PIM, o tempo de internação e os indicadores nutricionais utilizados. $\mathrm{O}$ indicador $\mathrm{CB} / \mathrm{E}$ apresentou boa correlação com a mortalidade. Os resultados sugerem que a antropometria foi útil na avaliação nutricional de crianças gravemente doentes em UTIP, sendo as medidas do braço as que puderam melhor discriminar a subnutrição e predizer a mortalidade nestes pacientes à admissão.

Descritores: Unidades de terapia intensiva pediátrica. Avaliação nutricional. Antropometria. Criança. Adolescente. 


\section{SUMMARY}

Zamberlan, P. The use of anthropometric indicators in the nutritional sequential assessment of critically ill children and adolescents admitted to an intensive care unit [dissertation]. São Paulo: Faculdade de Medicina, Universidade de São Paulo; 2009.

Despite technological progress, malnutrition is still very prevalent in the pediatric intensive care unit (PICU) setting. Critically ill children are at higher nutritional risk due to changes in intermediary metabolism caused by stress, which is characterized by increased basal metabolic rate and intense protein catabolism. Nutritional care studies have proposed that early intervention, targeted for nutritional assessment can prevent and minimize the complications of malnutrition. Although the anthropometric nutritional assessment (ANA) is particularly difficult to be performed in critically ill children and adolescents, the study of its effectiveness is of utmost importance for these patients. To classify infants, pre-school children, school children and adolescents according to their nutritional status, on admission and during their PICU stay, a prospective study was carried out. We evaluated 256 patients from January 2005 to January 2006, admitted to the PICU of Instituto da Criança, Hospital das Clínicas da Universidade de São Paulo. ANA was performed within the first 24 hours after admission and was repeated on a weekly basis until discharge from the PICU and included weight $(W)$, height/length $(H)$, arm circumference $(A C)$, triceps skinfold (TS), arm muscle circumference (AMC) and arm muscle area (AMA). The nutritional classification was performed with the Z-score for weight/age (W/A), height/age $(H / A)$, weight/height $(W / H)$, body mass index/age (BMI/A), arm circumference/age $(A C / A)$ and arm circumference/height $(A C / H)$, adopting the reference values of the National Center for Health Statistics (NCHS, 2000) for children over five years, and the WHO/2006 for those under five years old. The severity of the patient's condition was assessed by the score Pediatric Index of Mortality (PIM). Mean values, median and standard deviation of Z-scores were obtained for all indicators. Sequential evolution in children was performed by means of comparative analysis between admission and the seventh day of hospitalization with the paired Student $t$ test, to identify changes in anthropometric indicators over time. Nutritional status and its correlation with severity, mortality and length of hospitalization were analyzed by linear correlation and regression, using the Pearson's coefficient and the evolution trend. The median age was 58 months and the predominant age groups were school children and those under the age of two, and $84.76 \%$ of patients had an ailment. The median period of 
hospitalization was four days and the PIM score was 10.7. There were 38 deaths $(15 \%$ of cases), and malnutrition was found on admission in $37 \%$ of patients by the indicator $Z \mathrm{H} / \mathrm{A}, 23 \%$ for $Z \mathrm{~W} / \mathrm{A}, 12.7 \%$ for $\mathrm{ZW} / \mathrm{H}, 15.6 \%$ for $Z$ BMI $/ A, 43.2 \%$ for $Z$ AC/A , $23.8 \%$ for $Z \mathrm{AC} / \mathrm{H}, 28.5 \%$ for $\mathrm{TS}, 43 \%$ for $\mathrm{AMC}$ and $43 \%$ for AMA. There were no statistically significant changes in anthropometric indices during the period of hospitalization, and there was no correlation between the PIM, the time of hospitalization and the nutritional indicators used. The indicator $\mathrm{AC} / \mathrm{H}$ correlated to mortality. The results suggest that anthropometry is useful in nutritional assessment of critically ill children in the PICU setting, and the arm measurements can predict mortality and malnutrition in these patients at admission.

Descriptors: Pediatric intensive care units. Nutritional assessment. Anthropometry. Child. Adolescent. 
1 INTRODUÇÃO 


\subsection{Desnutrição Hospitalar}

Estado nutricional é o reflexo do equilíbrio entre a ingestão de alimentos e o consumo de energia necessário para manter as funções diárias do organismo. Sempre que existir algum fator que interfira em qualquer uma das etapas deste equilíbrio, os riscos de o indivíduo desenvolver desnutrição são iminentes (Waitzberg et al., 2000).

Segundo Jellife (1966), a desnutrição é definida como estado mórbido secundário a deficiência ou excesso, de um ou mais nutrientes essenciais. $\mathrm{Na}$ verdade, o termo desnutrição significa inadequado estado nutricional quando comparado a determinado referencial. Essa inadequação pode ser caracterizada por excesso (hipernutrição), como no caso da obesidade, ou déficit, que seria chamado de subnutrição.

As causas da desnutrição são freqüentemente complexas e envolvem múltiplos fatores. Porém, qualquer que seja a causa, as conseqüências clínicas podem ser comprometedoras, levando ao aumento da morbidade e da mortalidade.

$\mathrm{Na}$ criança, devido à grande velocidade de crescimento e maior necessidade de substratos energéticos, os efeitos da subnutrição costumam ser mais rápidos e graves, prejudicando o desenvolvimento físico e intelectual (Bruun et al., 1999; Monte, 2000; Pawellek et al., 2008); além de 
aumentar a incidência e gravidade de enfermidades infecciosas e reduzir a capacidade produtiva na idade adulta (Pelletier et al., 1993).

Quanto à sua origem, a desnutrição pode ser primária ou secundária. Quando primária, decorre de inadequação no consumo dietético, sem que haja nenhum outro fator de interferência. Já na desnutrição secundária, existem no indivíduo fatores que alteram a utilização normal de nutrientes, mesmo em vigência de consumo alimentar adequado. Isso pode ocorrer, em condições nas quais os processos de deglutição, digestão, absorção, e excreção encontram-se prejudicados (Marcondes, 1976; Waterlow, 1997).

Nas duas últimas décadas, acompanhando a tendência mundial, observa-se nos países em desenvolvimento, relevante diminuição da prevalência da subnutrição infantil em comparação ao notável aumento dos casos de obesidade. No Brasil, os dados apresentados pelo Ministério da Saúde (MS) da mais recente Pesquisa Nacional de Demografia e Saúde da Criança e da Mulher (PNDS-2006), mostraram que a prevalência da subnutrição, dimensionada pela proporção de crianças com déficit de crescimento, caiu quase pela metade: de $13 \%$ para $7 \%$. Já o excesso de peso em relação à altura foi encontrado em $7 \%$ das crianças avaliadas. Apesar disso, a subnutrição ainda constitui um dos maiores problemas de saúde nas sociedades em desenvolvimento nas quais um terço de todas as crianças menores de cinco anos é acometido (Onis et al., 2000).

Os números são mais alarmantes em menores hospitalizados nos quais a letalidade chega a ser quase dez vezes mais elevada, 
principalmente nos portadores de formas graves de subnutrição quando comparados aos eutróficos (Schofield e Ashworth, 1996).

A subnutrição hospitalar é aquela diagnosticada durante o período de internação. No início do novo milênio, é provavelmente uma das doenças de maior prevalência e incidência (Correia, 2000). O estado nutricional precário entre os pacientes hospitalizados tem sido bem documentado. Em 1996, a Sociedade Brasileira de Nutrição Parenteral e Enteral (SBNPE) propôs estudo multicêntrico, o Inquérito Brasileiro de Avaliação Nutricional Hospitalar (IBRANUTRI), objetivando quantificar a subnutrição hospitalar. Após a avaliação de 4.000 pacientes hospitalizados, o inquérito identificou $48,1 \%$ de pacientes com subnutrição, dos quais 12,6\% apresentavam subnutrição grave. Esta freqüência se elevou para $61,5 \%$ quando os pacientes permaneciam 15 dias ou mais na unidade hospitalar (Waitzberg et al., 2001).

Dentre as principais causas de subnutrição hospitalar podemos citar ingestão inadequada de nutrientes; alteração da absorção de nutrientes; administração de fármacos que interferem no processo nutricional; demora na indicação da terapia nutricional (TN); jejum prolongado para procedimentos; iatrogenia (Waitzberg et al., 2000). A piora do estado nutricional de pacientes hospitalizados resulta em numerosas deficiências funcionais, sendo associada à apatia, letargia, alterações da capacidade intelectual (Correia, 2001), além de perda de peso e de massa muscular; má cicatrização de feridas, alteração dos mecanismos que conferem competência imunológica, aumento da permanência e dos custos hospitalares (Giner et al., 1996; Correia e Waitzberg, 2003). 
Em crianças, vários estudos avaliaram o estado nutricional no âmbito hospitalar. A maioria avaliou a condição nutricional de pacientes à internação e encontrou alta prevalência de subnutrição, com predominância de subnutrição crônica (Merrit e Suskind, 1979; Luengas et al., 1983; Melgar et al., 1986; Leleiko et al., 1986; Alves et al., 1988; Moura, 1990; VasquezGaribay et al., 1993; Hendricks et al., 1995; Romaldini et al., 1996; Hankard et al., 2001; Pawellek et al., 2008).

Avaliação evolutiva durante o período de internação foi realizada por Becerra et al. (1986), no Chile, onde constataram que crianças com o índice peso para a idade $(\mathrm{P} / \mathrm{I})$ ou peso para a estatura $(\mathrm{P} / \mathrm{E})$ inferior a $90 \%$ do referencial apresentaram maior tempo de internação. Além disso, observaram que estas crianças apresentavam valores de circunferência do braço (CB) abaixo do percentil cinco (p5). Ferreira e França (2002), estudando a evolução nutricional de crianças internadas em um hospital universitário de Alagoas (Brasil), encontraram 71,2\% de subnutrição à admissão, condição que não se alterou por ocasião da alta hospitalar. Em uma enfermaria de pediatria geral do Hospital das Clínicas de Porto Alegre, Silveira et al. (2008) encontraram maior prevalência de subnutrição crônica entre aquelas que permaneceram internadas por mais tempo, em casuística de 426 crianças avaliadas.

Apesar dos inúmeros estudos sobre a subnutrição infantil durante a hospitalização, até o momento existem poucos relatos abordando a condição nutricional de crianças gravemente doentes. Sabe-se que o estado crítico exerce impacto significativo sobre o estado nutricional (Dimand e Kallas, 
1999; Hulst et al., 2004), e que a recíproca é verdadeira. As implicações clínicas da subnutrição incluem redução da imunidade (aumento na incidência de infecções) e alterações da mecânica ventilatória, com fadiga e insuficiência respiratória pelo consumo da proteína muscular, podendo contribuir para o aumento das taxas de mortalidade (Fonte et al., 2001; Slone, 2004). Weinsier et al. (1979) e Seltzer et al. (1979) mostraram índices de mortalidade três a 19 vezes maiores em pacientes subnutridos; assim como Ravasco et al. (2002) que encontraram maior mortalidade naqueles pacientes que apresentavam valores de CB inferiores ao $p 5$.

A mortalidade geral nas Unidades de Terapia Intensiva Pediátrica (UTIP) oscila entre seis e $25 \%$ e apesar das implicações clínicas do estado nutricional na evolução clínica, evidentemente, em situações de extrema gravidade, fica difícil evidenciar a influência de somente um fator associado, como a subnutrição, no desfecho clínico destas crianças (Pollack, 1992; Earle et al., 1997). Entretanto, a utilização de marcadores mais sensíveis, como o tempo de permanência em UTI, talvez possa demonstrar com maior clareza a contribuição da subnutrição para a morbi-mortalidade. Pichard et al. (2004) em seu estudo mostraram associação entre a massa corporal magra diminuída e o tempo de internação hospitalar. Observaram que pacientes com quantidade normal ou aumentada de massa livre de gordura (MLG) à admissão hospitalar tiveram tempo de internação significativamente menor (de 4,3 $\pm 7,2$ dias) em relação àqueles com pouca MLG (que ficaram $8,7 \pm 21$ dias internados; $p<0,0001)$. Kac et al. (2000) encontraram resultados semelhantes, com aumento estatisticamente significante $(p=0,026)$ na 
incidência de subnutrição hospitalar de 9,6\% entre meninos hospitalizados por um a cinco dias, para $26,6 \%$ naqueles que permaneceram por tempo superior a 17 dias.

Alguns estudos realizados há mais de 20 anos já demonstraram que 15 a $20 \%$ das crianças admitidas em UTIP apresentavam subnutrição aguda ou crônica.

Pollack et al. (1981) avaliaram o estado nutricional de 50 crianças, nas primeiras 48 horas de internação em UTIP, por período de sete meses. Foram obtidos dados de peso $(P)$, estatura $(E), C B$, dobra cutânea tricipital (DCT), circunferência muscular do braço $(\mathrm{CMB})$ e área muscular do braço (AMB). Utilizando o critério de Waterlow (Waterlow, 1972) constataram que $16 \%$ das crianças apresentavam subnutrição crônica, e outros $16 \%$ apresentavam subnutrição aguda. As reservas musculares e de gordura estavam deficientes (<p5) em $18 \%$ e $20 \%$ de todas as crianças, respectivamente. Em 1982, os mesmos pesquisadores, avaliando nesta mesma unidade 73 crianças (Pollack et al., 1982), encontraram resultados semelhantes, sendo $19 \%$ de subnutrição aguda e 18\% de subnutrição crônica pelo critério de Waterlow (Waterlow, 1972), bem como depleção protéica em $21 \%$ das crianças. Em geral, as menores de dois anos apresentavam pior estado nutricional quando comparadas às maiores de dois anos, e não houve diferença entre o estado nutricional de pacientes com afecções clínicas ou cirúrgicas. Além disso, crianças eutróficas e subnutridas não mostraram diferenças quanto ao tempo de internação. 
Em nosso meio, Leite et al. em 1993, avaliaram em estudo prospectivo realizado em período de cinco meses, 46 crianças portadoras de cardiopatias, neuropatias e pneumopatias, admitidas em UTIP. Utilizando medidas de $\mathrm{P}$ e comprimento $(\mathrm{C})$, constatou pelo critério de Waterlow (Waterlow, 1972) que 65\% das crianças apresentavam algum grau de subnutrição, com predominância da subnutrição crônica em dois terços delas. A taxa de mortalidade foi maior nas crianças subnutridas $(20 \%$ versus 12,5\%), e a subnutrição crônica foi associada à maior incidência de infecção (42\%). Dentre as 22 crianças que foram avaliadas sequencialmente, $36,4 \%$ apresentaram piora do estado nutricional, considerando o índice P/E.

Mota et al. (2002) estudaram a influência da subnutrição na utilização de ventilação mecânica em crianças admitidas em UTIP de um hospital de Porto Alegre e encontraram prevalência de ventilação mecânica no grupo de subnutridos de $36,8 \%$ contra $17,6 \%$ no grupo eutrófico, mostrando que a subnutrição pode influenciar a necessidade de ventilação mecânica e o tempo de permanência da mesma.

Embora sejam poucos os dados recentes sobre a prevalência da subnutrição em pacientes pediátricos em UTI, e principalmente, de sua evolução nutricional ao longo da internação, acredita-se que as porcentagens descritas anos atrás não tenham se modificado, apesar do avanço tecnológico destas unidades (Hulst et al., 2004; Feferbaum et al., 2009).

Hulst et al. (2004) estudaram o estado nutricional de crianças gravemente doentes da admissão até seis meses após a alta da UTI. Foram 
avaliadas 293 crianças, no período de um ano, admitidas na UTI-Neonatal e pediátrica. Nas primeiras 24 horas de admissão, foram realizadas medidas antropométricas - P, C, E, perímetro cefálico (PC), CB, dobra cutânea bicipital (DCB) e DCT; que foram repetidas diariamente nas primeiras duas semanas, depois semanalmente até a sexta semana, e seis meses após a alta hospitalar; bem como escore de gravidade. A subnutrição aguda foi definida como -2 desvios-padrão (dp) para o índice P/l e a crônica -2 dp para E/l. Valores 2 dp abaixo da média para CB foram associados à inadequada reserva protéica, assim como $-2 \mathrm{dp}$ para DCT a deficientes estoques de gordura. À admissão os pesquisadores encontraram $24 \%$ de subnutrição e os recém-nascidos (pré-termo e termo) apresentaram piora da condição nutricional durante o período de internação. Seis meses após a alta da UTI, houve recuperação nutricional de praticamente todas as crianças.

Em nosso meio, Delgado et al. (2008) avaliando a condição nutricional de 1.077 crianças e adolescentes admitidos em UTIP terciária pelo indicador $\mathrm{P} / \mathrm{l}$, diagnosticaram $53 \%$ dos pacientes com subnutrição moderada ou grave. 


\subsection{Resposta Metabólica no Paciente Gravemente Doente}

$\mathrm{O}$ organismo necessita diariamente de energia e nutrientes para a manutenção das funções vitais. A energia despendida para manter as funções teciduais e celulares fundamentais ao organismo é definida como taxa metabólica basal (TMB). Os principais fatores que podem alterar o metabolismo basal são: idade, sexo, composição corpórea, temperatura, distúrbios hormonais, agentes farmacológicos e estresse.

As necessidades de energia são supridas pela degradação de compostos contendo fosfato, principalmente o trifosfato de adenosina (ATP), sendo que os hidratos de carbono, as gorduras e os aminoácidos representam os principais substratos para a sua formação.

Em situações onde ocorre privação de alimentos, o organismo é capaz de se adaptar, o que acarreta alterações metabólicas visando principalmente o fornecimento de energia para as diversas células e tecidos. As reservas de glicogênio são as primeiras a serem utilizadas, com a transformação de glicogênio em glicose (glicogenólise) para a manutenção de níveis glicêmicos adequados, principalmente do cérebro. Após esse período, as proteínas musculares são mobilizadas para fornecer aminoácidos precursores de glicose, por intermédio da gliconeogênese, que ocorre principalmente no fígado. A manutenção da glicemia pela gliconeogênese é extremamente dispendiosa ao organismo, uma vez que as reservas protéicas são limitadas. Com o passar do tempo, para poupar proteínas corporais, ocorre mobilização das gorduras dos adipócitos e utilização de ácidos graxos como fonte energética. O organismo em jejum, 
sem estresse, além de alterar seu metabolismo para a manutenção de substratos energéticos circulantes, diminui seu gasto por meio da redução da TMB, num estado caracterizado como hipometabolismo, onde há menor consumo de energia (economia) e redução do desgaste corporal (Lavery e Glover, 2000; Baudouin e Evans, 2003; Plank e Hill, 2003).

A resposta metabólica do paciente gravemente doente é caracteristicamente acelerada; em geral ocorre aumento da TMB e proteólise (Lavery e Glover, 2000; Slone, 2004). A criança, e particularmente o neonato, são mais susceptíveis aos efeitos deletérios do estresse devido a presença de reservas corporais reduzidas e demandas nutricionais aumentadas (Shew e Jaksic, 1999; Agus e Jaksic, 2002). Vários estudos têm demonstrado aumento de 20 a $25 \%$ no metabolismo basal em crianças sépticas (Chwals, 1994; Coss-Bu et al., 2001; Feferbaum, 2001).

O estado hipermetabólico traduz resposta generalizada do organismo que é iniciada e perpetuada pela combinação de estímulos hormonais, neurais e ambientais e cuja resultante é o aumento progressivo no metabolismo dos hidratos de carbono, gorduras e proteínas, proporcional à gravidade da agressão corpórea (Shew e Jaksic, 1999; Delgado et al., 2000; Agus e Jaksic, 2002). A Figura 1 mostra as alterações descritas no metabolismo basal, ao longo do tempo, em função do grau de estresse (Long et al., 1979). 


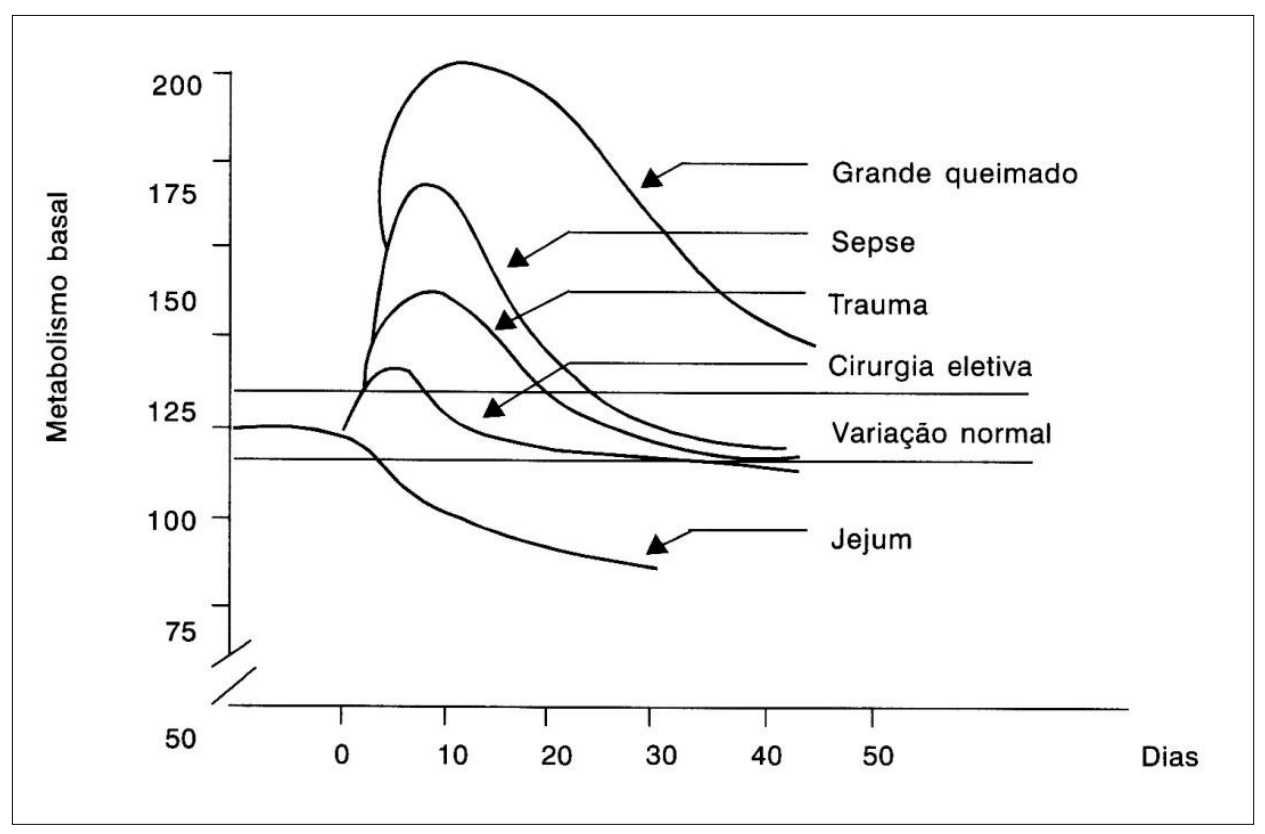

Figura 1 - Alterações no metabolismo basal no decorrer do tempo e de acordo com o tipo de estresse (modificado de Long et al., 1979)

Em geral, a resposta catabólica ao estresse é intensa para poder combater o agente agressor e reparar a lesão tissular. Esta resposta foi didaticamente dividida por Cuthbertson e Tilstone (1969) em duas fases: fase hipodinâmica (ebb phase) e fase hipermetabólica (flow phase). A primeira é iniciada minutos após a injúria e é caracterizada por queda da temperatura corporal, diminuição do débito cardíaco e do consumo de oxigênio. A flow phase que ocorre após compensação hemodinâmica, está associada a aumento do consumo de oxigênio, ativação do sistema imune e indução da produção hepática de proteínas de fase aguda, o que resulta em estado de hipermetabolismo (Hasenboehler et al., 2006). As principais características clínicas e metabólicas das fases de fluxo e refluxo estão descritas no Quadro 1. 


\section{Quadro 1 - Fases de fluxo e refluxo de Cuthbertson}

\begin{tabular}{|l|l|}
\hline \multicolumn{1}{|c|}{ Fase de fluxo (ebb) } & \multicolumn{1}{c|}{ Fase de refluxo (flow) } \\
\hline Hipometabólica & Hipermetabólica \\
Hipotermia & Aumento da temperatura corpórea \\
Catabolismão normal de glicose & Produção aumentada de glicose \\
Hiperglicemia & Catabolismo protéico aumentado \\
Catecolaminas aumentadas & Normo ou hiperglicemia \\
Glicocorticóides aumentados & Catecolaminas normais ou aumentadas \\
Insulina baixa & Glicocorticóides normais ou aumentados \\
Glucagon elevado & Insulina elevada \\
Débito cardíaco baixo & Glucagon normal ou elevado \\
Perfusão tecidual deficiente & Débito cardíaco elevado \\
Fase pré-reanimação & Perfusão tecidual normal \\
\hline
\end{tabular}

A resposta metabólica ao estresse determina instalação de resposta neuroendócrina que induz alterações no metabolismo intermediário que estão intimamente relacionadas à produção de citocinas (Coss-Bu et al, 1998; Lavery e Glover, 2000; Baudouin e Evans, 2003; Chwals, 2005), especialmente a interleucina-1 (IL-1), o fator de necrose tumoral alfa (TNF$\alpha)$, e a interleucina-6 (IL-6).

O entendimento sobre a organização do sistema imune e os fatores que regulam as funções imunológicas tem demonstrado estreita relação entre estado nutricional e imunidade (Keusch, 2003).

Há alguns anos estudos que tentam correlacionar concentrações de citocinas pró-inflamatórias e o estado nutricional têm sido realizados, como o de Delgado (2005) que analisando concentrações séricas das principais citocinas inflamatórias em pacientes gravemente doentes eutróficos e 
subnutridos portadores da síndrome da resposta inflamatória sistêmica (SRIS) e infectados durante a fase aguda e de recuperação em UTIP, encontrou elevação estatisticamente significante nas concentrações de TNF, IL-6, interleucina-8 (IL-8) e interleucina-10 (IL-10) no primeiro dia de estudo, tanto nos pacientes subnutridos como nos eutróficos, sugerindo resposta inflamatória inicial de intensidade semelhante em ambos os grupos. No entanto, os pacientes subnutridos apresentaram elevação estatisticamente significante dos mediadores pró-inflamatórios no décimo dia, o que sugere persistência da resposta inflamatória neste grupo.

\subsubsection{Metabolismo de carboidratos}

A hiperglicemia é reconhecida como uma das conseqüências mais marcantes da reação do organismo ao estresse, e ocorre pelo aumento da produção e redução da utilização de glicose (Baudouin e Evans, 2003).

Após evento traumático, ocorrem alterações hormonais caracterizadas pela liberação dos chamados hormônios contra-reguladores: catecolaminas, glicocorticóides, hormônio do crescimento e glucagon (Baudouin e Evans, 2003; Cartwright, 2004).

O glucagon que tem atividade glicogenolítica e gliconeogênica, promove queda na relação molar insulina/glucagon, favorecendo a liberação de glicose pelo fígado (Wolfe, 1999).

A liberação de IL-1 ativa a secreção do hormônio adenocorticotrófico (ACTH), com conseqüente estímulo para secreção adrenal de glicocorticóides. O aumento do cortisol estimula a gliconeogênese hepática 
(o que acelera a proteólise), diminuindo a secreção de insulina, além de promover resistência à ação periférica da mesma, favorecendo a captação de aminoácidos pelo fígado (promovendo síntese de proteínas de fase aguda).

A supressão da gliconeogênese por infusão exógena de glicose é pouco efetiva em pacientes sob estresse; com manutenção do catabolismo muscular protéico (Wolfe, 1999; Agus e Jaksic, 2002, Baudouin e Evans, 2003; Plank e Hill, 2003), da intolerância à glicose e da hiperglicemia.

A oferta adequada de energia é essencial para prover substratos suficientes para as funções metabólicas do organismo, principalmente, durante a fase aguda da doença. O excesso de energia ("overfeeding"), particularmente à custa de glicose, pode ser deletério ao paciente resultando em lipogênese, aumento da produção de dióxido de carbono $\left(\mathrm{CO}_{2}\right)$, esteatose e disfunção hepática (Joosten et al., 1999; Briassoulis et al., 2000; Coss-Bu et al., 2001; Turi et al., 2001; Kan et al., 2003). Por outro lado, quantidades inadequadas de energia e nutrientes (underfeeding) podem resultar em subnutrição, que está associada à diminuição da imunocompetência, aumento do risco de infecções e aumento da morbidade e mortalidade (Briassoulis et al., 2000; Slone, 2004). 


\subsubsection{Metabolismo de gorduras}

Embora a mais importante conseqüência dos desvios metabólicos ocorridos após o estresse seja a perda de massa protéica muscular para servir de substrato a gliconeogênese, a reserva lipídica tem se mostrado outra importante fonte energética para o paciente em estado grave (Chioléro et al., 1997; Joosten et al., 1999; Agus e Jaksic, 2002; Baudouin e Evans, 2003).

Durante o estresse a lipólise está aumentada (Wolfe, 1999; Coss-Bu et al., 2001) e a lipogênese diminuída, apesar da hiperglicemia e hiperinsulinemia presentes. A hipersecreção e a hiperatividade dos hormônios contra-reguladores e a diminuição da relação insulina/glucagon são estímulos potentes para esta condição.

O metabolismo lipídico sofre também importante influência de mediadores da resposta inflamatória. O TNF- $\alpha$ estimula a síntese hepática de triacilgliceróis e lipoproteínas, inibindo a lipase lipoprotéica, acarretando hipertrigliceridemia (Berberoglu, 2001). Há diminuição da atividade da carnitina com menor aproveitamento dos triacilgliceróis de cadeia longa (TCL). 


\subsubsection{Metabolismo de proteínas}

As alterações observadas no metabolismo protéico são desencadeadas por uma série de fatores hormonais e inflamatórios em conjunto, em especial o aumento dos níveis séricos de glicocorticóides, IL$1 \beta$, IL-6 e TNF- $\alpha$.

Ocorre proteólise intensa a fim de disponibilizar aminoácidos para a produção de energia e síntese hepática de proteínas de fase aguda; o que acarreta grande perda muscular (Agus e Jaksic, 2002; Plank e Hill, 2003; Hasenboehler et al., 2006). Conseqüentemente ocorre balanço nitrogenado negativo devido tanto à síntese protéica diminuída, como à degradação aumentada (Nandi et al., 2002). As principais fontes de aminoácidos para a gliconeogênese são a alanina e a glutamina.

A recomendação de ingestão de proteínas em maior quantidade em crianças em estado grave foi baseada no alto "turnover" protéico nesta população, quando comparado ao de crianças sadias (Coss-Bu et al., 2001). Alguns estudos têm mostrado que a ingestão protéica necessária para manter o balanço nitrogenado em pacientes em estado grave depende do grau de estresse e da magnitude da resposta inflamatória (Coss-Bu et al., 1998; Curley e Castillo, 1998; Joosten et al., 1999).

O balanço nitrogenado positivo resulta de ingestão adequada de energia e proteínas. Em pacientes em estado grave a supressão da proteólise é deficitária mesmo quando proteínas e energia são supridas de acordo com o recomendado. É observada melhora do balanço nitrogenado nestes pacientes, porém a custa do aumento da síntese protéica (Coss-Bu et al., 2001). 


\subsection{Avaliação nutricional}

Sabe-se hoje que o uso de intervenções nutricionais, terapia nutricional enteral (TNE) e/ou parenteral (TNP), pode reduzir o impacto da subnutrição que ocorre freqüentemente em pacientes portadores de doenças crônicas e estados hipermetabólicos (Stratton e Elia, 2007).

O objetivo principal da TN no paciente gravemente doente é fornecer quantidades adequadas de energia, macro e micronutrientes; a fim de evitar a subnutrição durante internação em UTI. Particularmente, as crianças são mais susceptíveis aos efeitos do estresse metabólico, por apresentarem menor porcentagem de gordura corporal e massa muscular em relação a adultos; além de maiores requerimentos de energia. A implementação precoce de TN adequada pode influenciar a morbidade e a mortalidade destes pacientes, e a utilização de protocolos de fornecimento de nutrientes de forma programada e monitorizada pode melhorar a qualidade dessa terapia (Martin et al., 2004; Skillman e Wischmeyer, 2008).

A TNP ou TNE está indicada quando o paciente não puder receber as necessidades calóricas e protéicas por via oral por período de tempo suficientemente prolongado. A via enteral é a preferencial por ser mais fisiológica, estar menos associada à disfunção hepatobiliar, estar associada a menor índice de alterações metabólicas, e apresentar custo inferior a TNP. No entanto, na impossibilidade da utilização do trato digestório a TNP pode ser a única alternativa para garantir oferta nutricional adequada durante a internação (Koletzko et al., 2005). A associação de TNP e TNE numa fase inicial, garantindo oferta adequada de macro e micronutrientes, pode ser útil 
nas primeiras 72 horas de internação na UTI ou, quando somente a TNE não for suficiente para suprir as demandas energéticas do paciente (Heidegger et al., 2007 e 2008, de Lorenzo et al., 2008).

A indicação da TN, bem como sua implementação pode ser direcionada pela avaliação do estado nutricional, que diagnostica os pacientes desnutridos e aqueles em risco de desnutrição (Bettler e Roberts, 2000; Sungurtekin et al., 2008; Feferbaum et al., 2009).

Avaliação nutricional é definida como o processo que estabelece o diagnóstico de um indivíduo com respeito às necessidades de macro e micronutrientes, e tem como objetivo estabelecer o prognóstico, direcionar para um tipo de terapia, e acompanhar o curso do tratamento (Delgado e Barbieri, 2005).

Estado nutricional do indivíduo é a resultante do balanço entre a disponibilidade, o consumo, a absorção e as necessidades individuais de nutrientes. Sendo assim, sua determinação deve envolver dados da história clínica, da alimentação, de exame físico, além da análise de indicadores antropométricos e laboratoriais (Bettler e Roberts, 2000; Sungurtekin et al., 2008; Koletzko, 2008; Benedini e Zamberlan, 2009).

Ao estabelecer os métodos de avaliação, devem-se eleger aqueles que melhor detectem o problema nutricional da população em estudo. Além disso, devem ser considerados os custos para sua utilização, o nível de habilidade requerido para aplicá-los adequadamente, o tempo necessário para executá-los e os possíveis riscos para a saúde (Heyward e Stolarczyk, 2000; Correia, 2001). 
A antropometria, que consiste em se realizar uma medida ou um conjunto de medidas em determinado indivíduo e comparar os resultados obtidos com valores de referência, constitui um dos instrumentos mais utilizados para avaliar a condição nutricional de crianças (Zemel et al., 1997; Leone, 1998). As principais medidas são P, E ou C, PC, CB e dobra cutânea (DC).

A partir da aferição do $\mathrm{P}$ e da $\mathrm{E}$ podem ser calculados os três índices antropométricos mais freqüentemente empregados e preconizados pela Organização Mundial de Saúde (OMS): P/I, E/I e P/E. Com base nestes índices, algumas classificações nutricionais foram propostas:

- Classificação de Gómez (Gómez, 1946) - trata-se de classificação centrada na intensidade da subnutrição e mantém-se como a mais empregada em crianças de até dois anos de idade. Baseada na relação $\mathrm{P} / \mathrm{I}$, define quatro categorias:

- Eutrofia: P/l superior a 90\% do p50 do padrão de referência.

- Desnutrição de 1ํ grau: P/l entre 76 e 90\% do p50 do padrão de referência.

- Desnutrição de $2^{\circ}$ grau: P/l entre 60 a 75\% do p50 do padrão de referência.

- Desnutrição de 3o grau: P/l inferior a 60\% do p50 do padrão de referência.

- Classificação de Waterlow (Waterlow, 1972) - baseia-se nas relações de $E / I$ e $P / E$, definindo quatro possibilidades:

- Não desnutrido: E/I superior a 95\% e P/E superior a $90 \%$ do p50 do padrão de referência. 
- Emagrecido ("wasted", desnutrição aguda): E/l superior a 95\% e P/E inferior ou igual a $90 \%$ do $p 50$ do padrão de referência.

- Retardo de crescimento ("stunted", desnutrição pregressa): E/I inferior ou igual a $95 \%$ e P/E superior a $90 \%$ do $p 50$ do padrão de referência.

- Retardo de crescimento com emagrecimento ("wasted and stunted", desnutrição crônica): E/l inferior ou igual a 95\% e P/E inferior ou igual a $90 \%$ do $p 50$ do padrão de referência.

- Classificação da OMS (WHO, 1995): são consideradas desnutridas todas as crianças cujos P/I, E/I e P/E estiverem abaixo de -2dp do p50 do padrão de referência, considerando-se desnutridas graves as classificadas abaixo de -3dp.

As medidas de $\mathrm{CB}$, DCT e AMB também são úteis para avaliar a condição nutricional da criança, especialmente as alterações de composição corpórea. A quantidade de gordura subcutânea e de massa muscular é indicadora de reservas calóricas e protéicas, respectivamente (Bettler e Roberts, 2000; Benedini e Zamberlan, 2009). Os padrões mais utilizados de CB e DCT são os publicados por Frisancho (1999).

Nos pacientes gravemente doentes as avaliações nutricional e metabólica são particularmente difíceis, principalmente na fase inicial da internação, onde as alterações hemodinâmicas e metabólicas tornam as medidas antropométricas e os dados laboratoriais de difícil interpretação (Ravasco et al., 2002; Sungurtekin et al., 2008). No caso do peso, por exemplo, a variabilidade diária devido a fatores não nutricionais como 
fluidos, edema, desidratação e conteúdo gastrointestinal pode afetar a qualidade da medida, bem como as relações que consideram seu valor como P/l e P/E (Ravasco et al., 2002; Hulst et al., 2004; Ista e Joosten, 2005). Esta é uma das razões pelas quais é importante conhecer as mudanças de composição corpórea e não apenas mudanças de P (Wells e Fewtrell, 2008; Lee e Gallagher, 2008).

No entanto, consideradas as limitações da medida de P, o índice P/E pode ser útil na avaliação do paciente em estado grave, uma vez que identifica quadro de subnutrição que ocorre em curto espaço de tempo. Visto que $\circ \mathrm{P}$ se correlaciona tanto com as reservas de gordura quanto de proteínas do organismo, sua queda em relação à E mostra depleção destas reservas, característica do paciente em estresse metabólico (Bettler e Roberts, 2000; Delgado e Barbieri, 2005).

Além de $P, E$ e suas relações, medidas de circunferências e DC têm sido utilizadas para avaliar e monitorizar alterações da composição corpórea. As medidas musculares dos membros são usadas primariamente para se obter mensuração da quantidade e da taxa de variação da proteína muscular esquelética. $O$ cálculo da quantidade de músculo do membro requer apenas duas medidas: a circunferência do membro e a DC correspondente (Heyward e Stolarczyk, 2000). A CB é o parâmetro nutricional antropométrico recomendado pela OMS para estimativa da proteína muscular esquelética total (Onis et al., 1997), e representa a somatória das áreas constituídas pelo tecido ósseo, muscular e gorduroso do braço; sendo possível derivar a $\mathrm{CMB}$ e a $\mathrm{AMB}$ por intermédio de relações matemáticas: 
$\mathrm{CMB}=\mathrm{CB}-(\mathrm{DCT} \times 0,314), \mathrm{AMB}=\mathrm{CMB}^{2} / 4 \pi$, que também consideram a DCT. Suas variações indicam alteração nas reservas de massa protéica.

A medida da DC constitui meio para estabelecer indiretamente a massa corpórea de gordura (Bettler e Roberts, 2000). Pelo fato de existirem valores de referência para sua medida, a DCT é a mais utilizada na avaliação da composição corpórea, especialmente em pediatria (Mascarenhas et al., 1998). Além disso, ela se mostra bom indicador das reservas de energia do organismo e se correlaciona satisfatoriamente com a gordura corporal total (Zemel et al., 1997).

A mensuração da DCT e da CB parece ser mais útil para avaliar mudanças que ocorrem em prazo mais longo nas reservas de tecido adiposo e muscular, respectivamente, em pacientes portadores de doenças crônicas ou em TN por período prolongado. Isto porque as medidas pouco se alteram durante a internação na UTI, que geralmente corresponde em curto espaço de tempo, também podendo sofrer influência de fatores não nutricionais, como o edema que ocorre nos pacientes em estado grave por causa da redistribuição corpórea de fluidos (Bettler e Roberts, 2000). Contudo, alguns autores demonstraram que as medidas de braço são melhores indicadoras de subnutrição quando comparadas a P e E (Huang et al., 2000; Ravasco et al., 2002; Israëls et al., 2008), bem como para prognóstico de mortalidade (Ravasco et al., 2002; Soler-Cataluña et al., 2005; Sungurtekin et al.,2008).

Apesar da grande variedade de medidas nutricionais não se dispõe, até o presente, de método de referência ou "gold standard" para se determinar e monitorar o estado nutricional, principalmente no paciente 
gravemente doente (Correia, 2001; Hulst et al., 2004), uma vez que todas as medidas de avaliação podem ser afetadas pela doença ou pelo trauma. No entanto, é consenso que o acompanhamento do estado nutricional dos pacientes em todas as fases da doença (hipermetabolismo, estabilização e recuperação) é de fundamental importância (Delgado e Barbieri, 2005; Delgado et al., 2008). A antropometria por ser método mundialmente empregado, simples, de baixo custo e reprodutível (Leite et al., 1993; Hulst et al., 2004), pode ser de grande valia neste monitoramento.

Com base na discussão sobre a efetividade da avaliação nutricional no paciente em estado grave, este estudo tem como hipótese que a avaliação nutricional antropométrica é útil, podendo ser suficiente para avaliação do estado nutricional de crianças e adolescentes gravemente doentes internados em UTI. 
2 Objetivos 


\subsection{Geral}

Classificar lactentes, pré-escolares, escolares e adolescentes, segundo o seu estado nutricional, à admissão e durante a internação em unidade de terapia intensiva de nível de atendimento terciário, por intermédio de indicadores antropométricos.

\subsection{Específicos}

a) Descrever indicadores de avaliação nutricional antropométrica e selecionar àqueles que melhor se apliquem a esta população de lactentes, pré-escolares, escolares e adolescentes gravemente doentes.

b) Verificar correlação entre o estado nutricional, o escore de gravidade, a mortalidade e o tempo de internação. 
3 Métodos 


\subsection{Descrição da População}

Trata-se de estudo descritivo e prospectivo. A seleção da população foi de conveniência, com análise seqüencial de lactentes, pré-escolares, escolares e adolescentes admitidos na UTIP do Instituto da Criança do Hospital das Clínicas da Faculdade de Medicina da Universidade de São Paulo (HC-FMUSP). Esta unidade tem 15 leitos de tratamento intensivo e é considerada de nível de atendimento terciário, prestando assistência, principalmente, a pacientes portadores de doenças crônicas, com freqüência, acompanhados nos ambulatórios de especialidades da instituição. O censo de 2007 da unidade, de forma semelhante a anos anteriores, mostrou que a maioria dos pacientes internados no ano apresentava doença de base (Tabela 1).

Tabela 1 - Distribuição das doenças de base (em porcentagem) dos pacientes internados na UTI do Instituto da Criança em 2007

\begin{tabular}{lc}
\hline \multicolumn{1}{c}{ Doença } & $\%$ \\
\hline Oncológica & 24,8 \\
Hepatológica & 21,6 \\
Neurológica & 21,2 \\
Respiratória & 13,4 \\
Hematológica & 12,4 \\
Renal & 9,5 \\
Cardiológica & 7,4 \\
Imunológica & 5,3 \\
Gastrintestinal & 2,8 \\
\hline
\end{tabular}


Foram avaliados 256 pacientes no período de janeiro de 2005 a janeiro de 2006. Todos os pais ou responsáveis foram instruídos pelo autor sobre o projeto de pesquisa e assinaram o termo de consentimento livre e esclarecido.

O estudo foi aprovado pela Comissão de Pesquisa e Ética do Instituto da Criança do HC-FMUSP e na Comissão de Análise de Projetos de Pesquisa da FMUSP (CAPPesq, protocolo número 916/04).

\subsubsection{Critérios de inclusão}

Foram incluídos no estudo todos os lactentes, pré-escolares, escolares e adolescentes, internados na UTIP do Instituto da Criança do HCFMUSP, no período de janeiro de 2005 a janeiro de 2006 e que não apresentavam os critérios de exclusão.

\subsubsection{Critérios de exclusão}

Foram excluídos do estudo os seguintes grupos de pacientes:

a) recém-nascidos;

b) aqueles que apresentaram óbito precoce, isto é, anterior à avaliação nutricional de admissão (primeiras 24 horas);

c) crianças cujos pais ou responsáveis não concordaram em participar, após exposição dos objetivos da pesquisa e procedimentos aos quais às mesmas seriam submetidas (consentimento livre e esclarecido). 


\subsection{Métodos}

\subsubsection{Avaliação geral}

Constou de dados do prontuário do paciente:
a) número de registro;
b) data de nascimento;
c) idade;
d) sexo;
e) data de admissão;
f) história da moléstia atual;
g) diagnóstico (s) clínico (s).

\subsubsection{Avaliação nutricional antropométrica}

Foi realizada nas primeiras 24 horas de admissão e repetida semanalmente até a alta da unidade, sempre pelo autor da pesquisa. Contemplou P, E ou C, CB e DCT, e seguiu a padronização proposta por Frisancho (Frisancho, 1974 e 1999).

O foi aferido em balança com escala de precisão, devidamente calibrada antes de cada pesagem.

As crianças maiores de $16 \mathrm{~kg}$ foram pesadas em pé, de costas para a escala da balança ${ }^{1}$ (escala de precisão de $100 \mathrm{~g}$ ), com afastamento lateral dos pés, em posição anatômica com o peso do corpo igualmente distribuído entre ambos os pés. O P dos lactentes foi mensurado em balança própria com escala de precisão de $5 \mathrm{~g}^{2}$.

\footnotetext{
${ }^{1}$ Welmy RI W $200^{\circledR}$

${ }^{2}$ Filizola Baby ${ }^{\circledR}$
} 
Naquelas crianças com impossibilidade de pesagem, a aferição foi feita através da técnica de desconto. Ou seja, a criança foi pesada no colo do avaliador ou do acompanhante, sendo subtraído o peso do mesmo do peso total obtido.

O C foi aferido em crianças até três anos de idade utilizando-se o antropômetro pediátrico com escala de precisão de $0,1 \mathrm{~cm}$. A medida foi realizada com a criança deitada, em superfície plana e reta, com a cabeça e a planta do pé apoiadas no equipamento.

A E foi obtida nas crianças maiores de três anos, com o uso do estadiômetro de madeira com escala de precisão de $0,1 \mathrm{~cm}$. A criança foi mantida em pé, descalçada, com os calcanhares juntos, peso distribuído entre ambos os pés, costas retas, e os braços estendidos ao lado do corpo.

Nas crianças com limitações que impossibilitaram a aferição da E por intermédio dos métodos convencionais (ventilação mecânica, medicações vasoativas, etc.), a mesma foi obtida utilizando-se a medida do comprimento joelho/tornozelo e as equações propostas por Chumlea et al. (1994):

a) meninas brancas $=43,21+(2,15 \times$ joelho/tornozelo $)$;

b) meninas negras $=46,59+(2,02 \times$ joelho/tornozelo $)$;

c) meninos brancos $=40,54+(2,22 \times$ joelho/tornozelo $)$;

d) meninos negros $=39,60+(2,18 \times$ joelho/tornozelo $)$.

Para obtenção da medida a criança foi mantida em posição supina. O comprimento entre o calcanhar e a superfície anterior da perna na altura do joelho (côndilo do fêmur) foi medido com o uso do antropômetro pediátrico. 
Com os dados de $\mathrm{P}$ e $\mathrm{E}$ ou $\mathrm{C}$, foram obtidos os índices P/I, E/I, P/E e o índice de massa corpórea para a idade (IMC/I), este com a fórmula: $\mathrm{IMC} / \mathrm{I}=\mathrm{P}(\mathrm{kg}) / \mathrm{E}^{2}(\mathrm{~m})$.

A CB foi avaliada com o auxílio de fita métrica com graduação oficial de $0,5 \mathrm{~cm}$ de largura, flexível e inelástica. A criança foi mantida com o braço flexionado em direção ao tórax formando ângulo de $90^{\circ}$, para a determinação do ponto médio da distância entre o acrômio e o olécrano. A circunferência foi então medida, exatamente neste ponto, com o braço estendido ao longo do corpo.

Para a obtenção da DCT utilizou-se um adipômetro ${ }^{3}$ com pressão constante de $10 \mathrm{~g} / \mathrm{mm}^{2}$ na superfície de contato. A medida foi realizada na face posterior do braço, paralelamente ao eixo longitudinal, no ponto médio da distância entre o acrômio e o olécrano, destacando-se com o polegar e o indicador esquerdo a gordura subcutânea sobre o tríceps $(a 1 \mathrm{~cm}$ do ponto marcado). Foram efetuadas três medidas consecutivas, sendo considerado o valor médio das leituras.

A CMB e a AMB foram obtidas a partir dos valores de CB e DCT com a aplicação das fórmulas matemáticas:

$$
\mathrm{CMB}(\mathrm{cm})=\mathrm{CB}-(\mathrm{PCT} \times \pi)
$$

$$
\left.\mathrm{AMB}\left(\mathrm{cm}^{2}\right)=\mathrm{CMB}^{2} / 4 \pi\right)
$$

\footnotetext{
${ }^{3}$ Lange Skinfold Caliper - Cambridge Scientific Industries, Cambridge, Md.
} 
O estado nutricional foi classificado, pela determinação do escore Z para $\mathrm{P} / \mathrm{I}, \mathrm{E} / \mathrm{l}, \mathrm{P} / \mathrm{E}$ e IMC/I, CB/I, CB/E, tomando como referencial os valores do "National Center for Health Statistics" (NCHS, 2000) para crianças maiores de cinco anos, e os da OMS/2006 (WHO, 2006) para as menores. O programa utilizado para os cálculos foi o EPI-Info/2000 e o The Who Anthro/2006. Para DCT, CMB e AMB foi determinado o percentil, seguindo o referencial de Frisancho (1999).

\subsubsection{Avaliação de risco e gravidade}

Os modelos de predição de mortalidade são desenvolvidos para encontrar variáveis que predizem a probabilidade de morte em grupos de crianças. Estes modelos são freqüentemente utilizados para mensurar a gravidade da doença, assumindo que crianças com elevado risco de óbito encontram-se em estado mais grave que aquelas que apresentem baixo risco de óbito.

Os pacientes admitidos foram avaliados quanto à gravidade aplicando-se o escore "Paediatric Index of Mortality" (PIM) (Shann et al, 1997); que utiliza modelo de regressão logarítmico, desenvolvido para predizer o risco de morte em crianças em terapia intensiva, baseado em oito variáveis explicativas que são coletadas no momento da admissão na UTI.

As variáveis requeridas para o cálculo deste escore (Quadro 2) foram obtidas dos resultados dos exames iniciais coletados no primeiro dia de internação na UTI e descritos no prontuário do paciente. 
Quadro 2 - Variáveis clínicas do PIM

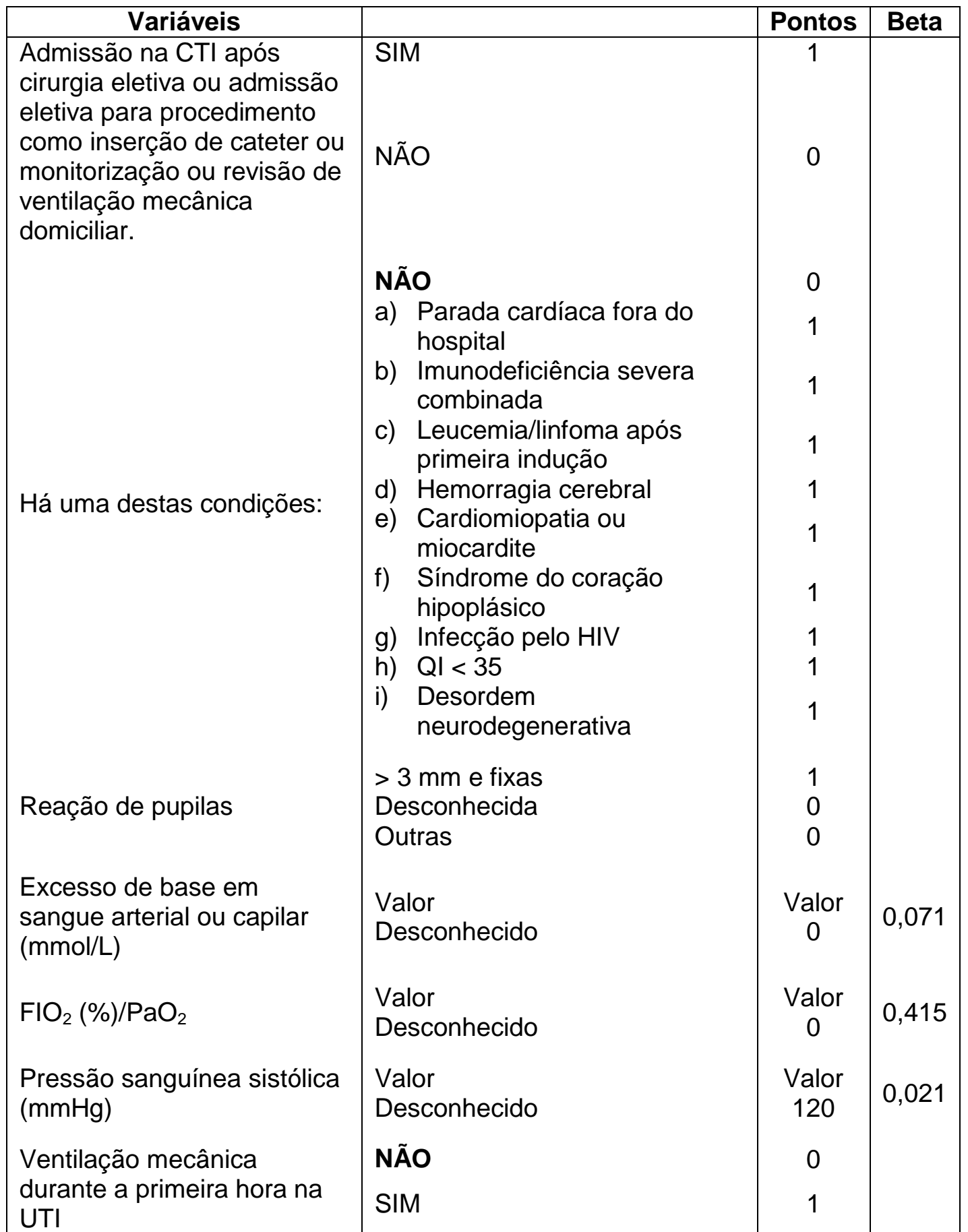

Log $=(-4,873)+($ valores $\times$ Beta $)+(0,021 \times$ (valor absoluto de pressão sanguínea sistólica -120$))+(0,071 \times$ valor absoluto do excesso de base $)+\left(0,415 \times\left(\mathrm{FiO}_{2} / \mathrm{PaO}_{2}\right)\right)$ Risco $=e^{\log /\left(1+e^{\log }\right)}$ 


\subsubsection{Terapia Nutricional (TN)}

A terapia nutricional foi iniciada após estabilização hemodinâmica, em média com 72 horas de internação, e seguiu o fluxograma determinado pela Equipe Multiprofissional de Terapia Nutricional (EMTN) do Instituto da Criança do HC-FMUSP, resumido na Figura 2. O incremento de calorias, macro e micronutrientes, quer por via parenteral ou enteral, foi realizado diariamente de acordo com a tolerância da criança, sempre com o objetivo de atender sua demanda nutricional. 


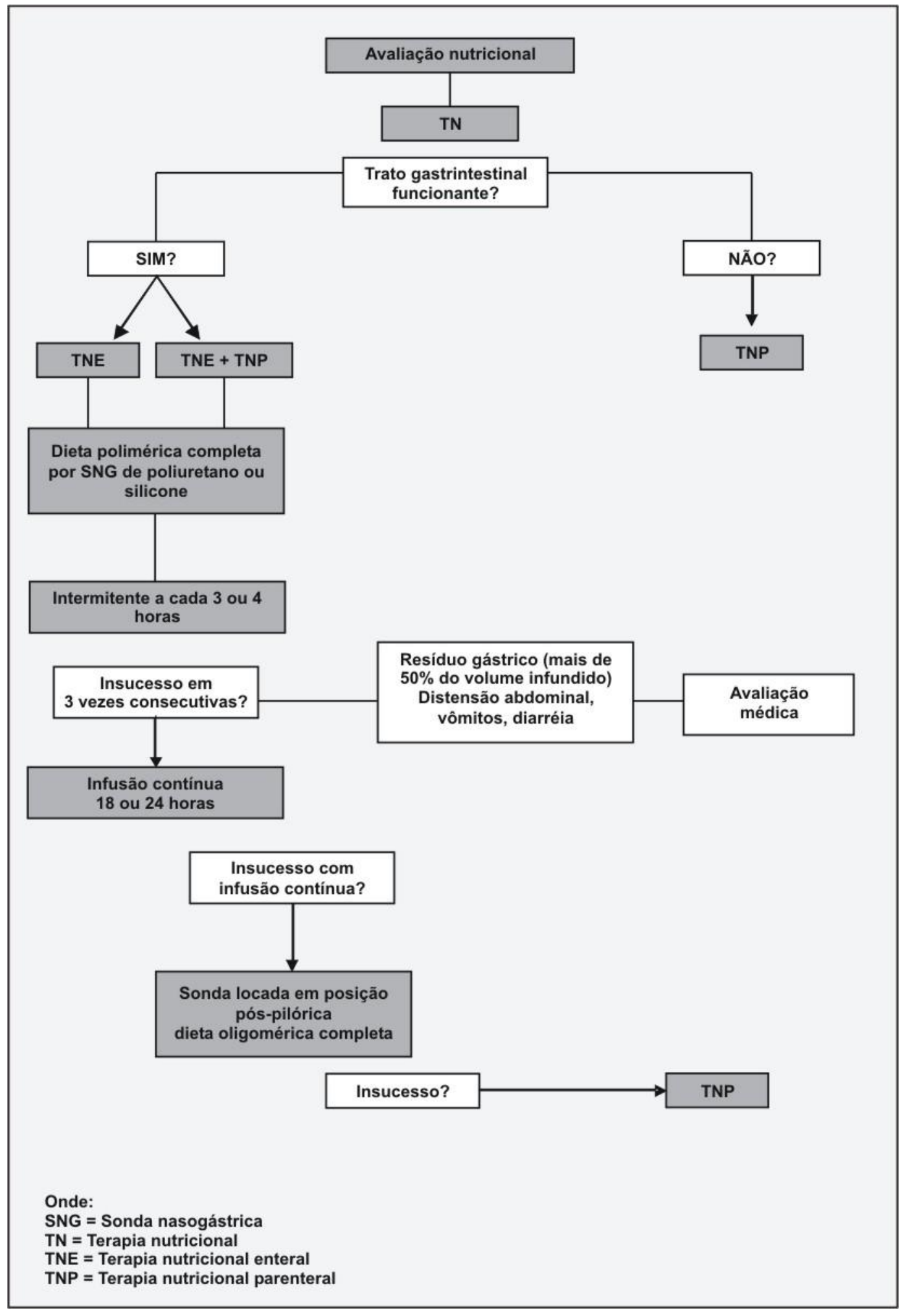

Figura 2 - Fluxograma de TN do Instituto da Criança do HC-FMUSP 
No sétimo dia de internação, que correspondeu à avaliação nutricional seqüencial, a maioria das crianças $(80 \%)$ recebia $\mathrm{TNE}$, sendo $35 \%$ por via oral, $60 \%$ por sonda nasogástrica (SNG) e 5\% por sonda locada na posição pós-pilórica. A TNP exclusiva foi utilizada em 10\% das crianças, em geral com volume e composição que supria as recomendações de macro e micronutrientes sugeridas pelas "Dietary Reference Intakes" (DRI); e a TN mista $($ TNP + TNE) pelos $10 \%$ restantes.

Dentre as crianças cuja dieta foi prescrita por via oral, mais da metade recebeu dieta sem restrição de nutrientes (adequada para a idade) e 35\% receberam dieta com restrição de sódio (hipossódica).

Por via gástrica, foi administrada dieta padronizada do tipo polimérica completa, adequada para cada faixa etária segundo as sugestões das DRI. Por via pós-pilórica optou-se pela utilização de dieta oligomérica completa com densidade calórica de $0,7 \mathrm{Kcal} / \mathrm{mL}$ e 2 a $3 \mathrm{~g} / 100 \mathrm{~mL}$ de proteínas.

A oferta calórica e protéica média, com uma semana de internação, correspondia a $82 \mathrm{Kcal} / \mathrm{kg} / \mathrm{dia} ; 2,7 \mathrm{~g} / \mathrm{kg} / \mathrm{dia}$ de proteínas e relação nitrogênio/calorias 1/160.

A Figura 3 resume os principais aspectos metodológicos do estudo. 


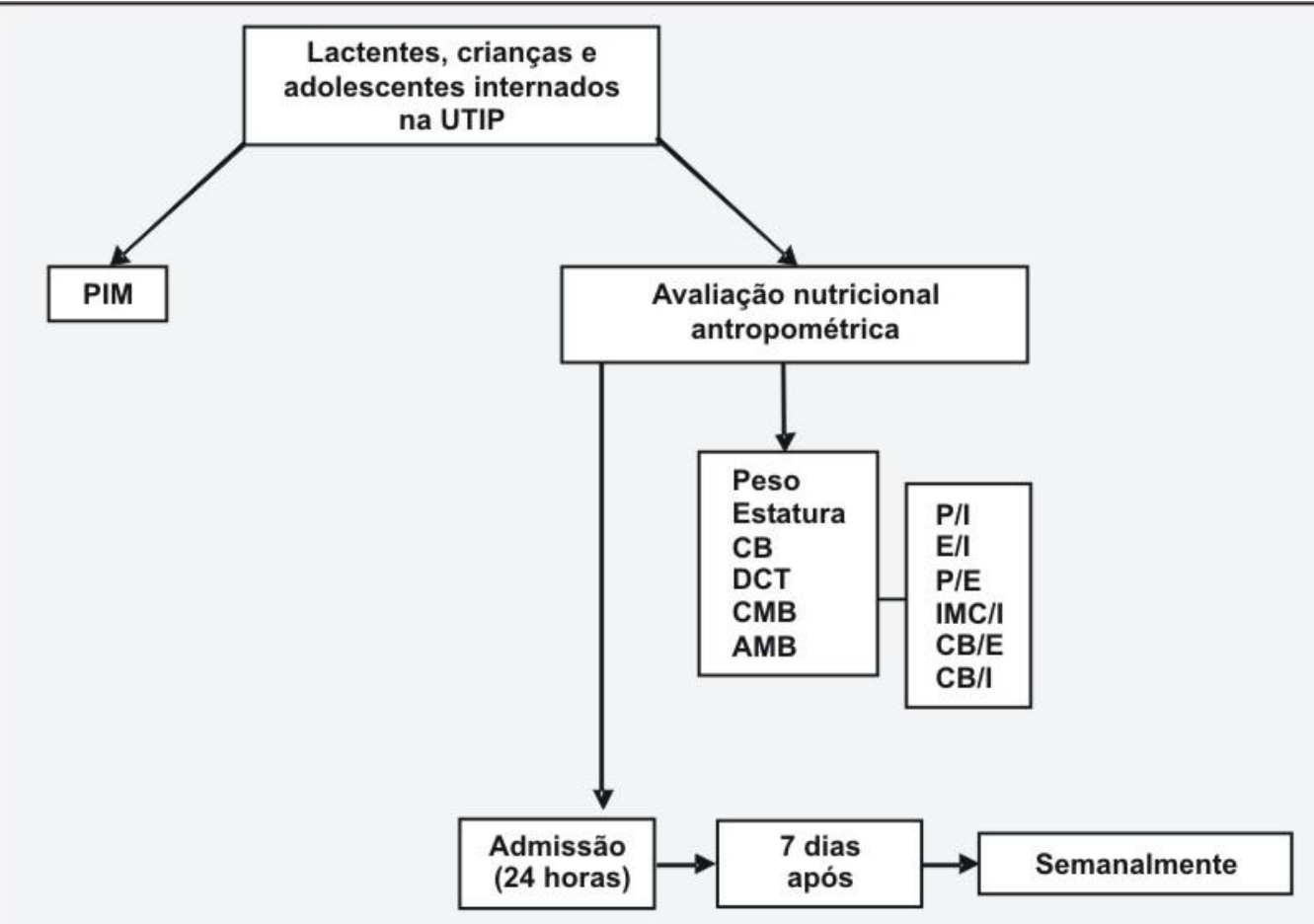

Onde:

AMB = Área muscular do braço

$\mathrm{CB}=$ Circunferência do braço

$\mathrm{CB} / \mathrm{E}=$ Circunferência do braço / estatura

$\mathrm{CB} / \mathrm{I}=$ Circunferência do braço/idade

CBM = Circunferência muscular do braço

DCT = Dobra cutânea tricipital

$\mathrm{E} / \mathrm{I} \quad=$ Estatura/idade

IMC/I = Índice de massa corpórea/idade

PIM = Paediatric Index of Mortality

$\mathrm{P} / \mathrm{I}=$ Peso/idade

$\mathrm{P} / \mathrm{E}=$ Pesolestatura

UTIP = Unidade de terapia intensiva pediátrica

Figura 3 - Metodologia do estudo 


\subsubsection{Análise estatística}

O tamanho da amostra foi baseado em nível de significância de 5\% (p $\leq 0,05)$. O erro beta considerado aceitável foi o de 0,1. A fórmula utilizada para o cálculo das amostras para comparar suas médias foi:

$$
N=\frac{\left\lfloor\left.(Z \alpha-Z \beta) T\right|^{2}\right.}{\Delta}
$$

Os resultados foram tabulados em planilha do tipo Excel ${ }^{\circledR}$. A média, a mediana e o dp do escore Z foram obtidos em todos os indicadores: P/l, E/l, $\mathrm{P} / \mathrm{E}$ e IMC/l, CB/I e CB/E; bem como nos valores absolutos de $\mathrm{CB}, \mathrm{DCT}$, $\mathrm{CMB}$ e $\mathrm{AMB}$.

Das 256 crianças admitidas, 90 foram avaliadas seqüencialmente, pois permaneceram internadas por no mínimo sete dias. Neste grupo foi realizada análise comparativa entre a admissão e o sétimo dia de internação com o teste t de Student emparelhado, visando identificar modificações dos indicadores antropométricos ao longo do tempo. Foram considerados dados estatisticamente significantes aqueles que apresentaram $p<0,05$ e para as medidas de tendência central foi estimado o intervalo de confiança de $95 \%$.

Os indicadores antropométricos do estado nutricional e suas relações com a gravidade, mortalidade e tempo de internação foram analisados por métodos de correlação e regressão linear, com cálculos do coeficiente de Pearson e da tendência de evolução.

Os cálculos foram realizados pelo programa SPSS 12.01. 
4 Resultados 


\subsection{População}

A população estudada foi composta por 256 pacientes, avaliados à admissão na UTI pediátrica, com mediana de idade de 58 meses (4,8 anos).

As faixas etárias predominantes foram as correspondentes a de escolares e a de menores de dois anos, que representaram $61,6 \%$ das internações. Não houve diferenças quanto ao sexo.

Durante a evolução ocorreram 38 óbitos, correspondendo a 15\% dos casos. Os Gráficos 1, 2 e 3 resumem as principais características das crianças avaliadas.

Gráfico 1 - Distribuição por faixa etária das crianças avaliadas na UTIP

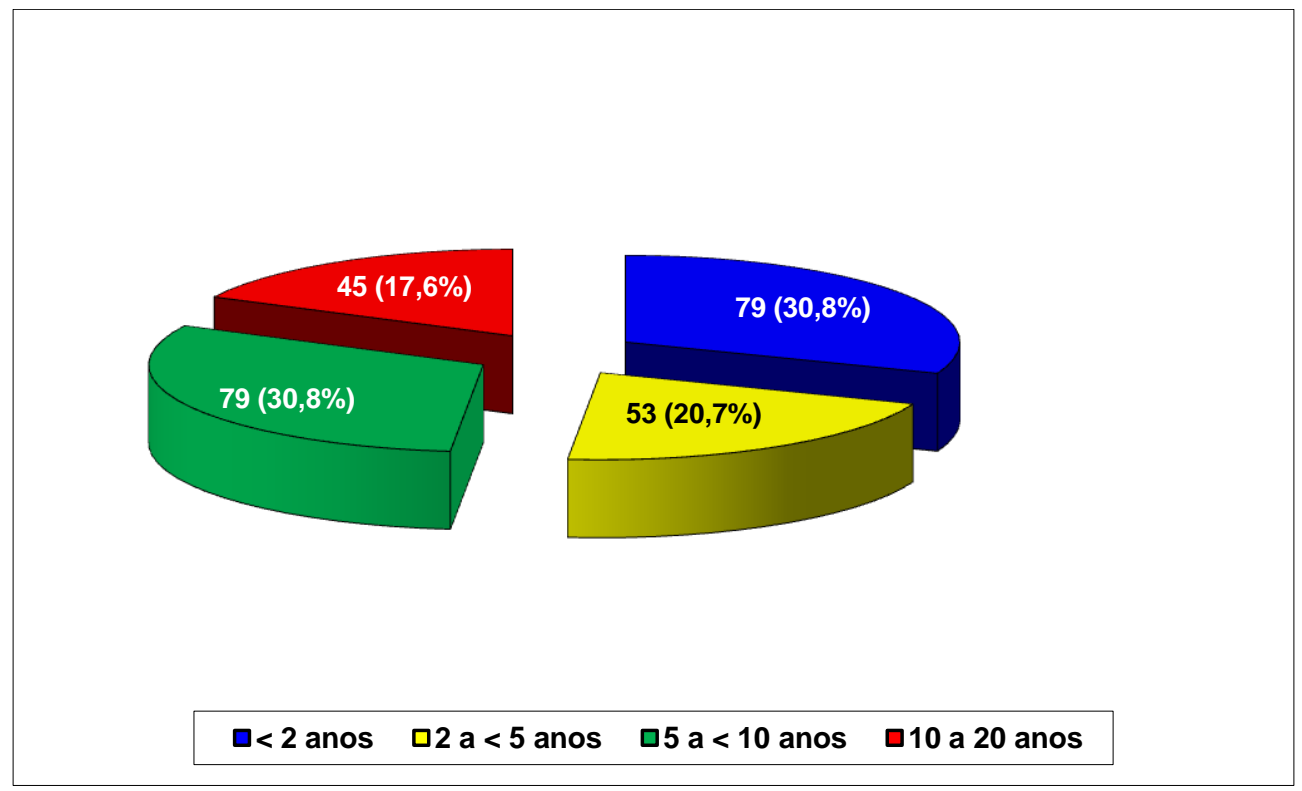


Gráfico 2 - Distribuição por sexo das crianças avaliadas na UTIP

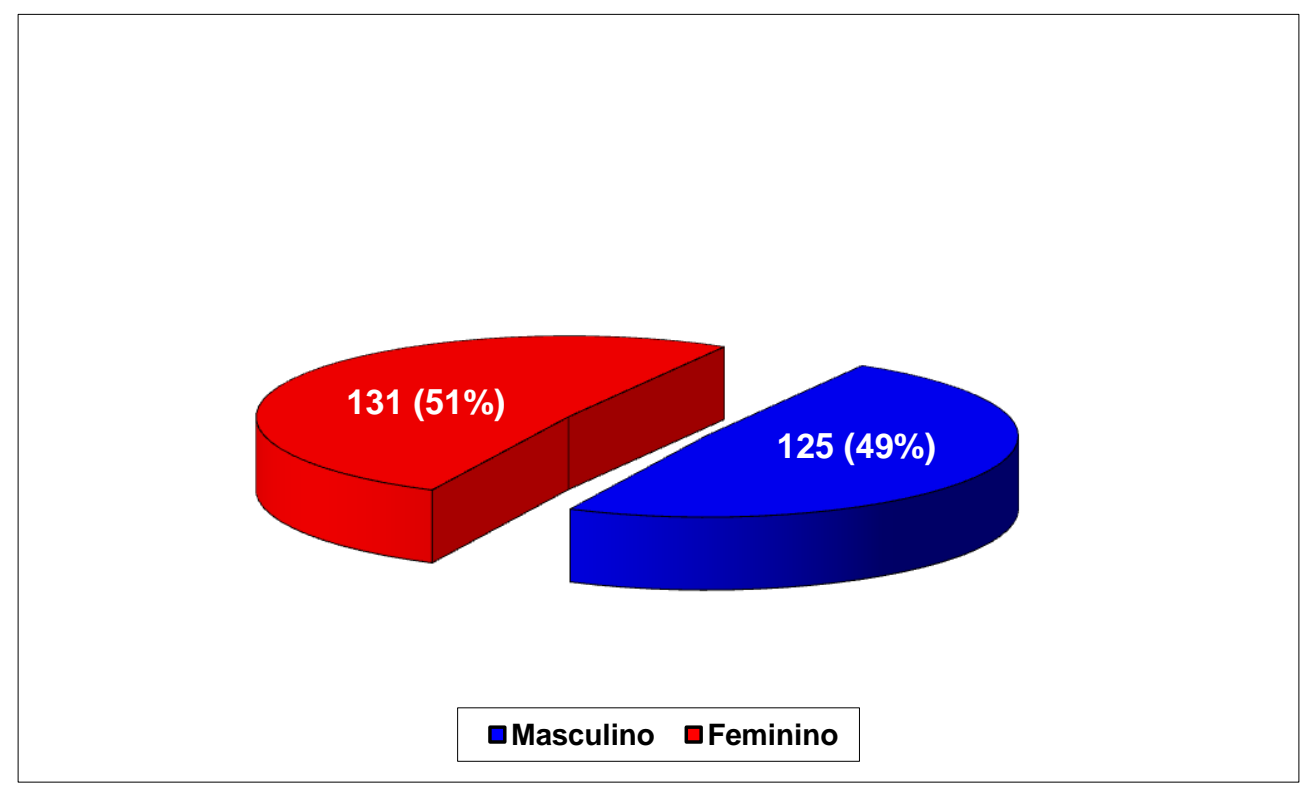

Gráfico 3 - Evolução das crianças avaliadas na UTIP

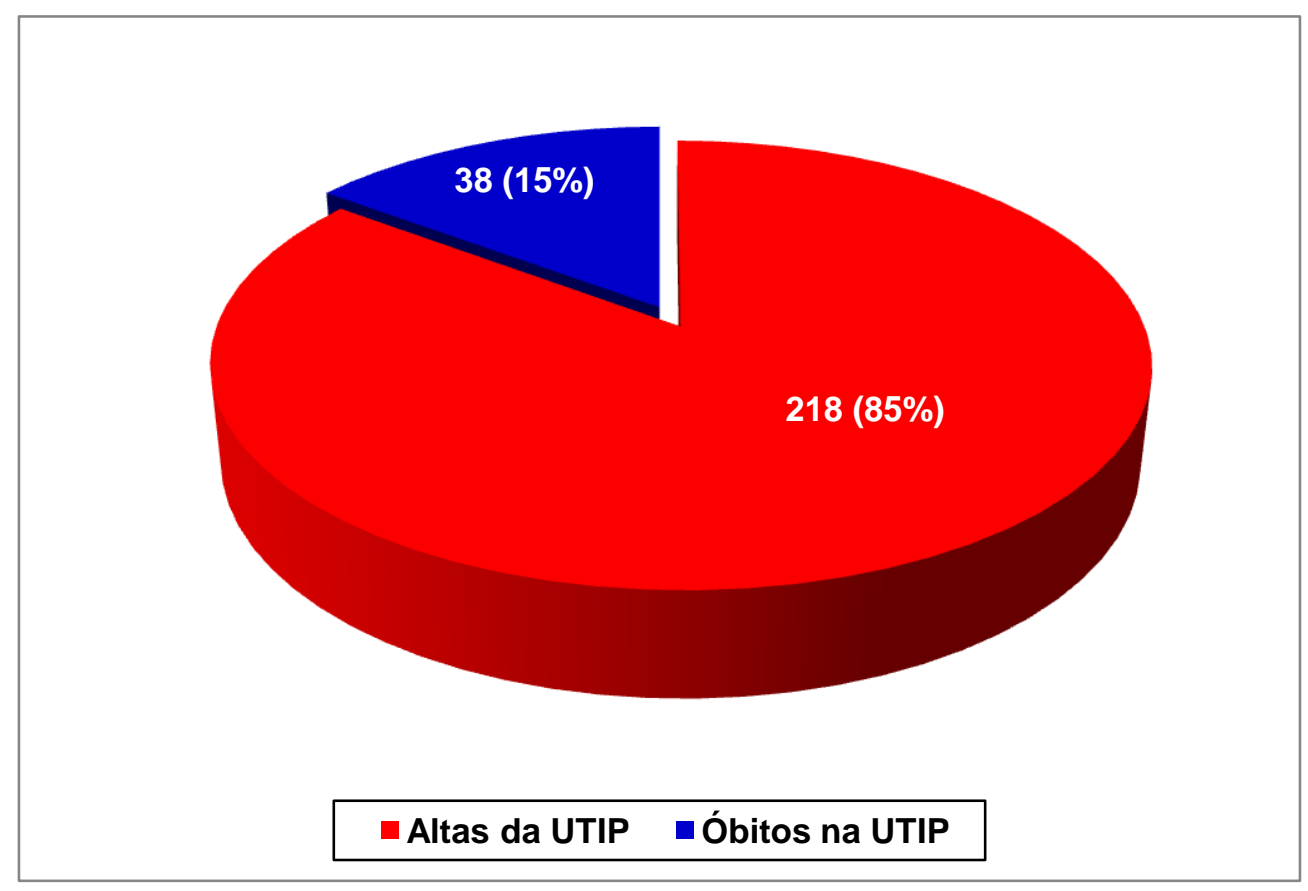

As causas de internação na UTI, todas relacionadas à SRIS, estão descritas na Tabela 2. 
Tabela 2 - Causas de internação na UTIP durante o estudo

\begin{tabular}{lc}
\hline \multicolumn{1}{c}{ Causa } & $\mathbf{N}(\%)$ \\
\hline Infecção sem sepse & $64(25)$ \\
Sepse ou choque séptico & $44(17,2)$ \\
Pós-operatório & $44(17,2)$ \\
Pós-operatório de transplante hepático & $25(9,7)$ \\
Insuficiência respiratória & $14(5,5)$ \\
Mal convulsivo & $5(2,0)$ \\
Outras & $60(23,4)$ \\
Total & $\mathbf{2 5 6}(100)$ \\
\hline
\end{tabular}

Dos 256 pacientes, 217 (84,76\%) apresentavam doenças de base. Dos 64 casos cuja causa de internação foi infecção e dos 44 casos de sepse/choque séptico, sete (11\%) e dez (15,6\%) respectivamente, eram portadores de doença oncológica.

A mediana do tempo de internação na UTI foi de quatro dias.

\subsection{Avaliação da Gravidade}

O escore PIM foi calculado pela autora na UTI, com dados de admissão (disponíveis nos prontuários) dos pacientes ou com os piores valores obtidos nas primeiras 24 horas de internação. A média foi 19,6 ( \pm 21,4), e a mediana foi de 10,7 . 


\subsection{Avaliação Nutricional Antropométrica}

\subsubsection{Avaliação nutricional antropométrica inicial}

A classificação nutricional foi realizada para os 256 pacientes com a utilização do escore Z para P/I, E/I, P/E e IMC/I, CB/I e CB/E (Tabela 3).

Tabela 3 - Média ( $\pm d p)$ e mediana dos indicadores antropométricos das crianças avaliadas na UTIP à admissão

\begin{tabular}{|c|c|c|c|}
\hline & Média & $( \pm d p)$ & Mediana \\
\hline$E / I z$ & $-1,4$ & 1,95 & $-1,4$ \\
\hline$P / I z$ & $-0,8$ & 1,68 & $-0,5$ \\
\hline P/E z & 1,06 & 1,87 & 0,6 \\
\hline IMC/I z & 0,1 & 1,86 & 0,4 \\
\hline $\mathrm{CB} / \mathrm{I} z$ & $-1,6$ & 1,68 & $-1,6$ \\
\hline CB/E z & $-1,0$ & 1,87 & $-1,2$ \\
\hline
\end{tabular}

A Tabela 4 mostra a freqüência de desnutrição à admissão entre as 256 crianças, de acordo com os diferentes indicadores utilizados na triagem antropométrica.

Tabela 4 - Freqüência de desnutrição à admissão na UTIP, de acordo com indicadores antropométricos

\begin{tabular}{lcc}
\hline \multicolumn{1}{c}{ Indicador } & Corte & \% pacientes \\
\hline E/I & $\leq-2 \mathrm{dp}$ & 37,0 \\
$\mathbf{P} / \mathbf{I}$ & $\leq-2 \mathrm{dp}$ & 23,0 \\
$\mathbf{P} / \mathbf{E}$ & $\leq-2 \mathrm{dp}$ & 12,7 \\
IMC/I & $\leq-2 \mathrm{dp}$ & 15,6 \\
CB/I & $\leq-2 \mathrm{dp}$ & 43,2 \\
CB/E & $\leq-2 \mathrm{dp}$ & 23,8 \\
DCT & $\leq p 5$ & 28,5 \\
CMB & $\leq p 5$ & 43,0 \\
AMB & $\leq p 5$ & 43,0 \\
\hline
\end{tabular}


A Tabela 5 mostra os valores médios das mensurações da DCT (avaliação do tecido adiposo), CMB e AMB (avaliação do tecido muscular).

Tabela 5 - Média ( $\pm d p)$ e mediana dos valores de DCT, AMB e CMB das crianças avaliadas na UTIP à admissão

\begin{tabular}{lccc}
\hline & Média & $\mathbf{( \pm d p )}$ & Mediana \\
\hline DCT $(\mathbf{m m})$ & 10,3 & 6,6 & 8,0 \\
AMB $\left(\mathbf{c m}^{2}\right)$ & 14,8 & 7,3 & 13,4 \\
CMB $(\mathbf{c m})$ & 13,4 & 4,1 & 13,0 \\
\hline
\end{tabular}

As figuras subseqüentes mostram a correlação entre o estado nutricional e o escore de gravidade (PIM).

Gráfico 4 - Correlação entre o escore de gravidade (PIM) e o escore Z de E/I à admissão

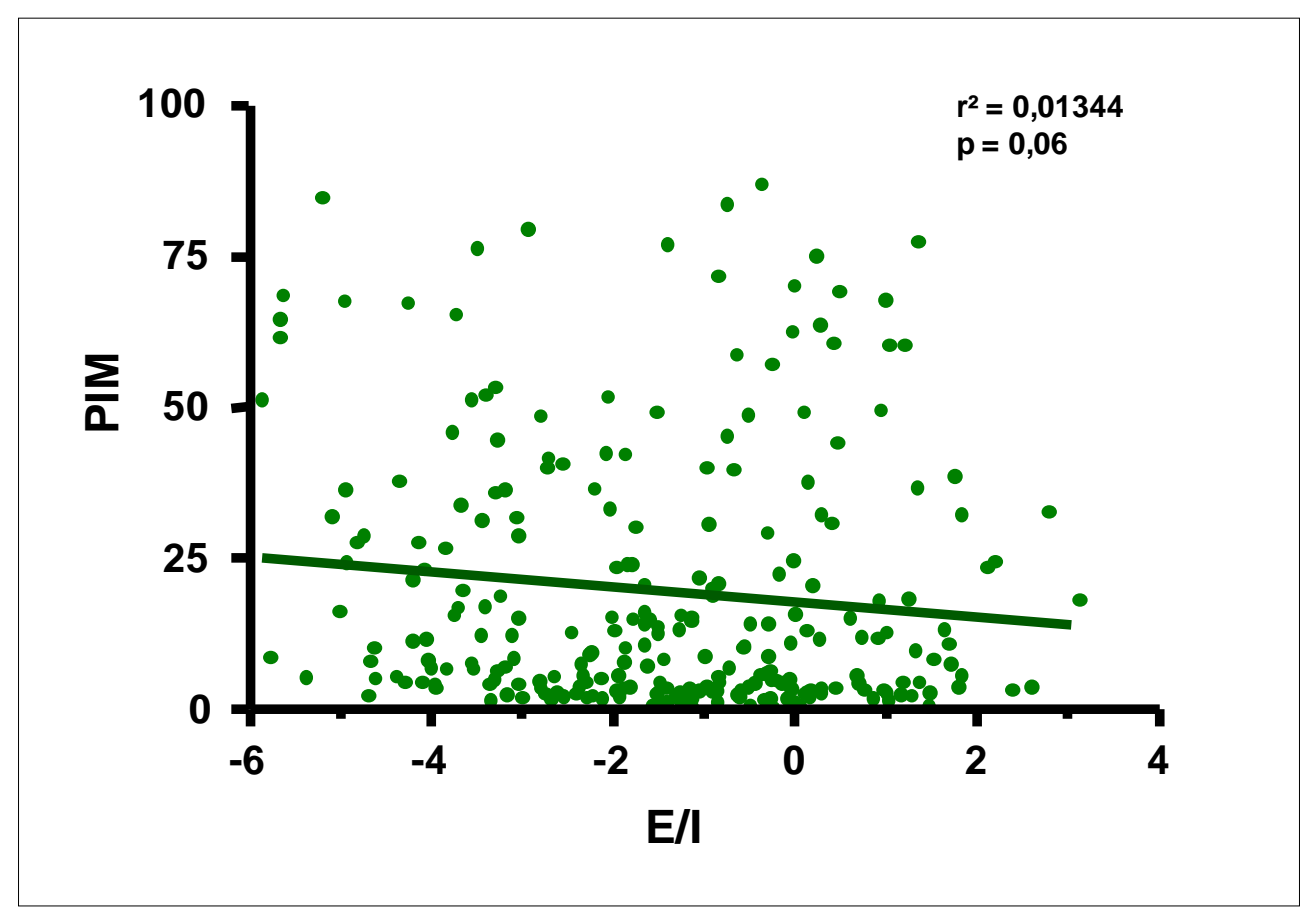


Gráfico 5 - Correlação entre o escore de gravidade (PIM) e o escore Z de $P / I$ à admissão

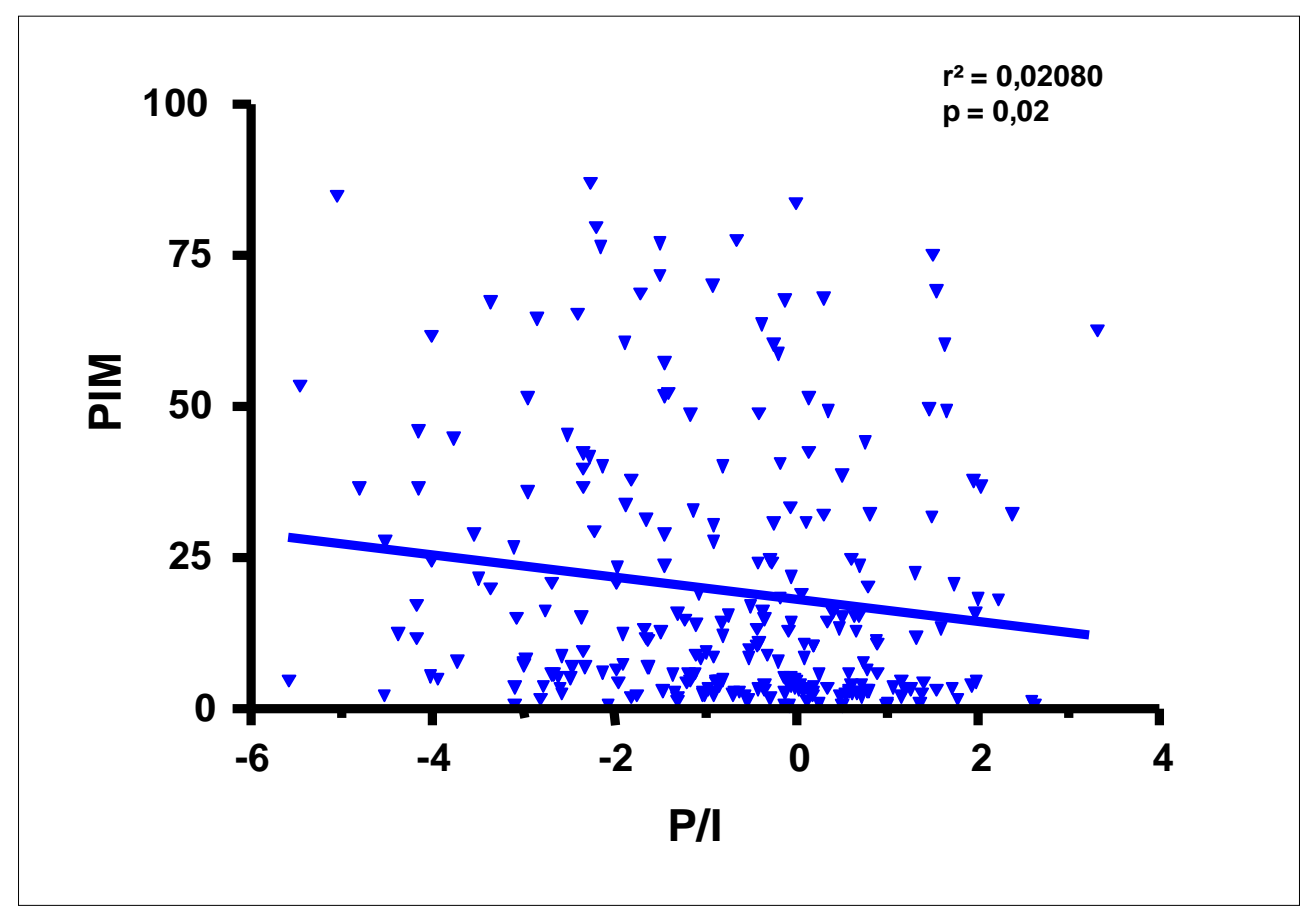

Gráfico 6 - Correlação entre o escore de gravidade (PIM) e o escore Z de $P / E$ à admissão

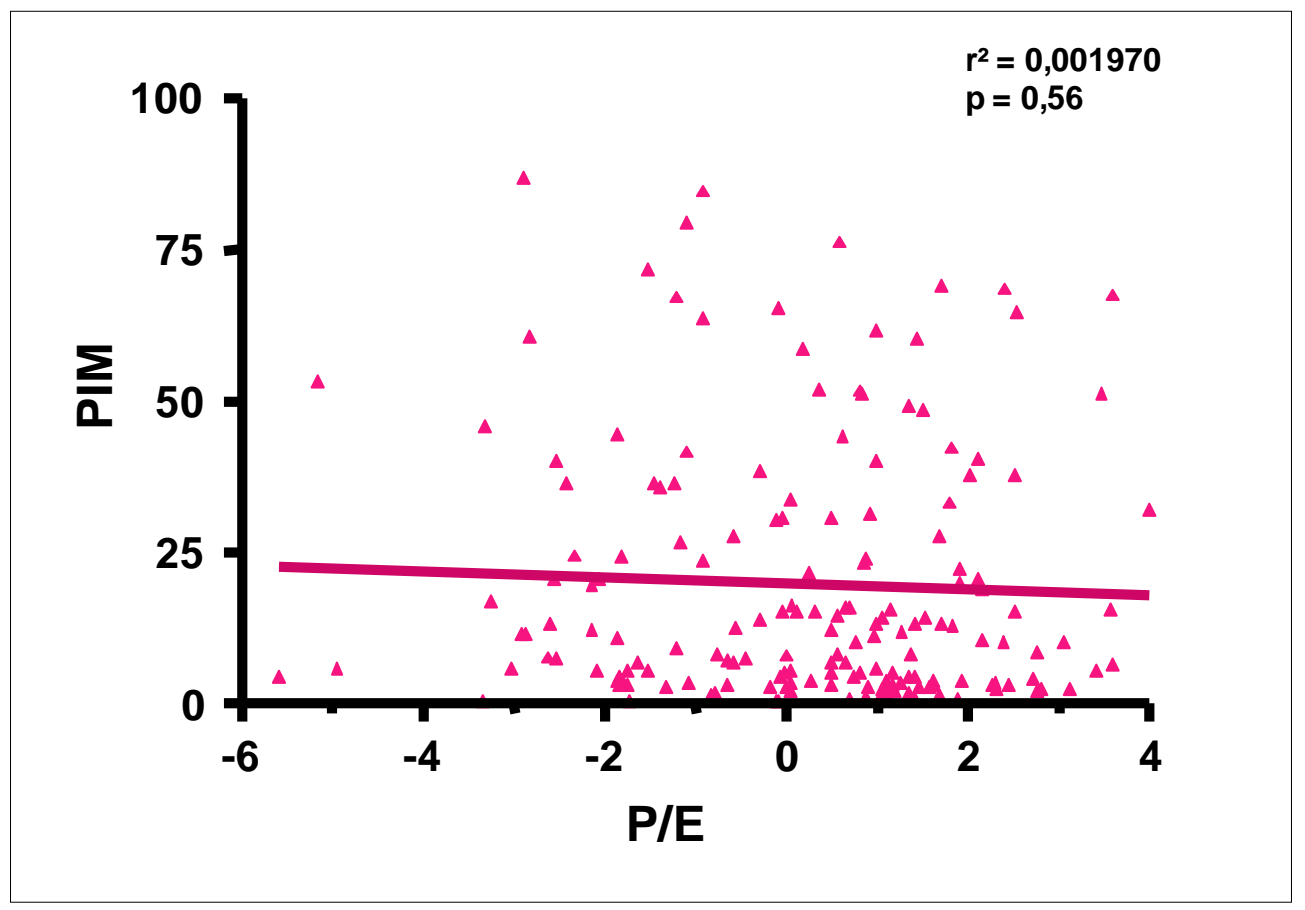


Gráfico 7 - Correlação entre o escore de gravidade (PIM) e o escore Z de IMC/I à admissão

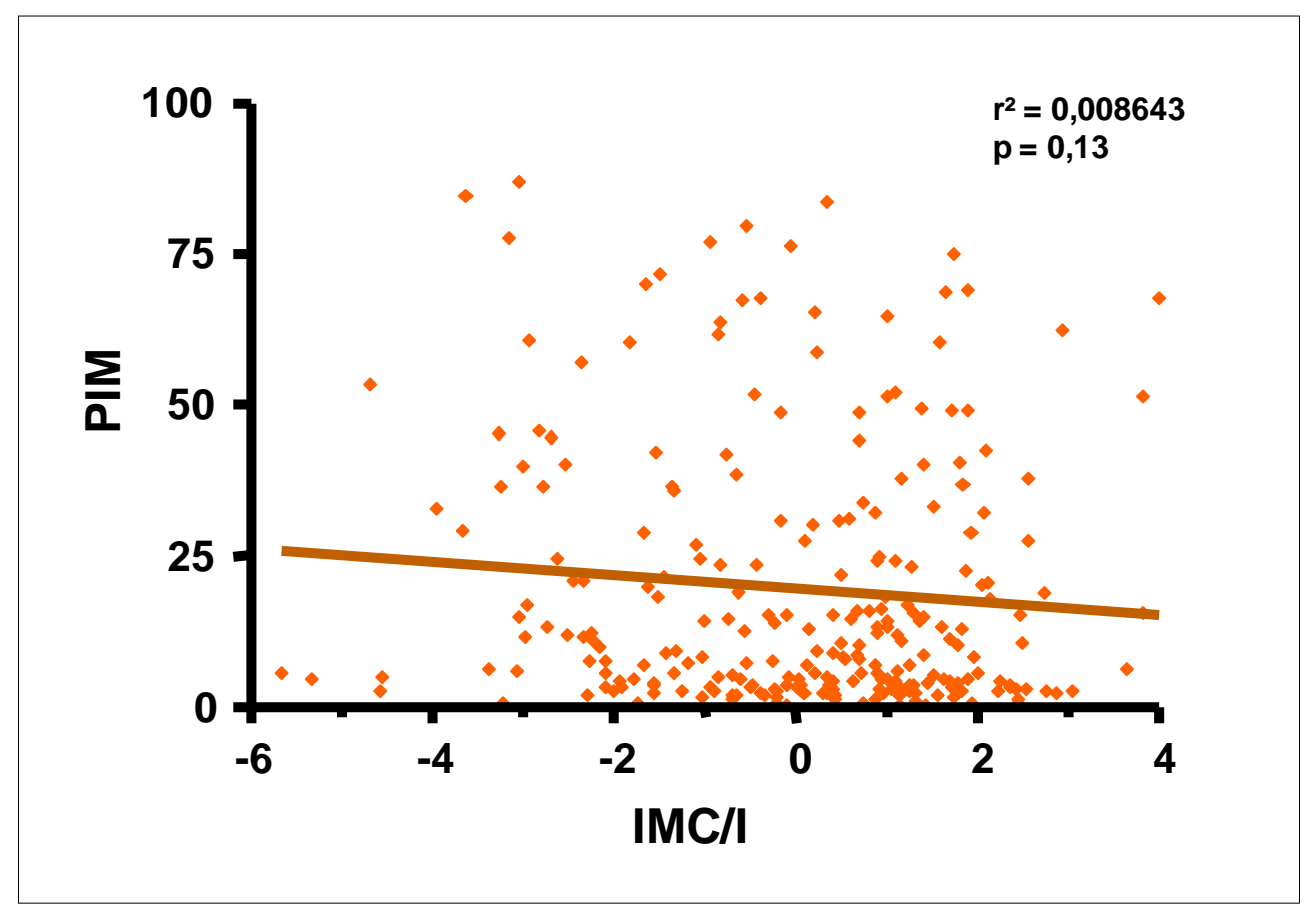

Gráfico 8 - Correlação entre o escore de gravidade (PIM) e o escore Z de $C B / E$ à admissão

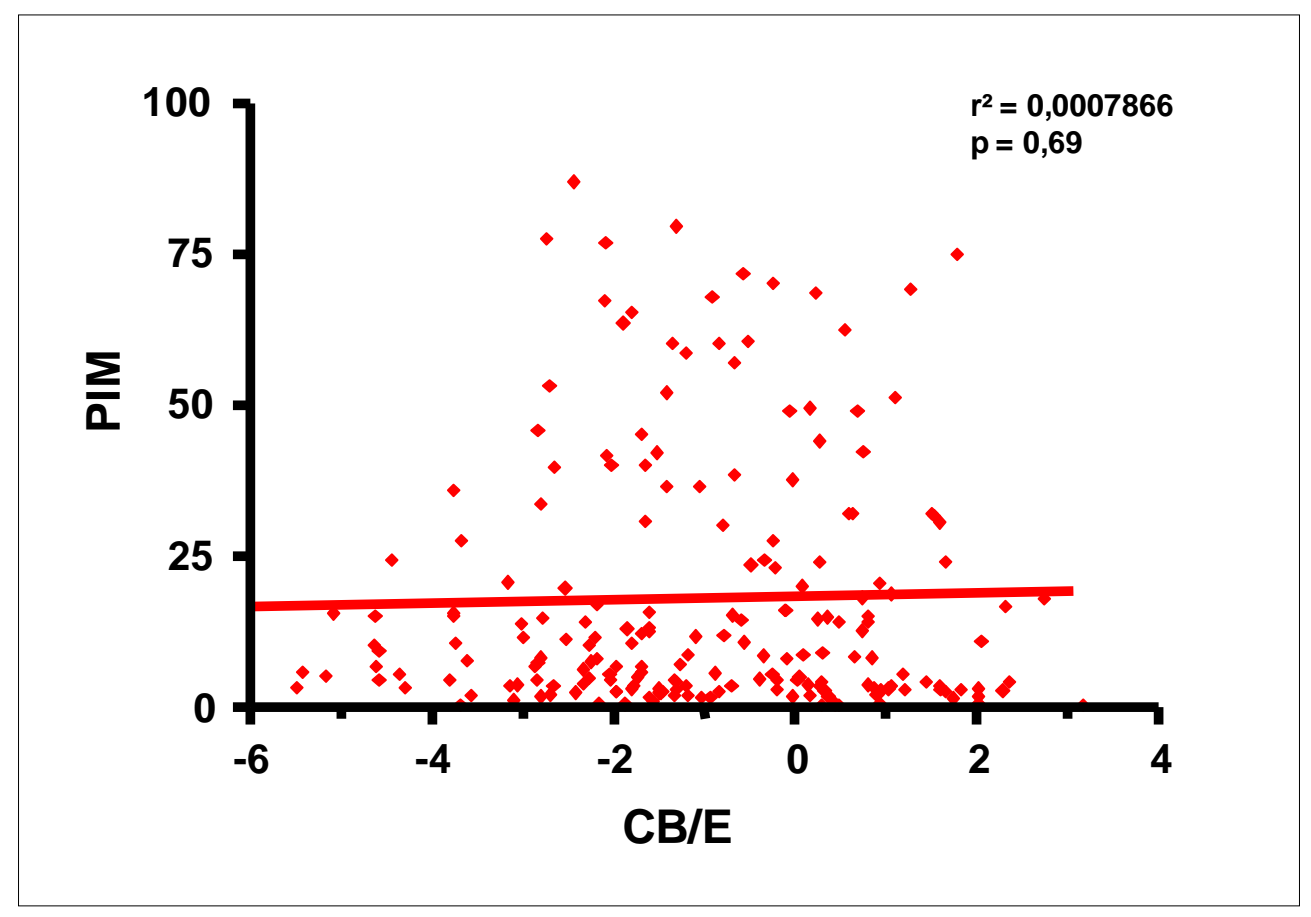


A correlação entre o estado nutricional e o tempo de internação em dias, está demonstrada nos Gráficos de 9 a 13.

Gráfico 9 - Correlação entre o escore Z de E/l e o tempo de internação na UTIP

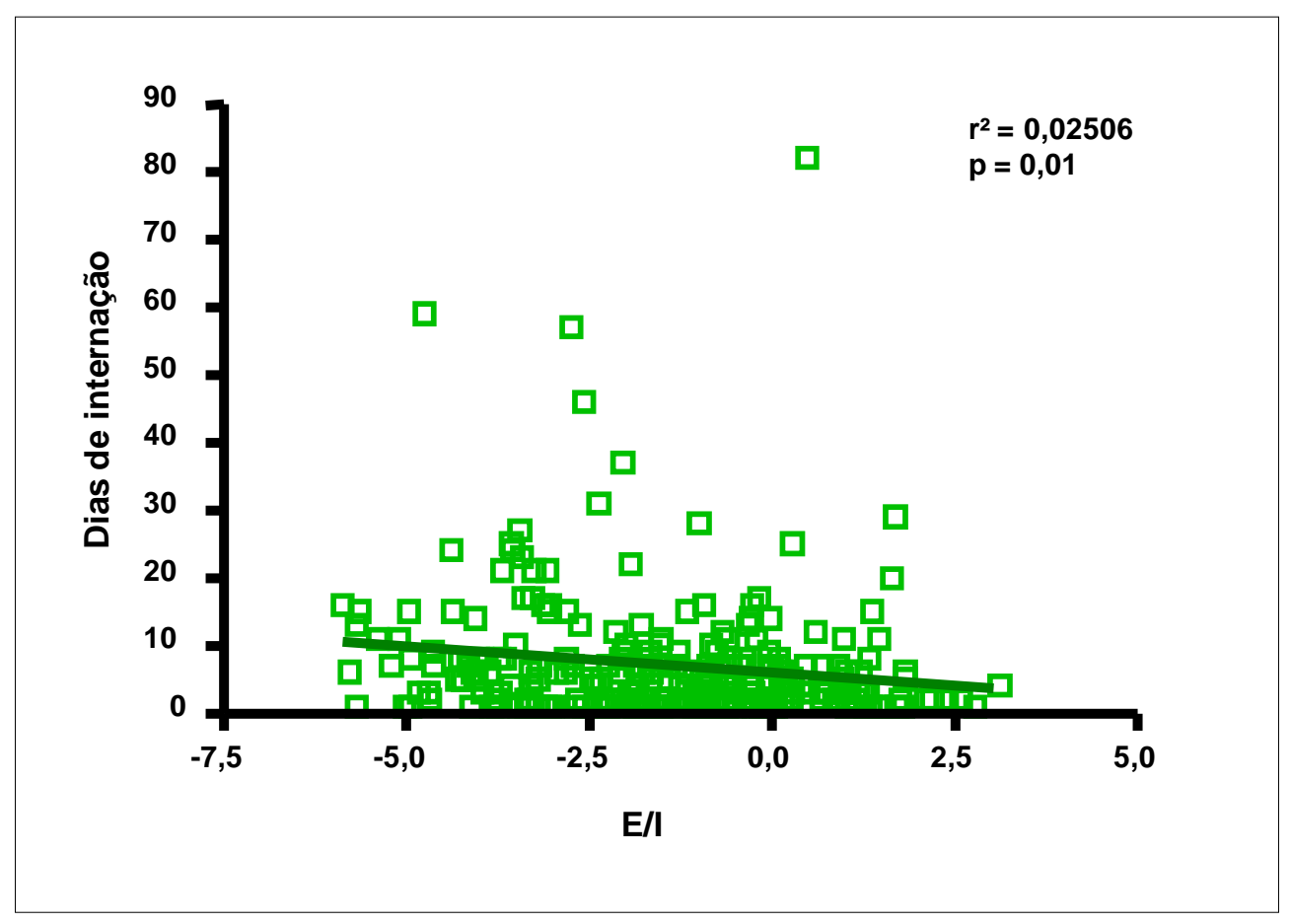


Gráfico 10 - Correlação entre o escore Z de P/l e o tempo de internação na UTIP

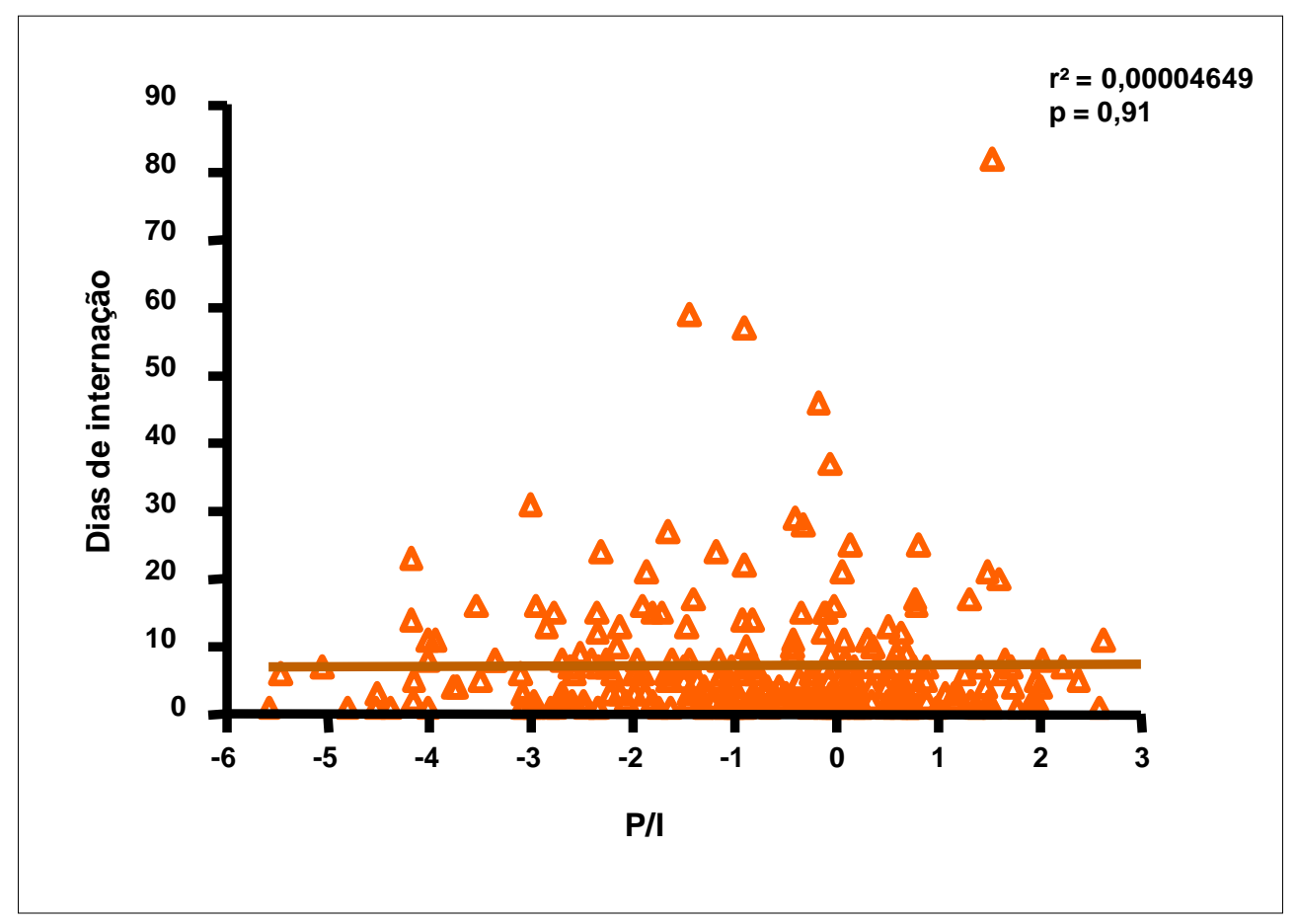

Gráfico 11 - Correlação entre o escore Z de P/E e o tempo de internação na UTIP

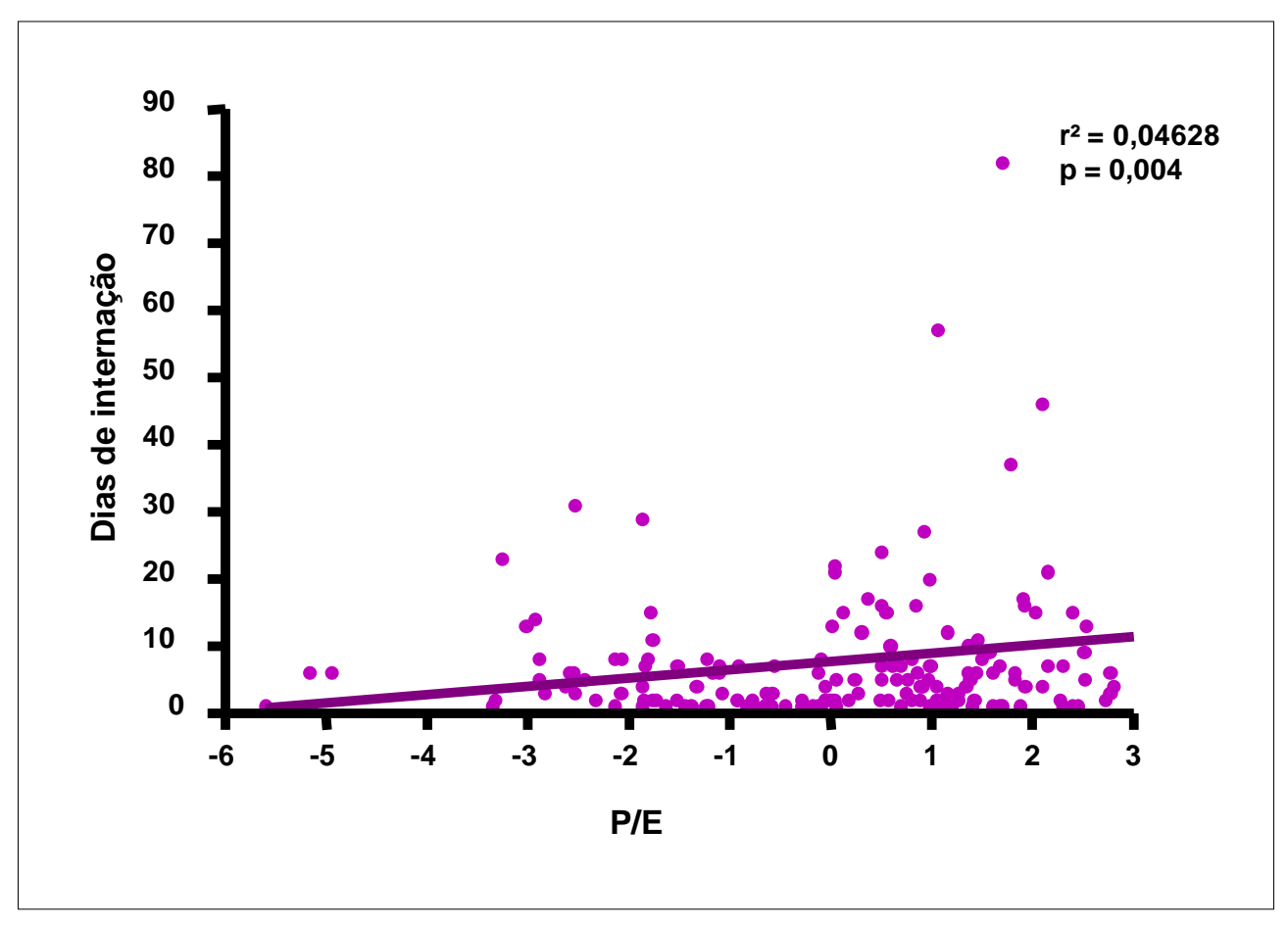


Gráfico 12 - Correlação entre o escore Z de IMC/I e o tempo de internação na UTIP

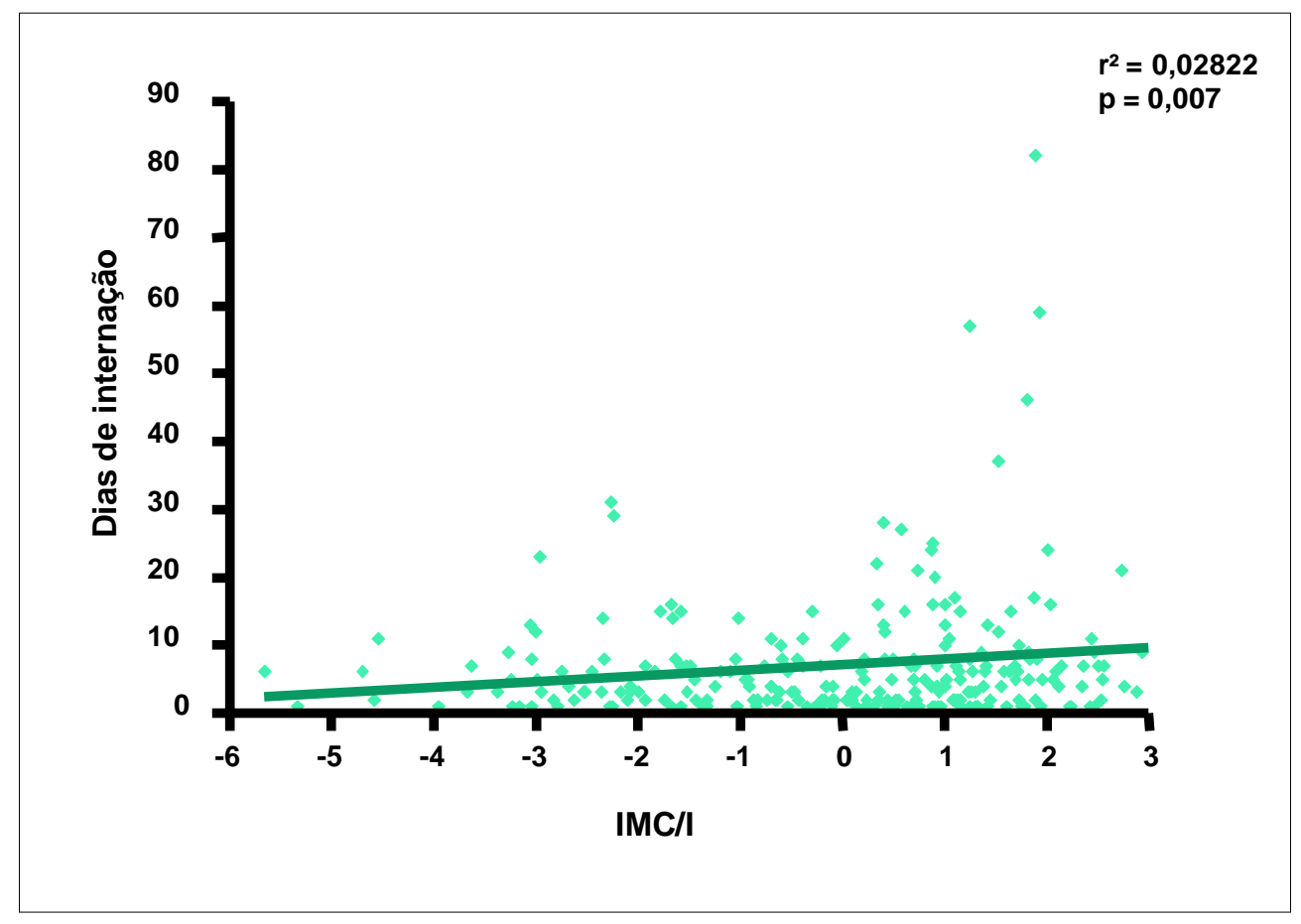

Gráfico 13 - Correlação entre o escore $Z$ de $C B / E$ e 0 tempo de internação na UTIP

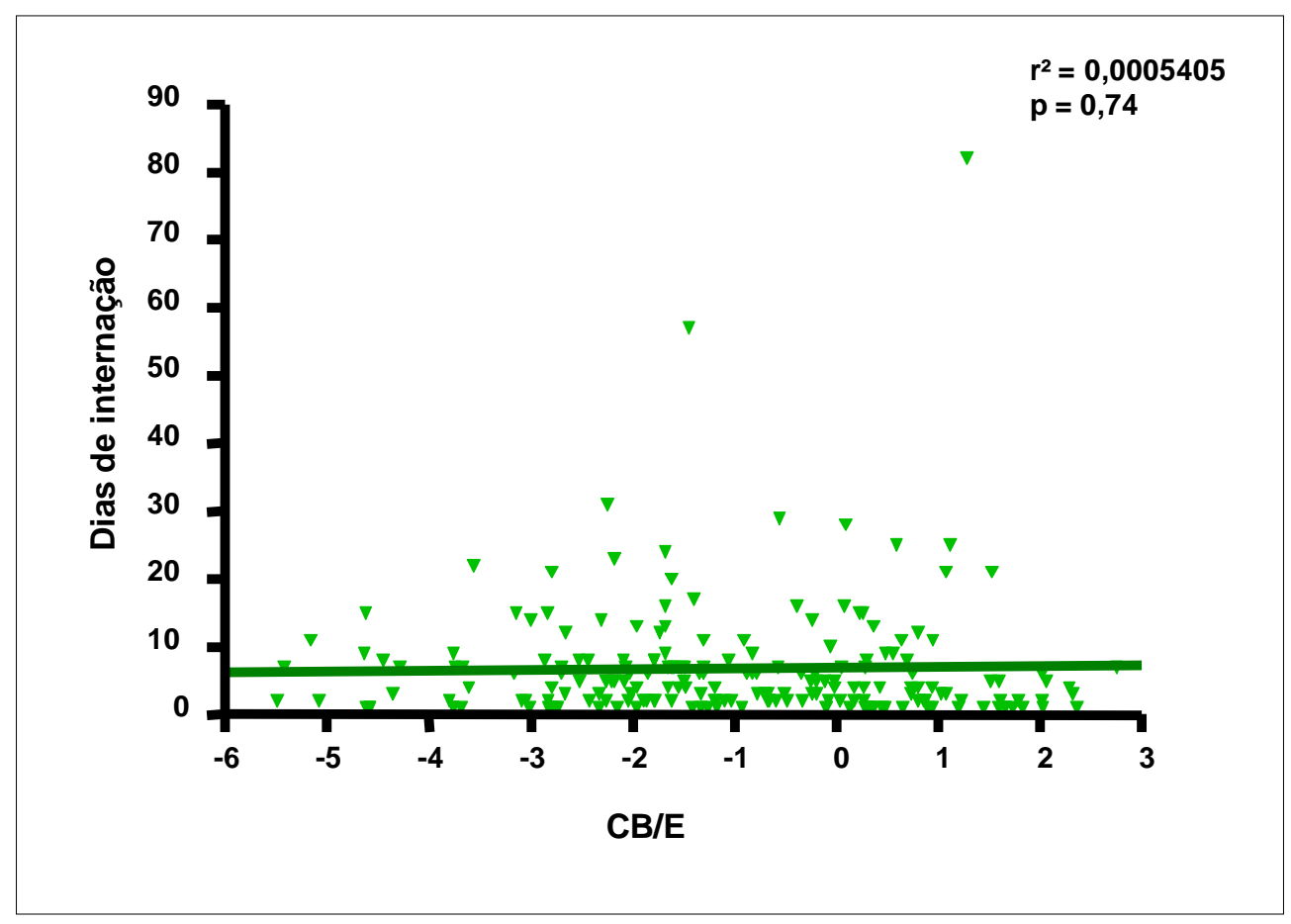


A Tabela 6 mostra a comparação da mediana de escore $Z$ dos indicadores antropométricos entre o grupo de pacientes que evoluiu a óbito e os que receberam alta da UTIP. Houve diferença estatisticamente significante somente para CB/E.

Tabela 6 - Comparação da mediana de escore Z dos indicadores antropométricos entre o grupo de pacientes que evoluiu a óbito e os que receberam alta da UTIP

\begin{tabular}{lccc}
\hline $\begin{array}{c}\text { Indicador } \\
\text { (mediana) }\end{array}$ & $\begin{array}{c}\text { Altas } \\
(\mathbf{n}=\mathbf{2 1 8})\end{array}$ & $\begin{array}{c}\text { Óbitos } \\
(\mathbf{n}=\mathbf{3 8})\end{array}$ & $\mathbf{p}$ \\
\hline Z E/I & $-1,3$ & $-1,4$ & 0,8503 \\
Z P/I & $-0,5$ & $-0,8$ & 0,7041 \\
Z P/E & 0,5 & 0,6 & 0,4210 \\
Z IMC/I & 0,4 & 0,5 & 0,8531 \\
Z CB/E & $-0,9$ & $-2,2$ & $0,0025^{*}$ \\
\hline
\end{tabular}

* Estatisticamente significante

O Gráfico 14 em "box-plot”, cujas barras superior, central e inferior representam o p75, a mediana e o p25, respectivamente; confirma esta diferença. 
Gráfico 14 - Comparação da mediana de escore $Z \mathrm{CB} / \mathrm{E}$ entre 0 grupo de pacientes que evoluiu a óbito e os que receberam alta da UTIP

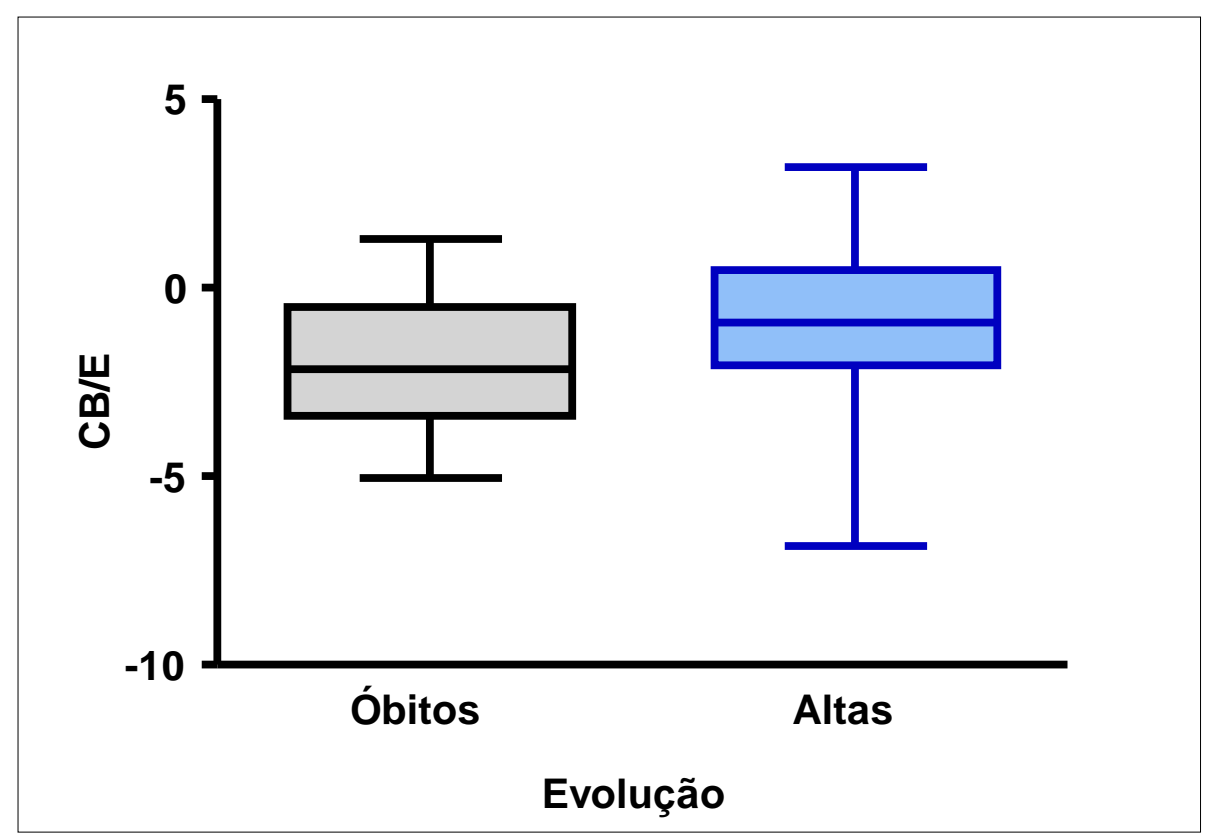

\subsubsection{Avaliação nutricional antropométrica evolutiva}

Das 256 crianças avaliadas à admissão, 90 foram avaliadas sequencialmente, pois permaneceram internadas por no mínimo sete dias.

$\mathrm{Na}$ análise comparativa (teste t emparelhado) entre a avaliação inicial (admissão) e o sétimo dia de internação, houve diferença estatisticamente significante nos índices E/l e CB/E, e nos valores de DCT, conforme mostram nos Gráficos subseqüentes. 
Gráfico 15 - Comparação dos valores de escore Z E/l obtidos à admissão e no sétimo dia de internação das crianças avaliadas na UTIP

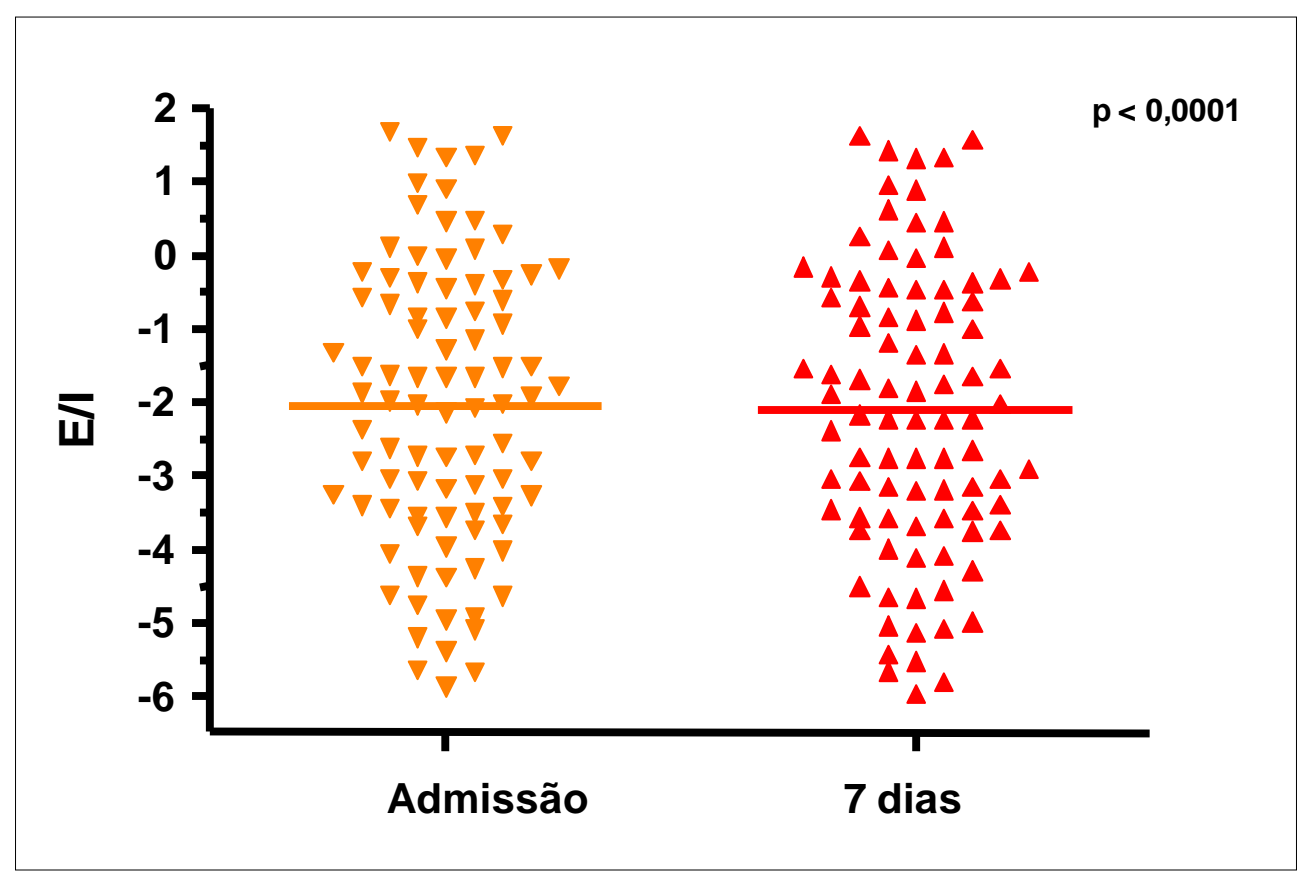

Gráfico 16 - Comparação dos valores de escore Z P/l obtidos à admissão e no sétimo dia de internação das crianças avaliadas na UTIP

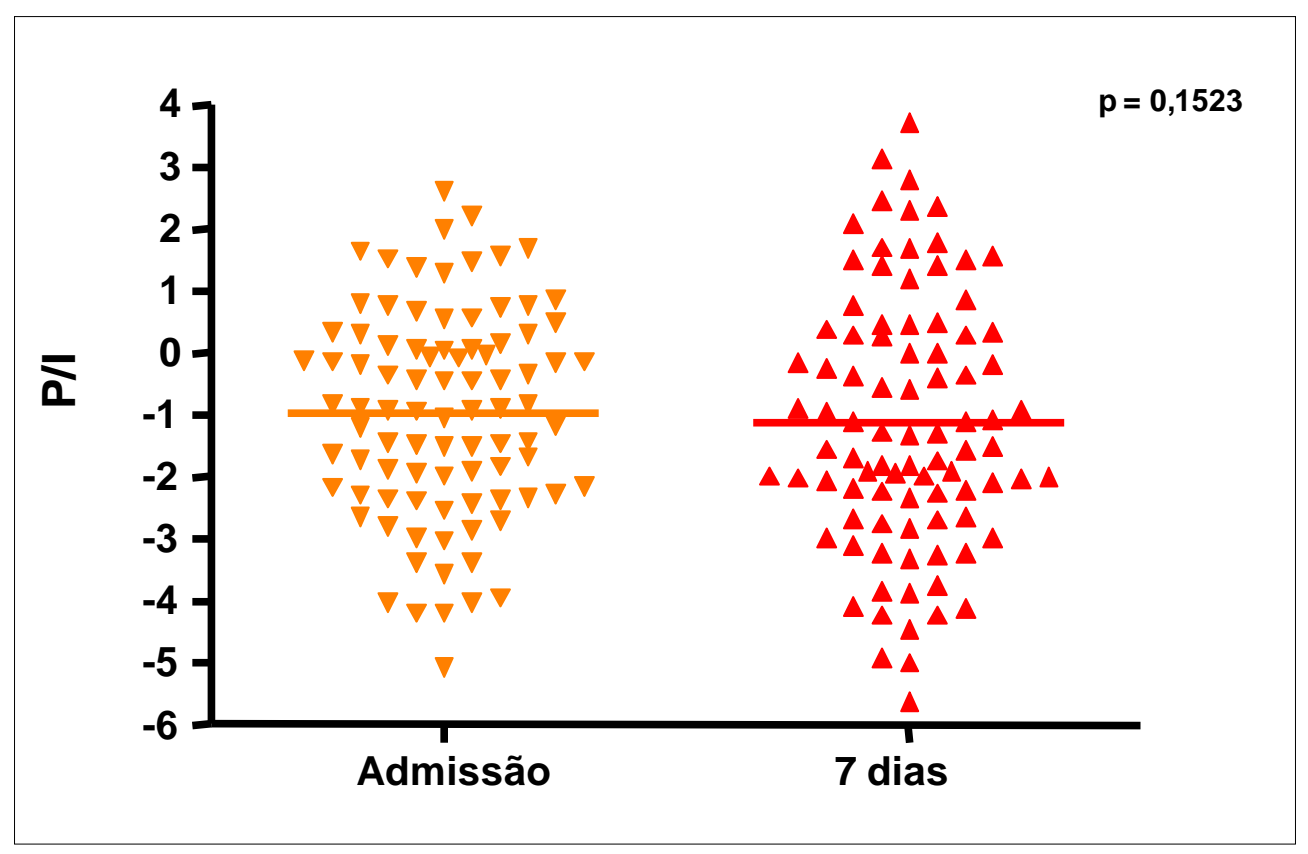


Gráfico 17 - Comparação dos valores de escore Z IMC/I obtidos à admissão e no sétimo dia de internação das crianças avaliadas na UTIP

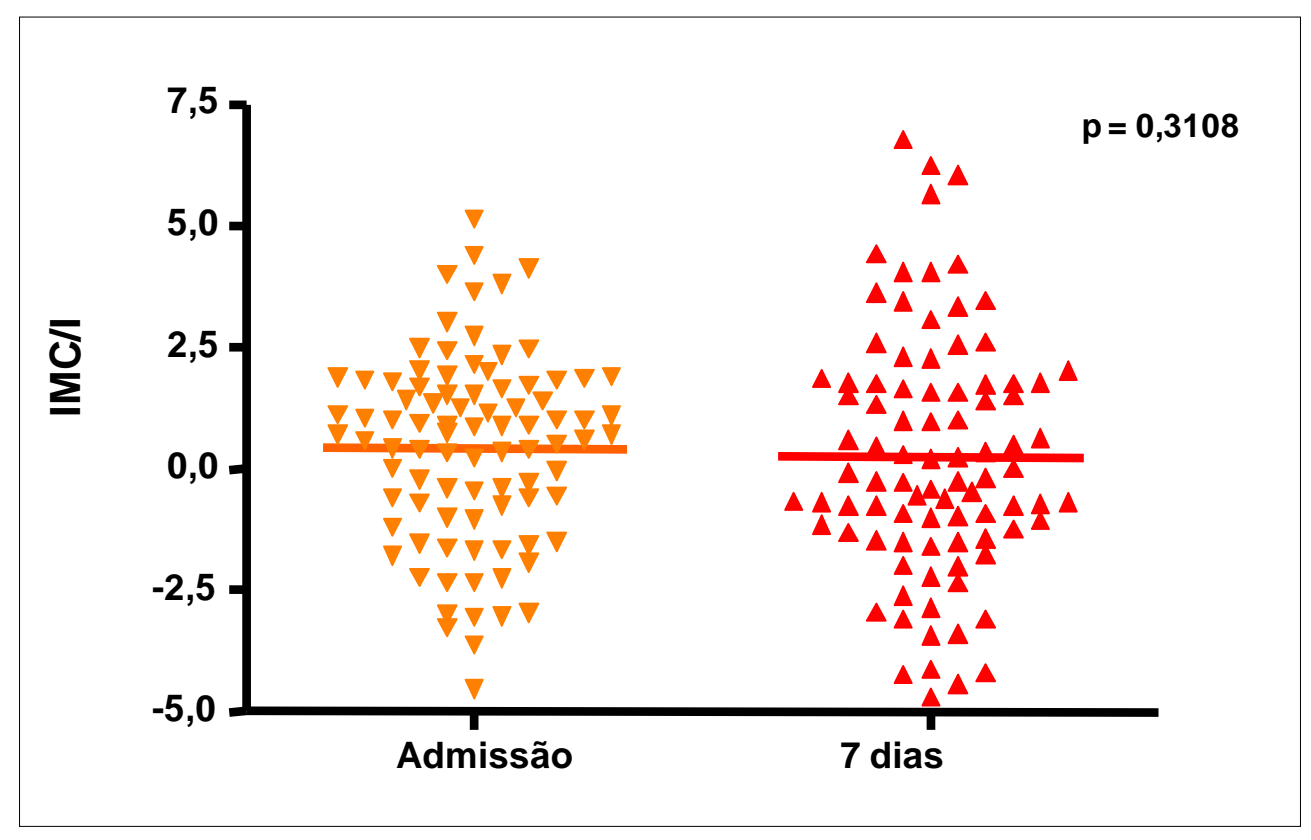

Gráfico 18 - Comparação dos valores de escore Z CB/E obtidos à admissão e no sétimo dia de internação das crianças avaliadas na UTIP

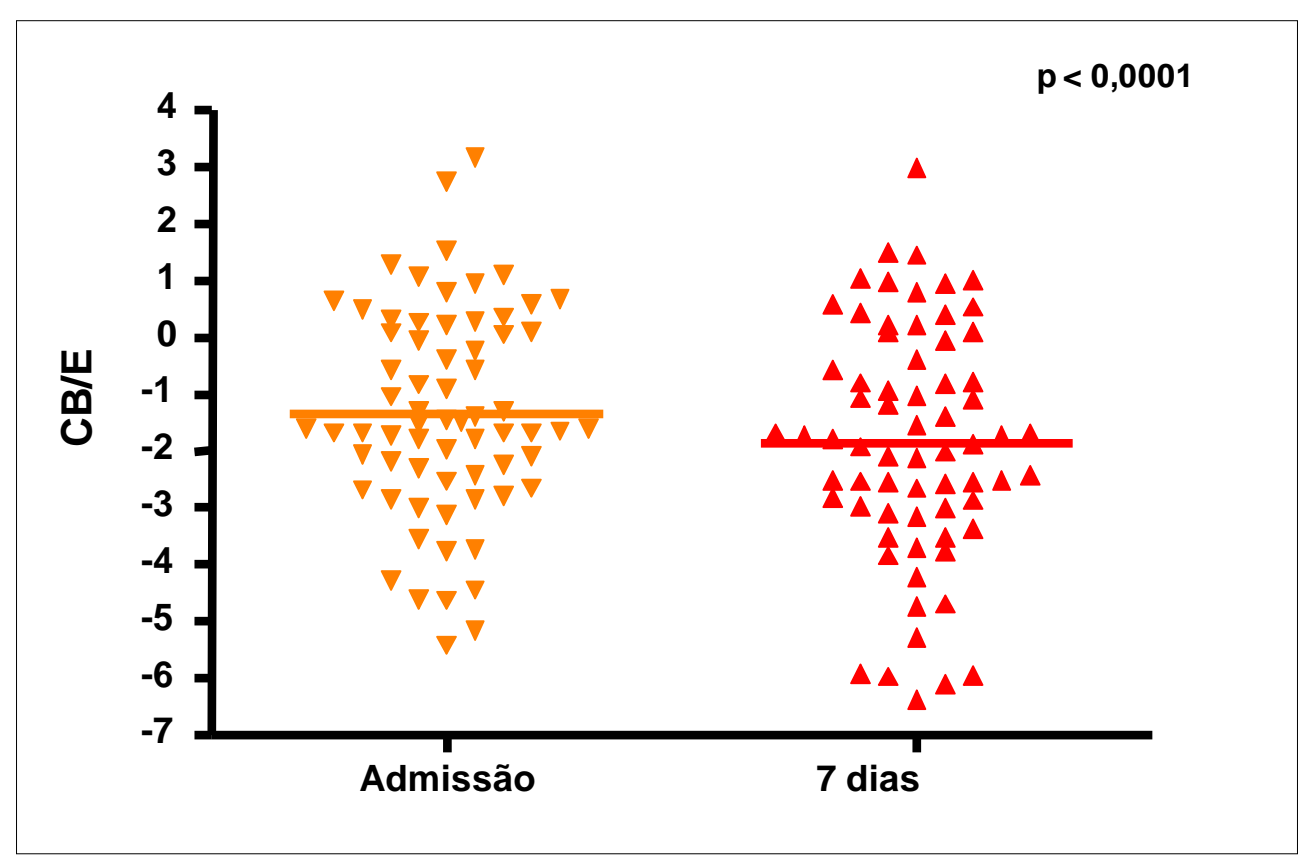


Gráfico 19 - Comparação dos valores absolutos de DCT obtidos à admissão e no sétimo dia de internação das crianças avaliadas na UTIP

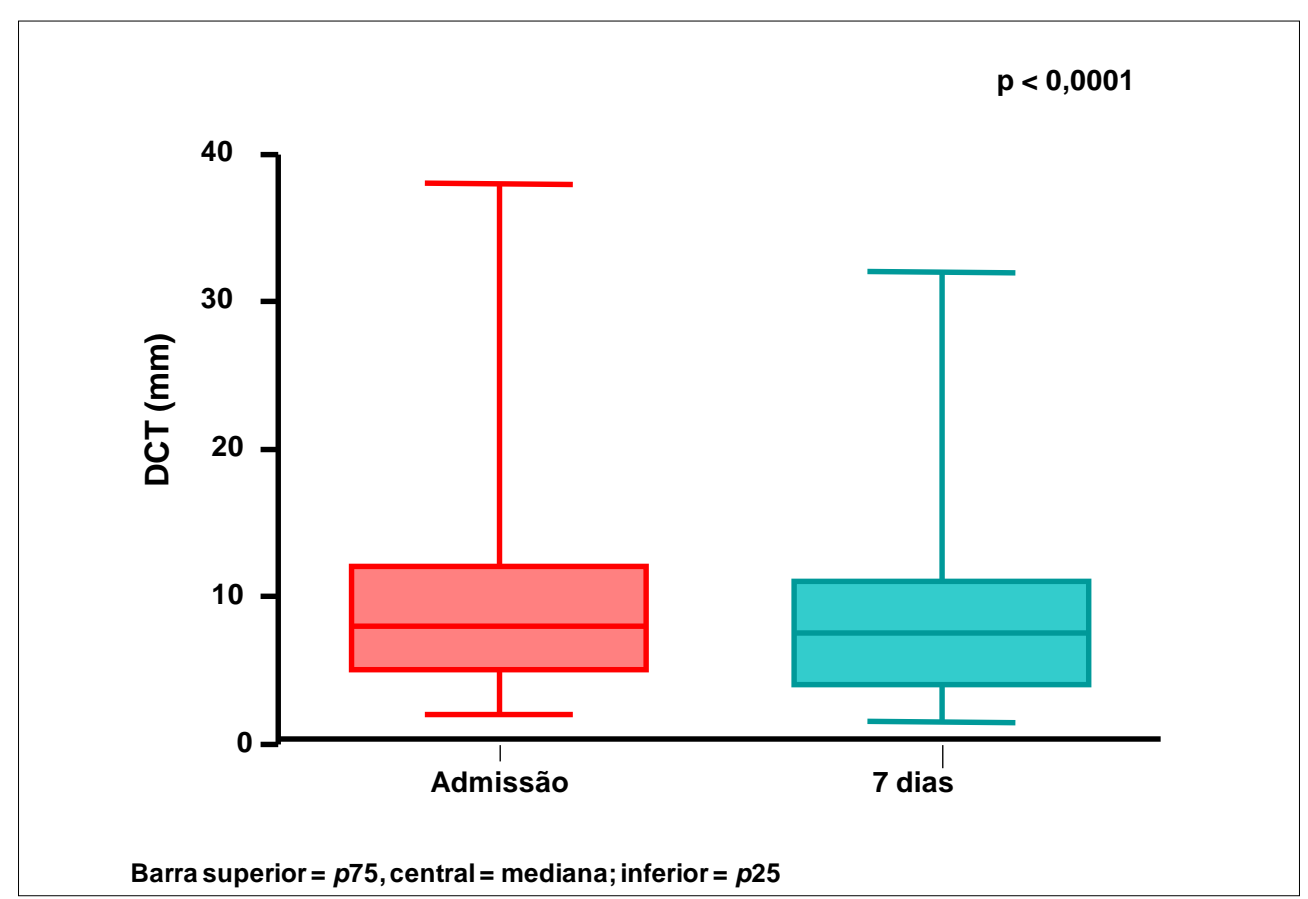

Gráfico 20 - Comparação dos valores absolutos de CMB obtidos à admissão e no sétimo dia de internação das crianças avaliadas na UTIP

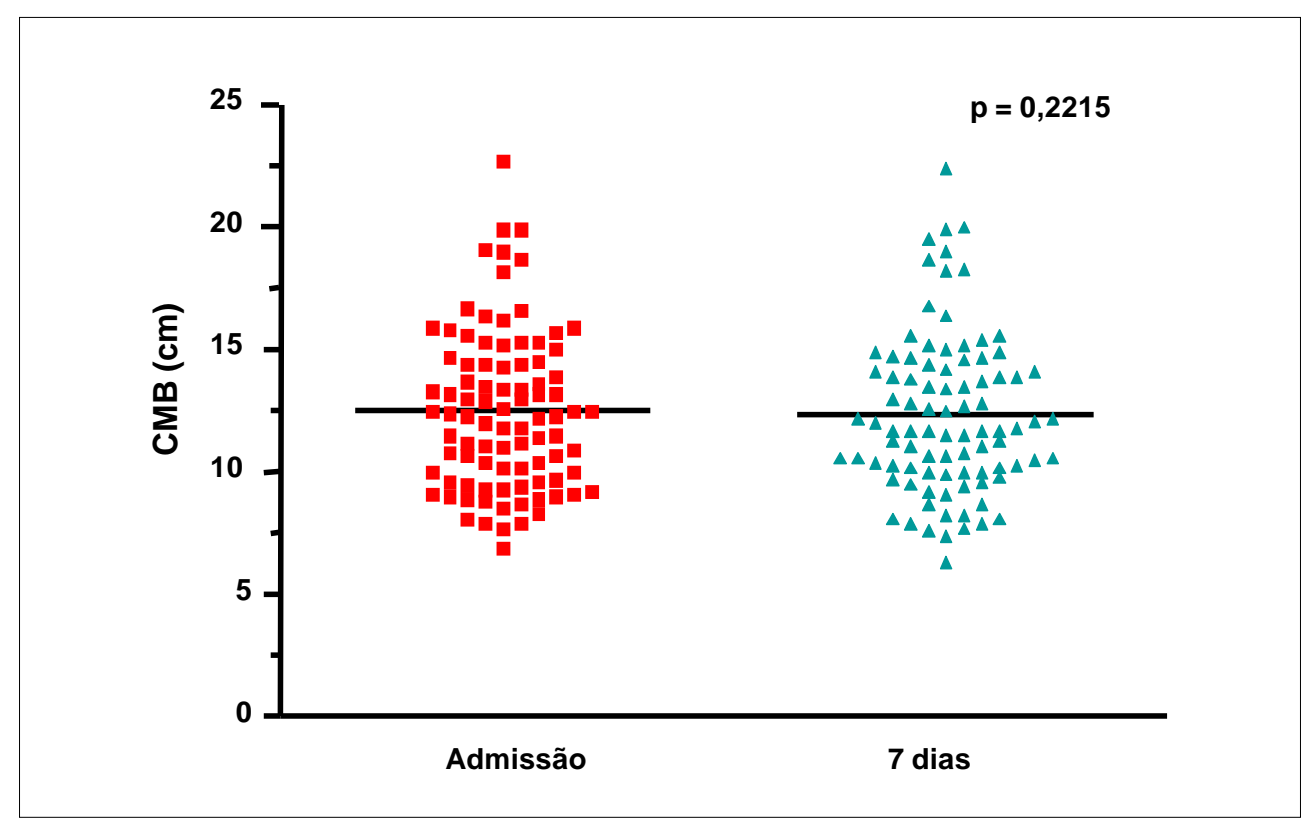


Gráfico 21 - Comparação dos valores absolutos de AMB obtidos à admissão e no sétimo dia de internação das crianças avaliadas na UTIP

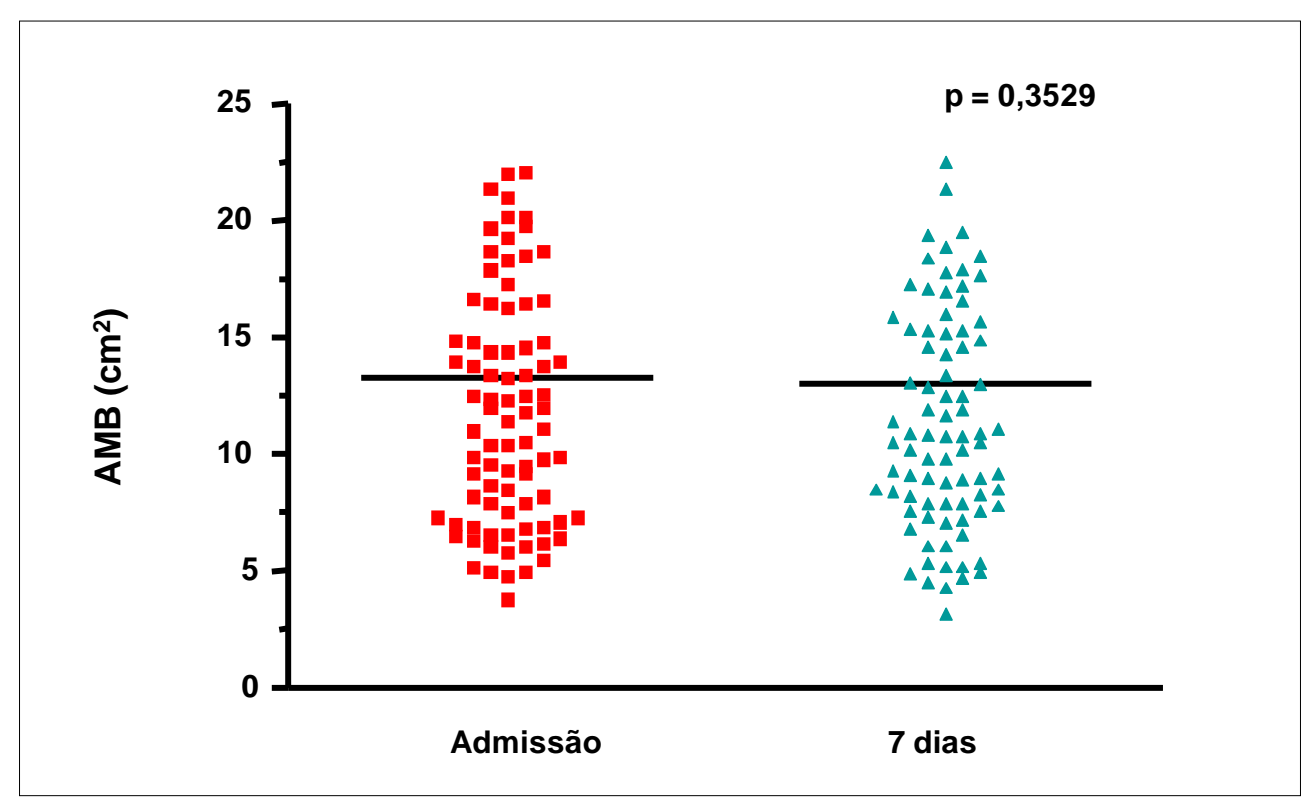




\section{Discussão}


A maior necessidade de nutrientes em relação aos adultos, e as limitadas reservas de energia, predispõem a criança a maior risco de desenvolver deficiências nutricionais. Este risco aumenta especialmente na criança doente, onde o estresse metabólico e a oferta inadequada de nutrientes podem levar a subnutrição (Briassoulis et al., 2001; Joosten e Hulst, 2008). Assim, a avaliação, monitorização e terapêutica nutricional são cada vez mais importantes no cuidado destas crianças.

A avaliação nutricional dos pacientes em estado grave é particularmente difícil, e provavelmente por este motivo, a subnutrição seja frequentemente mencionada e enfatizada, mas muito pouco documentada. A antropometria constitui componente básico para o diagnóstico nutricional, uma vez que apresenta valores padronizados de referência por faixa etária, diferentemente de outros indicadores bioquímicos (Hulst et al., 2004); sendo utilizada pela maioria dos pesquisadores que objetivam mensurar a condição nutricional de uma dada população (Ravasco et al., 2002).

Analisando as características gerais da população, não foram encontradas diferenças quanto ao sexo e houve predominância de crianças com menos de dois anos de idade e de escolares, sendo a mediana de idade de 4,8 anos. A maior parte das crianças e adolescentes apresentava alguma doença de base. A UTIP do Instituto da Criança do HCFMUSP, constituída de 
15 leitos, é considerada de nível terciário de assistência e atende crianças de zero a 18 anos e 11 meses de idade, principalmente aquelas acompanhadas nos vários ambulatórios de especialidades do instituto; o que justifica a heterogeneidade da amostra estudada quanto à idade e, principalmente, quanto aos diagnósticos e causas de internação, como mostrou Delgado et al. (2008) avaliando esta mesma população e Alievi et al. (2007) estudando crianças em UTIP também de nível terciário, em Porto Alegre.

O escore de gravidade (PIM), validado e amplamente utilizado, proporcionou melhor avaliação da população e detecção de possíveis alterações clínicas e laboratoriais relacionadas à condição de base que levou o paciente à internação. A mediana do PIM foi 10,7; superior ao valor encontrado por Alievi et al. (2007), de 2,6 em crianças internadas em UTIP terciária; confirmando a maior gravidade dos lactentes, crianças e adolescentes estudados. A escolha do escore mostrou-se adequada, pois o mesmo foi de fácil aplicação e reprodutibilidade e não necessitou de recursos de maior complexidade para sua utilização. Diversos trabalhos que avaliaram o PIM mostraram que ele apresenta desempenho satisfatório para predizer morte (Gemke e van Vught, 2002; Tibby et al., 2002; Slater, 2004), com a vantagem em relação ao Pediatric Risk of Mortality (ainda o escore mais amplamente conhecido e utilizado nas UTIP), de ser baseado em apenas oito variáveis clínicas e laboratoriais coletadas no momento da internação (Jones et al., 2000).

A mediana do tempo de internação das crianças avaliadas foi de quatro dias, semelhante à encontrada por Alievi et al. (2007), na UTIP do Hospital de Clínicas de Porto Alegre, também de nível de assistência terciário. 
Quanto à mortalidade, vários estudos têm relatado taxas de mortalidade em UTI de 9\% a 38\% (Rocker et al., 2004; Colpan et al., 2005). Em nosso estudo $15 \%$ das crianças evoluíram a óbito, concordando com os dados da literatura.

Em estudo no qual foi avaliado o estado nutricional de crianças internadas em UTIP e neonatal terciária na Holanda, Hulst et al. (2004) descreveram que estes pacientes apresentavam pior condição nutricional quando comparados à população em geral. Neste estudo, $24 \%$ das crianças apresentavam subnutrição e os autores concluíram que considerável proporção de pacientes necessita de TN especializada durante a internação na UTI. Estas características foram similares às encontradas no presente estudo, com alta prevalência de subnutrição $(E / I=37 \%, P / I=23 \%, I M C / I=$ $15,6 \%, C B / I=43,2 \%$ ) entre as crianças e adolescentes admitidos em nossa UTIP; o que poderia ser explicado pela elevada incidência de doenças de base nos pacientes estudados (84,76\%). Ao compararmos nossos resultados aos de Pollack et al. da década de 80 (Pollack et al., 1981 e 1982) que encontraram de $32 \%$ a $37 \%$ de subnutrição (entre aguda e crônica) e aos de Leite et al. (1993), que encontraram 65\% de subnutrição em seus pacientes, a maioria em pós-operatório de cirurgia cardíaca, verificamos que a condição de subnutrição nas UTIP não se alterou nos últimos 20 anos, sendo ainda muito prevalente nestas unidades.

$\mathrm{Na}$ avaliação da criança saudável (sem morbidades associadas), os indicadores nutricionais estão bem estabelecidos, sendo os mais utilizados $\mathrm{P} / \mathrm{I}, \mathrm{E} / \mathrm{I}, \mathrm{P} / \mathrm{E}$ e IMC/I. No entanto, a criança em estado grave encontra-se 
acamada, o que impossibilita a aferição precisa da estatura. Além disso, pode apresentar desequilíbrios hidroeletrolíticos, disfunção renal e hepática com edema e ascite, ou massas tumorais, que interferem na qualidade da medida de peso. Uma vez prejudicadas as mensurações de peso e estatura, o diagnóstico preciso da condição nutricional por intermédio destes indicadores estaria comprometido, assim como o planejamento da terapia e sua monitorização. Apesar deste viés da antropometria, nós encontramos $23 \%$ de subnutrição $(P / I \leq-2 d p)$ entre as crianças avaliadas, número que ainda pode ter sido subestimado pela interferência dos fatores acima descritos. Delgado et al. (2008) encontraram 58\% de subnutrição em outro estudo realizado com esta população de crianças e adolescentes. Mais de um terço das crianças apresentava subnutrição crônica avaliada com o escore mais indicado para esta situação ( $E / l \leq-2 \mathrm{dp})$, o que pode ser justificado pela alta prevalência de doenças de base e a grande influência dessas sobre o estado nutricional ao longo do tempo. Romaldini et al. (1996) observaram resultados semelhantes quanto à subnutrição crônica (32\%), avaliando população com características semelhantes em relação à faixa etária e doenças de base, porém internadas na enfermaria de especialidades do Instituto da Criança do HCFMUSP. Hulst et al. (2004) encontraram $22 \%$ de crianças cronicamente subnutridas em sua UTIP terciária.

Avaliando os pacientes por intermédio de P/E e IMC/I, encontramos subnutrição em apenas $12,7 \%$ e $15,6 \%$ dos pacientes, respectivamente. Estes resultados evidenciam que os referidos indicadores parecem ser menos sensíveis para o diagnóstico nutricional à admissão de crianças 
gravemente doentes, corroborando alguns achados da literatura. Ravasco et al. (2002) avaliando 44 pacientes em UTI, observaram que a porcentagem de peso ideal, bem como o IMC, foram significativamente influenciados por edema; subestimando, assim, a subnutrição. Apenas $6,8 \%$ dos pacientes foram diagnosticados como subnutridos por este indicador e $22,7 \%$ com sobrepeso. No estudo de Huang et al. (2000) o IMC também classificou a maioria dos pacientes em UTI como eutróficos.

No paciente em estado grave, além de edema e desequilíbrio hidroeletrolítico, ocorre intenso catabolismo protéico e mudanças na composição corporal devido à perda de massa muscular e à redistribuição da água corporal total. Assim, medidas que definem com maior detalhamento os compartimentos corporais se tornam mais importantes, inclusive como índices prognósticos na avaliação deste paciente (Wells e Fewtrell, 2008; Yeong e Dympna, 2008). Na avaliação antropométrica, as medidas da circunferência e dobras cutâneas se destacam como método simples de estimar a composição corpórea uma vez que refletem tanto o seu componente de gordura (MG), quanto o de MLG.

Vários estudos têm mostrado as medidas do braço como indicadores sensíveis para o diagnóstico da subnutrição em alguns grupos de pacientes. Israëls et al. (2008) avaliaram 128 pacientes pediátricos portadores de câncer, por intermédio dos principais indicadores antropométricos, e encontraram subnutrição em $59,3 \%$ das crianças pela CMB e DCT, contra apenas $17,2 \%$ diagnosticada pelo indicador P/E. No estudo de Huang et al. (2000), todos os pacientes classificados como eutróficos pelo IMC, 
apresentavam valores médios de CMB e AMB inferiores ao $\mathrm{p} 5$. Ravasco et al. (2000) constataram que a subnutrição foi subestimada em seus pacientes pelo IMC, encontrando $43 \%$ desta condição diagnosticada pela CB e CMB. Estes números são semelhantes aos nossos, onde a subnutrição foi diagnosticada em $43 \%$ dos pacientes, pelos indicadores CB/I, CMB e AMB. Nós encontramos ainda que $15 \%$ dos pacientes diagnosticados como eutróficos por $\mathrm{P} / \mathrm{l}$ e E/l, apresentavam valores de $\mathrm{CB} / \mathrm{l} \leq-2 \mathrm{dp}$. Nossos achados corroboram a literatura e confirmam que as medidas do braço parecem ser os indicadores antropométricos mais sensíveis para discriminar a subnutrição em pacientes gravemente doentes à admissão.

A subnutrição está relacionada ao aumento da morbidade e mortalidade em adultos e crianças, incluindo maior risco de infecções devido a alterações do sistema imunológico e gastrintestinal; maior dependência de ventilação mecânica e aumento do tempo de internação (Briassoulis et al., 2001; Joosten e Hulst, 2008; Sungurtekin et al., 2008; Delgado et al., 2008). Em nosso estudo, verificamos existência de correlação entre o estado nutricional e a gravidade, o tempo de internação e a mortalidade.

A associação entre gravidade e subnutrição parece não constituir relação de causa e efeito entre estas variáveis. É difícil estabelecer se a subnutrição agrava o quadro de doença, ou se a doença grave, pelo aumento das demandas metabólicas, é responsável pelo rápido desenvolvimento da subnutrição. Pollack et al. (1985), não estabeleceram relação causa e efeito, definida entre escore de gravidade e subnutrição, estudando 60 crianças admitidas em UTIP. No presente estudo apenas o 
indicador $\mathrm{P} / \mathrm{l}$ teve algum nível de correlação com a gravidade $\left(\mathrm{r}^{2}=0,02080\right)$; mostrando que, provavelmente, a condição nutricional do paciente não foi o principal fator determinante da condição clínica dos pacientes. Delgado et al. (2008) não encontraram diferenças na gravidade, demonstrada por dois escores, entre pacientes eutróficos e subnutridos na UTIP.

Vários autores têm advogado que a subnutrição está associada ao aumento do tempo de internação (Briassoulis et al., 2001; Sungurtekin et al., 2008), e que a recíproca é verdadeira. Pichard et al. (2004) e Kac et al. (2000) encontraram piora da condição nutricional em pacientes que permaneceram internados por mais tempo. No presente estudo, quando avaliamos a relação E/l (relacionada à subnutrição prévia e crônica) encontramos tempo de internação significativamente mais elevado, sugerindo que há possível influência da subnutrição à admissão sobre o tempo de permanência do paciente na UTIP terciária. Este achado não foi evidenciado nos outros indicadores. Nos estudos de Pollack et al. (1981 e 1982) não houve associação entre subnutrição e tempo de internação das crianças na UTIP.

Colpan et al. (2005), utilizando análise univariada, descreveram que os mais importantes fatores de risco para mortalidade foram idade, gravidade, uso de corticosteróides ou quimioterápicos, necessidade de ventilação mecânica e infecção. A subnutrição correlaciona-se com a mortalidade, uma vez que aumenta o risco de infecções. Estas por sua vez, contribuem para o agravo da condição nutricional. Assim, o ciclo subnutrição-infecção é de particular importância em crianças admitidas em 
UTI, pois constitui uma das principais causas de óbito nestas unidades (Leite et al., 1993; Delgado, 2005).

No presente estudo, verificando a associação entre estado nutricional e mortalidade, encontramos diferença estatisticamente significante entre a mediana do escore $Z$ de $C B / E$ do grupo de crianças que foram a óbito e os que receberam alta da UTIP. Ou seja, a taxa de mortalidade foi maior entre as crianças diagnosticadas como subnutridas pelo indicador $\mathrm{CB} / \mathrm{E}$. Briassoulis et al. (2001) avaliando 71 crianças gravemente doentes sob ventilação mecânica, também encontraram maior mortalidade entre crianças que apresentavam depleção das reservas protéicas e de gordura.

Há anos as medidas do braço, além de indicadoras de subnutrição, têm se mostrado um bom indicador para predizer mortalidade em estudos populacionais (Vella et al., 1993; Pelletier et al., 1993; Collins, 1996). Alguns autores estudando grupos específicos de pacientes têm sugerido que a depleção de massa muscular é o principal fator responsável pelos efeitos deletérios atribuídos à subnutrição, e que em geral, aumentam o risco de morte.

Soler-Cataluña et al. (2005) estudando a mortalidade em 96 pacientes do sexo masculino, portadores de doença pulmonar obstrutiva crônica, encontraram na análise multivariada, que valores de AMB inferiores ao p25, foram indicadores independentes de pior prognóstico nestes pacientes, até mesmo naqueles que apresentavam peso normal ou sobrepeso. Os autores concluíram que a depleção muscular mensurada pela AMB se mostrou melhor para predizer de mortalidade quando comparado ao IMC nestes pacientes. 
Ravasco et al. (2002) encontraram maior mortalidade entre pacientes avaliados na UTI, com valor de CB inferior ao $p 5$. Nestes pacientes $\mathrm{CB}<$ p15, foi também capaz de predizer mais complicações.

Nossos dados são concordantes com os da literatura descrita. Nas 256 crianças avaliadas, a CB se mostrou mais sensível para discriminar a desnutrição, bem como para predizer mortalidade; sugerindo, assim, que este indicador nutricional seja o que melhor se aplique a esta população, à admissão em UTIP terciária.

O presente estudo avaliou a condição nutricional de crianças tanto à admissão, na fase aguda do estresse; como também durante o período de permanência na UTI. Encontramos diferença estatisticamente significante no indicador E/l durante a avaliação nutricional seqüencial, e consideramos que este achado foi ocasionado por potencial erro de mensuração nos casos onde houve maior dificuldade técnica para obtenção da estatura/comprimento.

Uma das principais alterações metabólicas do estresse é a proteólise intensa que acarreta grande perda muscular. Dentro da antropometria, as medidas do braço, especialmente, a CMB e a AMB, são capazes de estimar mudanças no compartimento protéico corpóreo; sendo possível que os pacientes gravemente doentes apresentem redução dos valores destes indicadores durante a internação na UTI. No presente estudo, houve redução estatisticamente significante nos valores da mediana da DCT e não foi evidenciada modificação significativa da mediana da CMB e AMB. Delgado et al. (2000) obtiveram achados semelhantes, justificados pelo curto período de internação (ao redor de sete dias) destes pacientes na UTI. 
O principal fator que predispõe o paciente ao desenvolvimento ou persistência da subnutrição durante a permanência na UTI é, provavelmente, a ingestão inadequada de nutrientes, seja pela não prescrição ou interrupção da alimentação (Briassoulis et al., 2001; Hulst et al., 2004). Embora nosso estudo tenha sido apenas descritivo quanto a TN empregada, sem a intenção de correlacioná-la ao estado nutricional, observamos que a mesma, instituída precocemente (em média nas primeiras 72 horas de internação), mostrou-se adequada, com oferta média de $80 \mathrm{Kcal} / \mathrm{kg} / \mathrm{dia}$ e $2,7 \mathrm{~g} / \mathrm{kg} / \mathrm{dia}$, tendo possivelmente contribuído para a manutenção da condição nutricional dos pacientes estudados. Em nossa UTIP, a TN é parte fundamental do cuidado ao paciente. Delgado (2005) em estudo nesta mesma UTIP, concluiu que houve benefício com a terapêutica nutricional precoce e padronizada na redução da proteína C-reativa e elevação da pré-albumina em crianças gravemente doentes com SRIS.

Os pacientes gravemente doentes apresentam risco de desenvolver subnutrição, pelas alterações metabólicas ocasionadas pelo estresse e pela oferta inadequada de nutrientes. Apesar das dificuldades de avaliação nutricional na UTI, nosso estudo demonstrou que a antropometria pode auxiliar no diagnóstico da subnutrição nestas unidades, bem como na monitorização do paciente. Portanto, a realização sistematizada da avaliação nutricional de crianças e adolescentes internados em UTI deve ser estimulada e incorporada como rotina em hospitais públicos e privados; o que poderá minimizar a incidência da subnutrição e das suas complicações. 


\section{ConClusões}


a) Houve subnutrição à admissão em $37 \%$ dos pacientes pelo indicador Z E/I, 23\% por Z P/I, 12,7\% por Z P/E, 15,6\% por Z IMC/I, 43,2\% por Z CB/I, 23,8\% por Z CB/E, $28,5 \%$ por DCT/I, $43 \%$ por $\mathrm{CMB} / \mathrm{l}$ e $43 \%$ por $\mathrm{AMB} / \mathrm{l}$.

b) As medidas do braço foram as que melhor diagnosticaram a subnutrição no grupo de crianças gravemente doentes na UTIP à admissão.

c) Não houve alteração estatisticamente significante nos indicadores antropométricos durante o período de internação na UTIP, com exceção de redução no Z E// e DCT//; sugerindo que a TN precoce e possivelmente adequada contribuiu para a manutenção da condição nutricional dos pacientes.

d) Não houve correlação entre o escore de gravidade e os indicadores nutricionais utilizados, exceto para Z P/l; sugerindo que outros fatores relacionados à gravidade do paciente, apresentaram maior significância quando comparados à condição nutricional.

e) Houve correlação entre Z CB/E e mortalidade, sugerindo que este indicador, além de ser o que melhor discrimina a subnutrição, é também o melhor indicador para prognóstico de mortalidade nas crianças gravemente doentes na UTIP.

f) $O$ indicador $E / l$ teve boa correlação com o tempo de internação, denotando maior necessidade de hospitalização nos cronicamente subnutridos. 
8 AnEXos 


\section{Anexo A - Aprovação da CAPPesq}

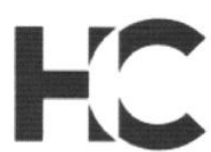

\section{APROVAÇÃO}

A Comissão de Ética para Análise de Projetos de Pesquisa - CAPPesq da Diretoria Clínica do Hospital das Clínicas e da Faculdade de Medicina da Universidade de São Paulo, em sessão de 10.11.04, APROVOU o Protocolo de Pesquisa $n^{\circ}$ 916/04, intitulado: "Evolução nutricional de crianças internadas em Unidade de Terapia Intensiva Pediátrica" apresentado pelo Departamento de PEDIATRIA, inclusive o Termo de Consentimento Livre e Esclarecido.

$$
\text { Cabe ao pesquisador elaborar e apresentar à }
$$

CAPPesq, os relatórios parciais e final sobre a pesquisa (Resolução do Conselho Nacional de Saúde $n^{\circ} 196$, de 10.10.1996, inciso IX.2, letra "c").

Pesquisador(a) Responsável: Prof. Dr. Rubens Feferbaum Pesquisador(a) Executante: Sra. Patrícia Zamberlan dos Santos

CAPPesq, 10 de Novembro de 2004.

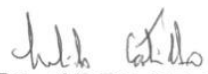

PROF. DR. EUCLIDES AYRES DE CASTILHO Presidente da Comissão de Ética para Análise de Projetos de Pesquisa 


\section{Anexo B - Termo de consentimento livre e esclarecido}

\section{HOSPITAL DAS CLÍNICAS}

DA

FACULDADE DE MEDICINA DA UNIVERSIDADE DE SÃO PAULO

\section{TERMO DE CONSENTIMENTO LIVRE E ESCLARECIDO}

(Instruções para preenchimento no verso)

\section{I - DADOS DE IDENTIFICAÇÃO DO SUJEITO DA PESQUISA OU RESPONSÁVEL LEGAL}

1. NOME DO PACIENTE .

DOCUMENTO DE IDENTIDADE № : SEXO : $M$ \&s $F$ sos

DATA NASCIMENTO: ........................

ENDEREÇO

BAIRRO:

CEP:

TELEFONE: DDD

\section{CIDADE}

№

APTO:

2.RESPONSÁVEL LEGAL

NATUREZA (grau de parentesco, tutor, curador etc.)

DOCUMENTO DE IDENTIDADE :

SEXO: $M$ so $F$ sos

DATA NASCIMENTO.: ....................

ENDEREÇO:

BAIRRO:

CEP:

№

APTO:

TELEFONE: DDD )

\section{II - DADOS SOBRE A PESQUISA CIENTÍFICA}

1. TÍTULO DO PROTOCOLO DE PESQUISA

AVALIAÇÃO NUTRICIONAL DE CRIANÇAS INTERNADAS EM UNIDADE DE TERAPIA INTENSIVA PEDIÁTRICA

PESQUISADOR: RUBENS FEFERBAUM

CARGO/FUNÇÃO: MÉDICO

INSCRIÇÃO CONSELHO REGIONAL №: 20494

UNIDADE DO HCFMUSP: INSTITUTO DA CRIANÇA

3. AVALIAÇÃO DO RISCO DA PESQUISA:

$\begin{array}{llll}\text { SEM RISCOX } & \text { RISCO MÍNIMO } & \text { sos } & \text { RISCO MÉDIO so } \\ \text { RISCO BAIXO } & \text { so } & \text { RISCO MAIOR so } & \end{array}$

(probabilidade de que o indivíduo sofra algum dano como consequência imediata ou tardia do estudo)

4.DURAÇÃO DA PESQUISA : 1 ANO 


\section{III - REGISTRO DAS EXPLICAÇÕES DO PESQUISADOR AO PACIENTE OU SEU REPRESENTANTE LEGAL SOBRE A PESQUISA, CONSIGNANDO:}

1. justificativa e os objetivos da pesquisa: Prezado (a) Senhor (a), como já lhe foi dito, seu filho se encontra num momento mais crítico e grave da doença e precisará de tratamento na UTI (unidade de terapia intensiva), para que seja acompanhado mais de perto. Crianças internadas em UTI, pelo estado clínico mais crítico, podem ter dificuldades na alimentação. Muitas vezes não podem alimentar-se pela boca, e a dieta tem que ser colocada pela veia ou através de um tubo inserido no nariz e que chega até o estômago. Esta dificuldade de alimentação pode prejudicar ou não a parte nutricional da criança. Ou seja, a criança pode chegar nutrida na UTI e durante o tempo de internação, se desnutrir. Ou ao contrário, pode entrar desnutrida e se nutrir. Ou ainda, pode manter-se como chegou. A piora da situação nutricional da criança pode debilitá-la ainda mais, prejudicando sua recuperação e saída da UTI. O objetivo deste estudo do qual seu filho (a) vai participar, é exatamente verificar como as crianças evoluem da parte nutricional (se ganham ou perdem peso, gordura, músculo, água) durante o período de internação na UTI, para que possamos planejar uma alimentação mais apropriada para elas. A verificação da parte nutricional será feita logo na internação, 3 e 7 dias depois desta primeira avaliação, e repetida 1 vez por semana até a alta da UTI (será realizada inclusive na alta). Isto é claro, não quer dizer que seu filho ficará internado por semanas, mas enquanto estiver internado será esta a rotina de avaliação. Para a avaliação serão utilizados dois aparelhos (um chamado adipômetro e outro chamado impedância bioelétrica), que não furam, não machucam, não causam dor nem desconfortos, não emitem radiação e não interferem no funcionamento de outros aparelhos que a criança eventualmente esteja utilizando (monitor, ventilador), exceto marcapasso. A verificação é rápida, no máximo dez minutos por avaliação. Se o (a) senhor (a) não quiser que seu filho (a) participe da pesquisa tem todo o direito de se recusar e ele (a) receberá assim mesmo o tratamento mais adequado para a sua doença. Caso comece na pesquisa e depois deseje desistir também estará garantido para a sua criança o melhor tratamento possível.

2. procedimentos que serão utilizados e propósitos, incluindo a identificação dos procedimentos que são experimentais: Será realizada: pesagem em balança para verificar se a criança ganhou ou perdeu peso; medida da altura/comprimento com régua própria para verificar se a criança cresceu; medida do tamanho (largura) e da dobra do braço com adipômetro para verificar se a criança ganhou ou perdeu gordura e/ou músculo; e impedância bioelétrica com aparelho próprio para também verificar se a criança ganhou ou perdeu músculo e gordura, além de água corporal.

3. desconfortos e riscos esperados: nenhum.

4. benefícios que poderão ser obtidos: conhecimento da situação e evolução da parte nutricional da criança, para um planejamento mais adequado de sua alimentação. Isto contribuirá para uma recuperação clínica mais rápida, com um risco menor de complicações, bem como redução do tempo de internação.

5. procedimentos alternativos que possam ser vantajosos para o indivíduo: nenhum. 


\section{IV - ESCLARECIMENTOS DADOS PELO PESQUISADOR SOBRE GARANTIAS DO SUJEITO DA PESQUISA:}

1. acesso a qualquer tempo, às informações sobre procedimentos, riscos e benefícios relacionados à pesquisa, inclusive para dirimir eventuais dúvidas SIM.

2. liberdade de retirar seu consentimento a qualquer momento e de deixar de participar do estudo, sem que isto traga prejuízo à continuidade da assistência SIM.

3. salvaguarda da confidencialidade, sigilo e privacidade - SIM.

4. disponibilidade de assistência no HCFMUSP, por eventuais danos à saúde, decorrentes da pesquisa - SIM. Porém a pesquisa não oferece nenhum risco à saúde.

5. viabilidade de indenização por eventuais danos à saúde decorrentes da pesquisa - a pesquisa não oferece nenhum risco à saúde.

\section{INFORMAÇÕES DE NOMES, ENDEREÇOS E TELEFONES DOS RESPONSÁVEIS PELO ACOMPANHAMENTO DA PESQUISA, PARA CONTATO EM CASO DE INTERCORRÊNCIAS CLÍNICAS E REAÇÕES ADVERSAS.}

\section{ENVOLVIDOS NA PESQUISA:}

Nome: Patrícia Zamberlan dos Santos e Prof. Dr. Rubens Feferbaum.

Endereço: Av. Dr. Enéas de Carvalho Aguiar, 647 CEP: 05403-900 SP.

Fone para contato: 30698558, 30698590, 97383719.

\section{OBSERVAÇÕES COMPLEMENTARES:}

\section{VII - CONSENTIMENTO PÓS-ESCLARECIDO}

Declaro que, após convenientemente esclarecido pelo pesquisador e ter entendido o que me foi explicado, consinto em participar do presente Protocolo de Pesquisa.

São Paulo, de de 2

assinatura do sujeito da pesquisa

ou responsável legal assinatura e carimbo do pesquisador 
Anexo C - Instrumento utilizado para a coleta dos dados

PROTOCOLO

1. Identificação

Nome:

RG:

Data de nascimento:

Idade:

Data de internação:

2. História da moléstia atual

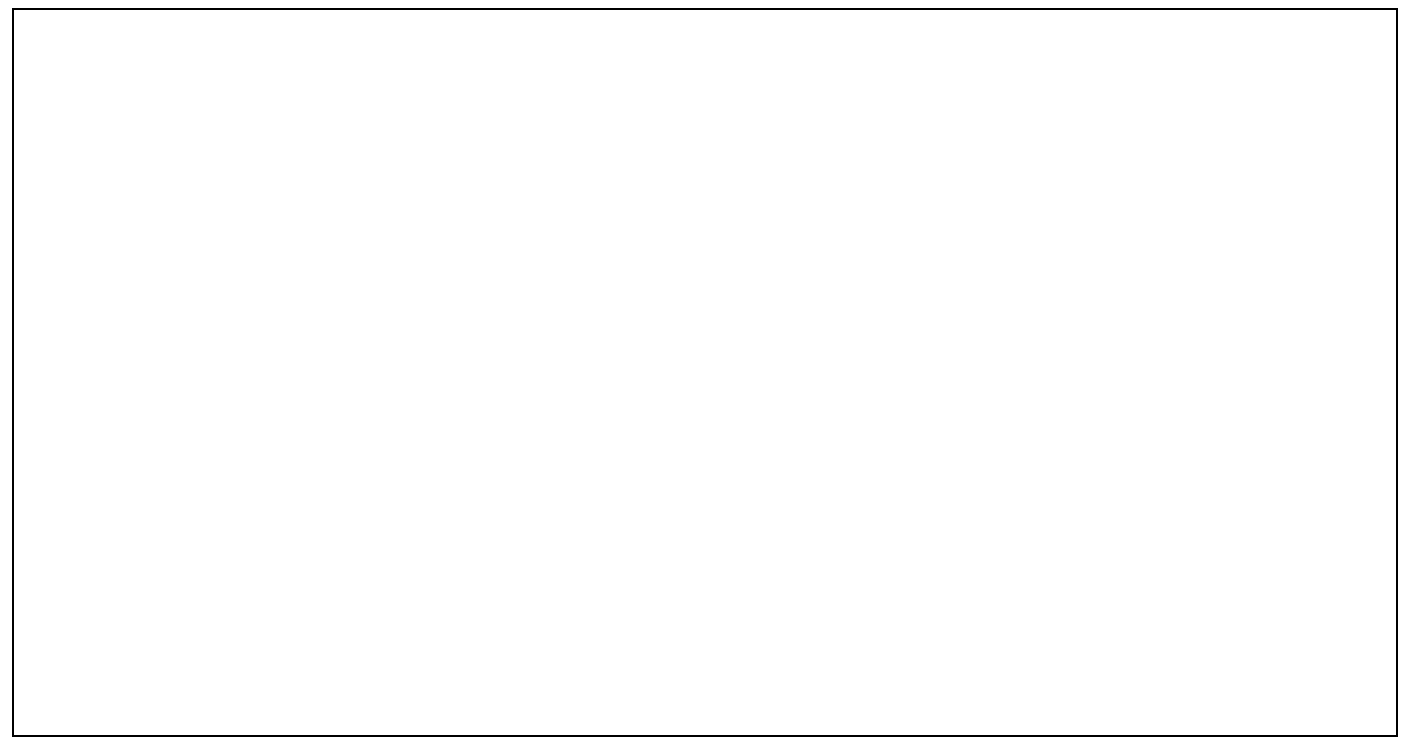

3. Diagnóstico (s) clínico (s) 


\section{Escore de gravidade (PIM)}

\section{Avaliação nutricional}

\begin{tabular}{|c|c|c|c|c|c|}
\hline & Admissão & $7^{\circ}$ dia & & & \\
\hline \multicolumn{6}{|c|}{ Antropometria } \\
\hline \multicolumn{6}{|l|}{ Peso (Kg) (p) } \\
\hline \multicolumn{6}{|c|}{ Estatura/comp (cm) (p) } \\
\hline \multicolumn{6}{|c|}{ IMC (Kg/m2) (p) } \\
\hline \multicolumn{6}{|l|}{ CB (cm) (p) } \\
\hline \multicolumn{6}{|l|}{$\overline{P C T}(m m)(p)$} \\
\hline \multicolumn{6}{|l|}{ CMB (cm) (p) } \\
\hline \multicolumn{6}{|l|}{ AMB (cm2) (p) } \\
\hline \multicolumn{6}{|l|}{ AGB (cm2) (p) } \\
\hline \multicolumn{6}{|c|}{ Impedância bioelétrica } \\
\hline \multicolumn{6}{|c|}{ Resistência (ohms) } \\
\hline \multicolumn{6}{|c|}{ Reactância (ohms) } \\
\hline \multicolumn{6}{|c|}{ Impedância (ohms/cm²) } \\
\hline \multicolumn{6}{|c|}{ Ângulo de fase $\left(^{\circ}\right)$} \\
\hline MLG (Kg) (\%) & (A) & (A) & (A) & (A) & (A) \\
\hline \multicolumn{6}{|l|}{ MG (Kg) (\%) } \\
\hline \multicolumn{6}{|c|}{ Água corporal total (I) } \\
\hline \multicolumn{6}{|l|}{ Intra } \\
\hline Extra & & & & & \\
\hline
\end{tabular}


Anexo D - Análises estatísticas

Correlação entre o estado nutricional e o escore de gravidade (PIM)

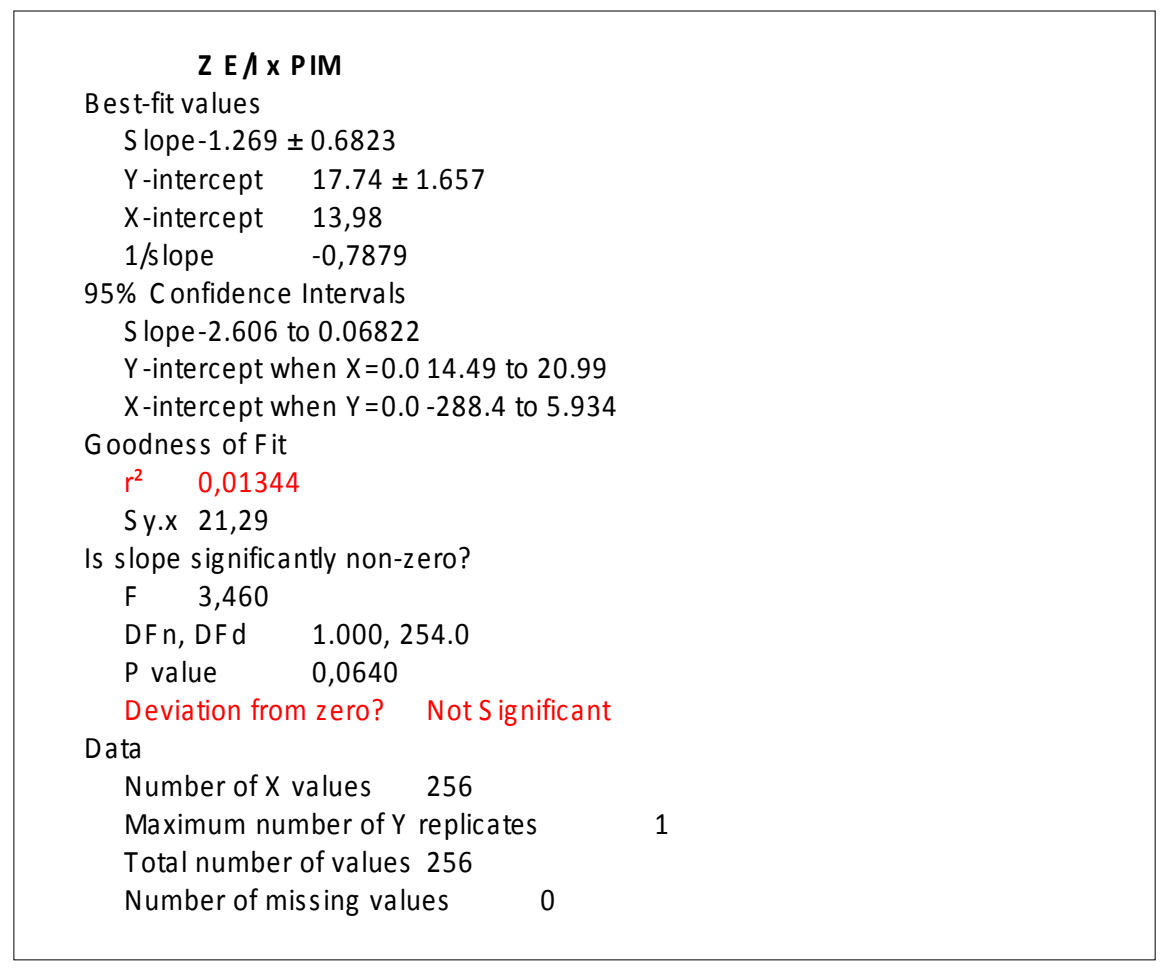

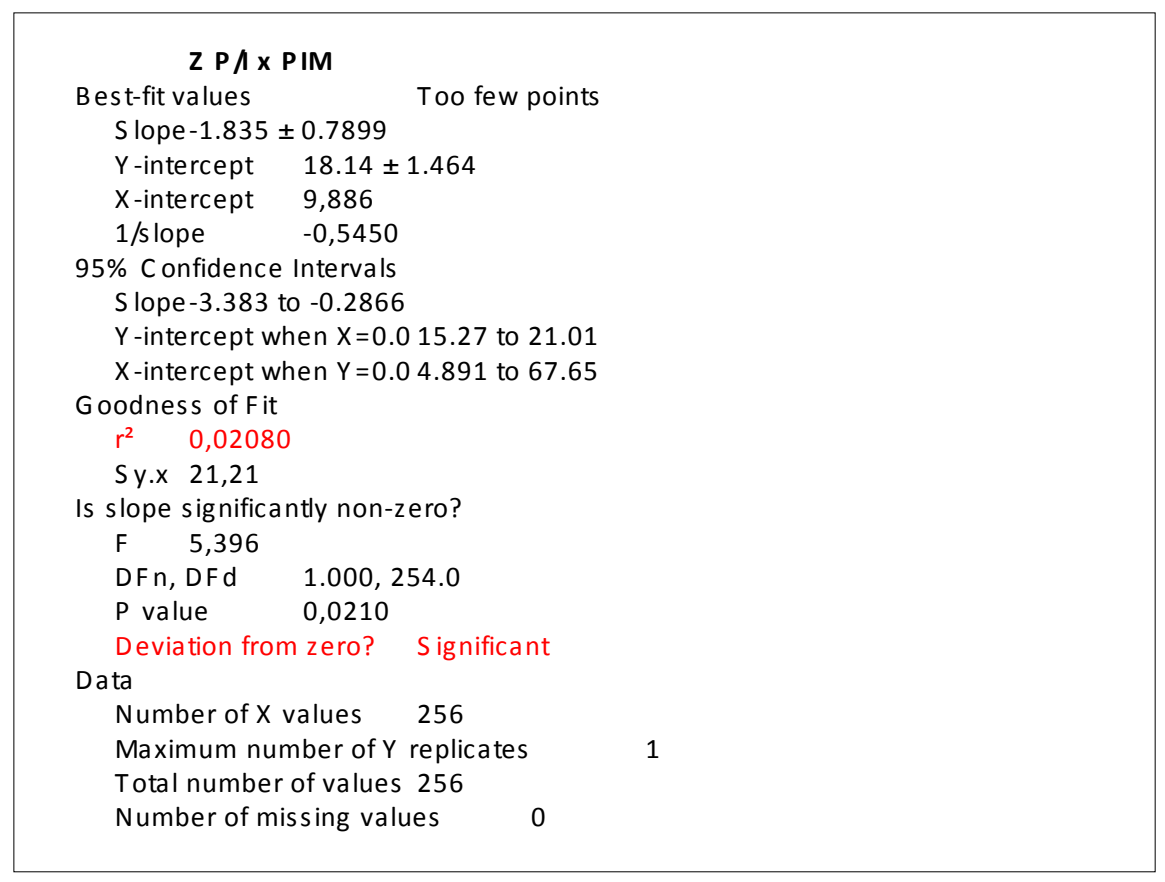




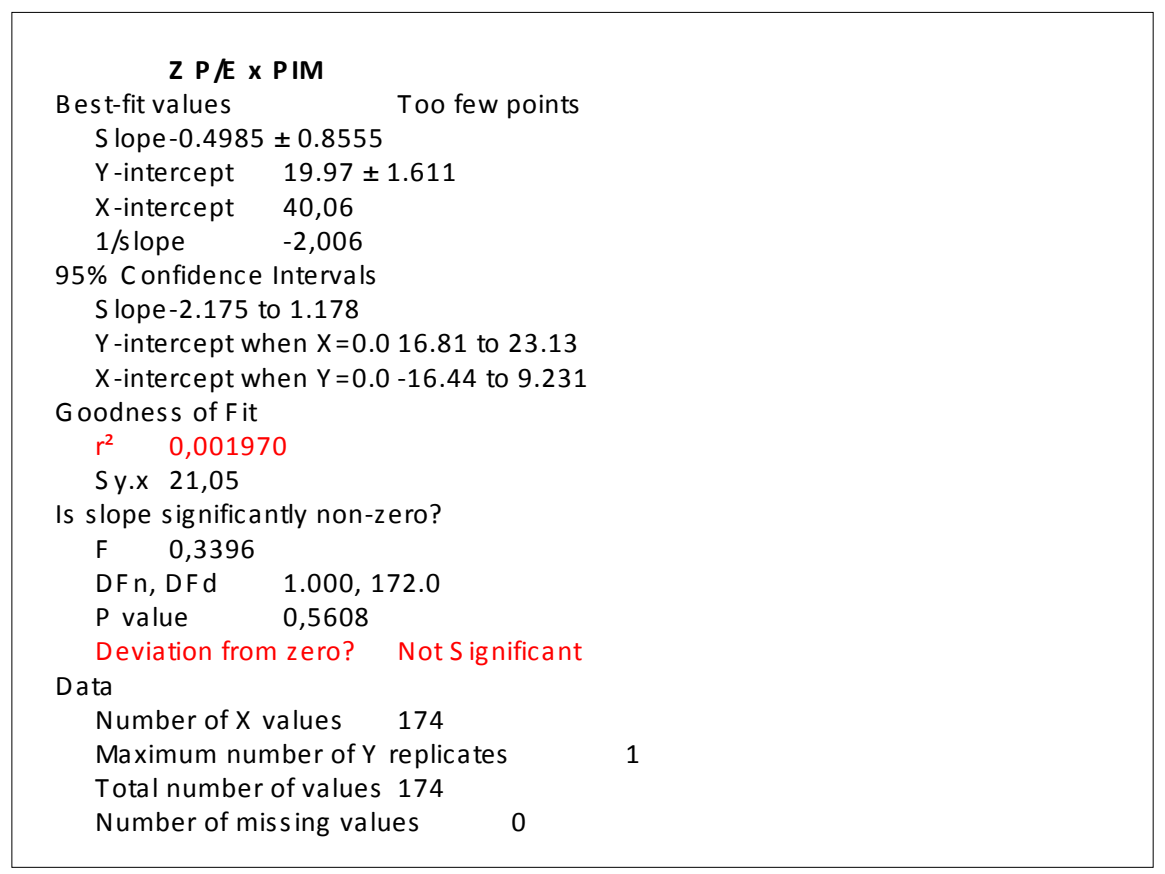

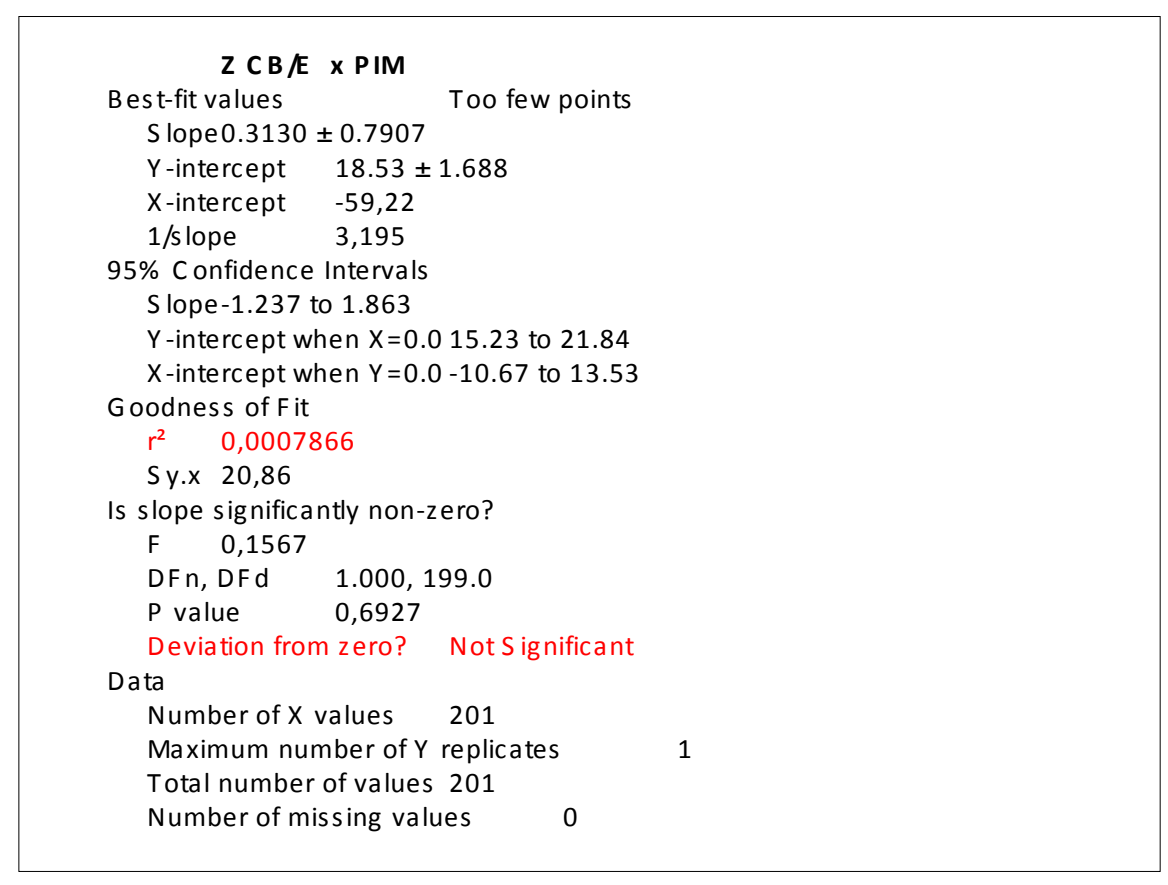


Z IMC $x$ PIM

Best-fit values Too few points

S lope-1.069 \pm 0.7183

$\mathrm{Y}$-intercept $\quad 19.67 \pm 1.335$

$\mathrm{X}$-intercept 18,40

$1 /$ slope $\quad-0,9355$

95\% C onfidence Intervals

S lope-2.477 to 0.3390

$\mathrm{Y}$-intercept when $\mathrm{X}=0.017 .06$ to 22.29

$X$-intercept when $Y=0.0-57.55$ to 7.868

Goodness of Fit

$r^{2} \quad 0,008643$

S y.x 21,34

Is slope significantly non-zero?

F 2,214

DFn, DFd 1.000, 254.0

$P$ value $\quad 0,1380$

Deviation from zero? Not S ignificant

Data

Number of $X$ values 256

Maximum number of $Y$ replicates

1

Total number of values 256

Number of missing values 


\section{Correlação entre o estado nutricional e o tempo de internação}
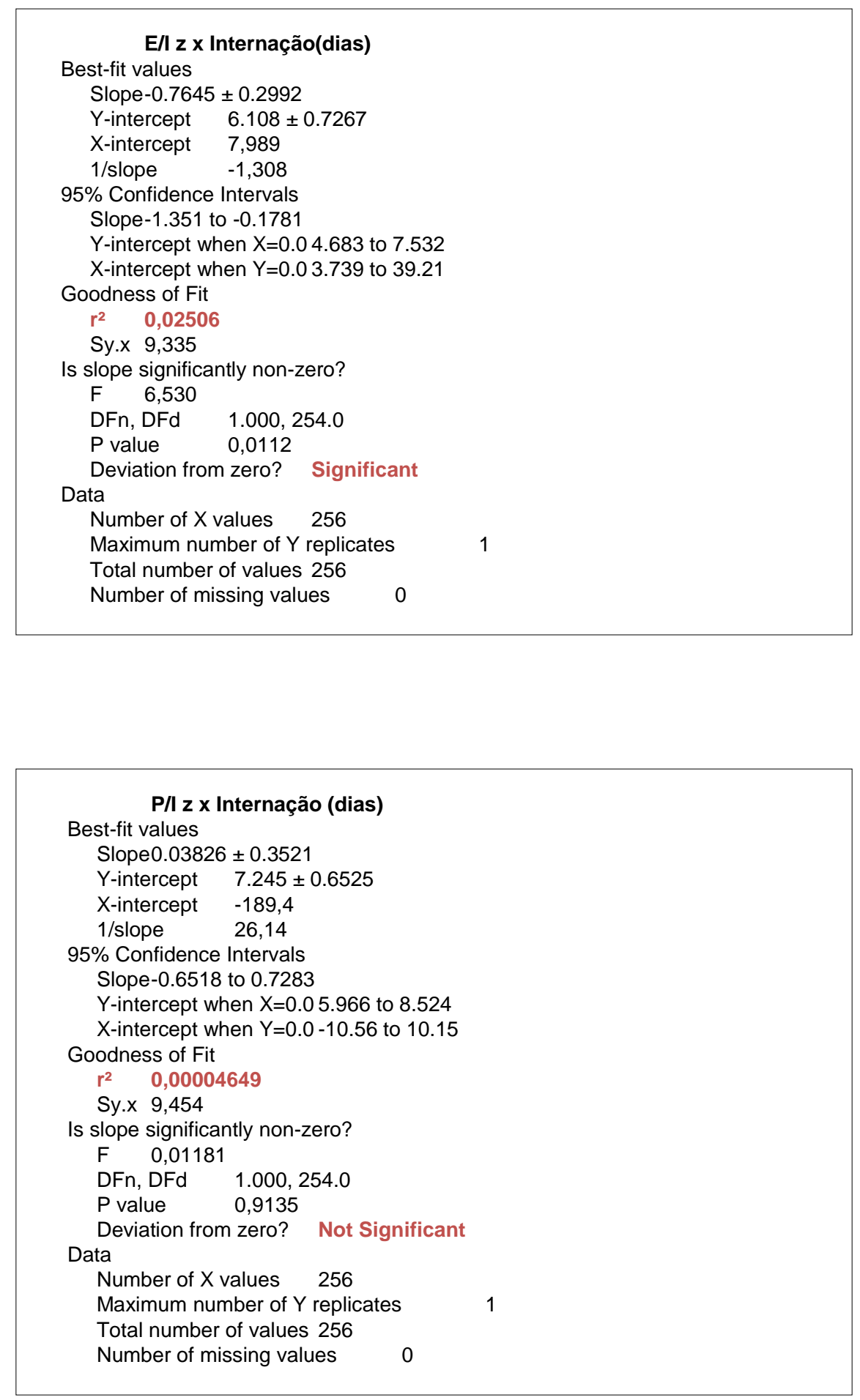
Best-fit values

Slope $1.239 \pm 0.4288$

Y-intercept $\quad 7.734 \pm 0.8076$

X-intercept $\quad-6,242$

$1 /$ slope $\quad 0,8071$

95\% Confidence Intervals

Slope 0.3985 to 2.079

Y-intercept when $X=0.06 .151$ to 9.317

$X$-intercept when $Y=0.0-20.13$ to -3.436

Goodness of Fit

$$
\begin{array}{ll}
r^{2} & 0,04628 \\
\text { Sy.x } & 10,55
\end{array}
$$

Is slope significantly non-zero?

F 8,347

DFn, DFd $\quad 1.000,172.0$

$P$ value $\quad 0,0044$

Deviation from zero? Significant

Data

Number of $X$ values $\quad 174$

Maximum number of $Y$ replicates

Total number of values 174

Number of missing values

\section{IMC/Iz x Internação (dias)}

Best-fit values

Slope $0.8519 \pm 0.3137$

Y-intercept $\quad 7.141 \pm 0.5831$

X-intercept $\quad-8,383$

$1 /$ slope $\quad 1,174$

95\% Confidence Intervals

Slope 0.2371 to 1.467

Y-intercept when $X=0.05 .999$ to 8.284

$X$-intercept when $Y=0.0-30.49$ to -4.687

Goodness of Fit

$r^{2} \quad 0,02822$

Sy.x 9,319

Is slope significantly non-zero?

F 7,376

DFn, DFd $1.000,254.0$

$P$ value $\quad 0,0071$

Deviation from zero? Significant

Data

Number of $X$ values 256

Maximum number of $Y$ replicates

Total number of values 256

Number of missing values 


\section{CB/Ez x Internação (dias)}

Best-fit values

Slope $0.1103 \pm 0.3361$

Y-intercept $\quad 6.901 \pm 0.7176$

$X$-intercept $\quad-62,60$

$1 /$ slope $\quad 9,070$

95\% Confidence Intervals

Slope-0.5485 to 0.7690

$Y$-intercept when $X=0.05 .495$ to 8.308

$X$-intercept when $Y=0.0-9.702$ to 11.16

Goodness of Fit

$r^{2} \quad 0,0005405$

Sy.x 8,867

Is slope significantly non-zero?

F $\quad 0,1076$

DFn, DFd $\quad 1.000,199.0$

$P$ value $\quad 0,7432$

Deviation from zero? Not Significant

Data

Number of $X$ values 201

Maximum number of $Y$ replicates

Total number of values 201

Number of missing values 


\section{Correlação entre o estado nutricional e a mortalidade}

Parameter E/lz Value

Table Analyzed Data 1

Column A Obitos

vs vs

Altas

Mann Whitney test
$P$ value

Exact or approximate $P$ value? Gaussian

Approximation

$P$ value summary ns

Are medians signif. different? $(P<0.05)$ No

One- or two-tailed $P$ value? Two-tailed

Sum of ranks in column A,B 4803, 28093

Mann-Whitney U 4062

Parameter P/lz Value

Table Analyzed Data 1

Column A Obitos

vs vs

Column B Altas

Mann Whitney test

$P$ value 0,7041

Exact or approximate $P$ value? Gaussian Approximation

$P$ value summary ns

Are medians signif. different? $(P<0.05)$

One- or two-tailed $P$ value? Two-tailed

Sum of ranks in column A,B 4723, 28170

Mann-Whitney $U \quad 3982$ 


\section{Parameter P/Ez Value}

Table Analyzed Data 1

Column A Obitos

vs vs

Column B Altas

Mann Whitney test

$P$ value $\quad 0,4210$

Exact or approximate $\mathrm{P}$ value? Gaussian Approximation

$P$ value summary

Are medians signif. different? $(P<0.05)$

No

One- or two-tailed $P$ value?

Two-tailed

Sum of ranks in column A,B 2647, 12578

Mann-Whitney U

1847

\section{Parameter CB/Ez Value}

Table Analyzed Data 1

Column A Obitos

vs vs

Column B Altas

Mann Whitney test
$P$ value
0,0025

Exact or approximate $\mathrm{P}$ value? Gaussian Approximation

$P$ value summary

Are medians signif. different? $(P<0.05) \quad$ Yes

One- or two-tailed $P$ value? Two-tailed

Sum of ranks in column A,B 1965, 18336

Mann-Whitney U 1559 
Parameter IMC/Iz Value

Table Analyzed Data 1

Column A Obitos

vs vs

Altas

Mann Whitney test

$P$ value $\quad 0,8531$

Exact or approximate $P$ value? Gaussian Approximation

$P$ value summary ns

Are medians signif. different? $(P<0.05)$

No

One- or two-tailed $P$ value? Two-tailed

Sum of ranks in column A,B 4962, 27930

Mann-Whitney U

4064 


\section{Avaliação nutricional antropométrica evolutiva}

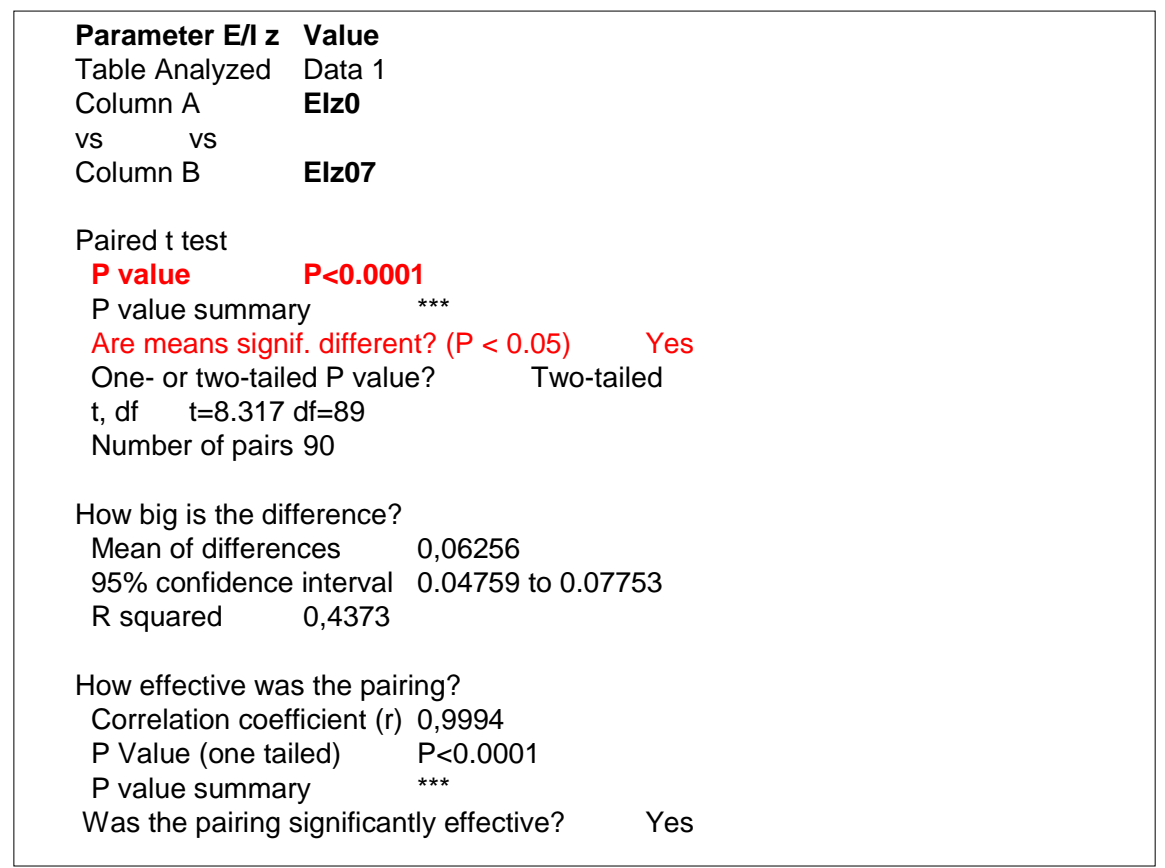

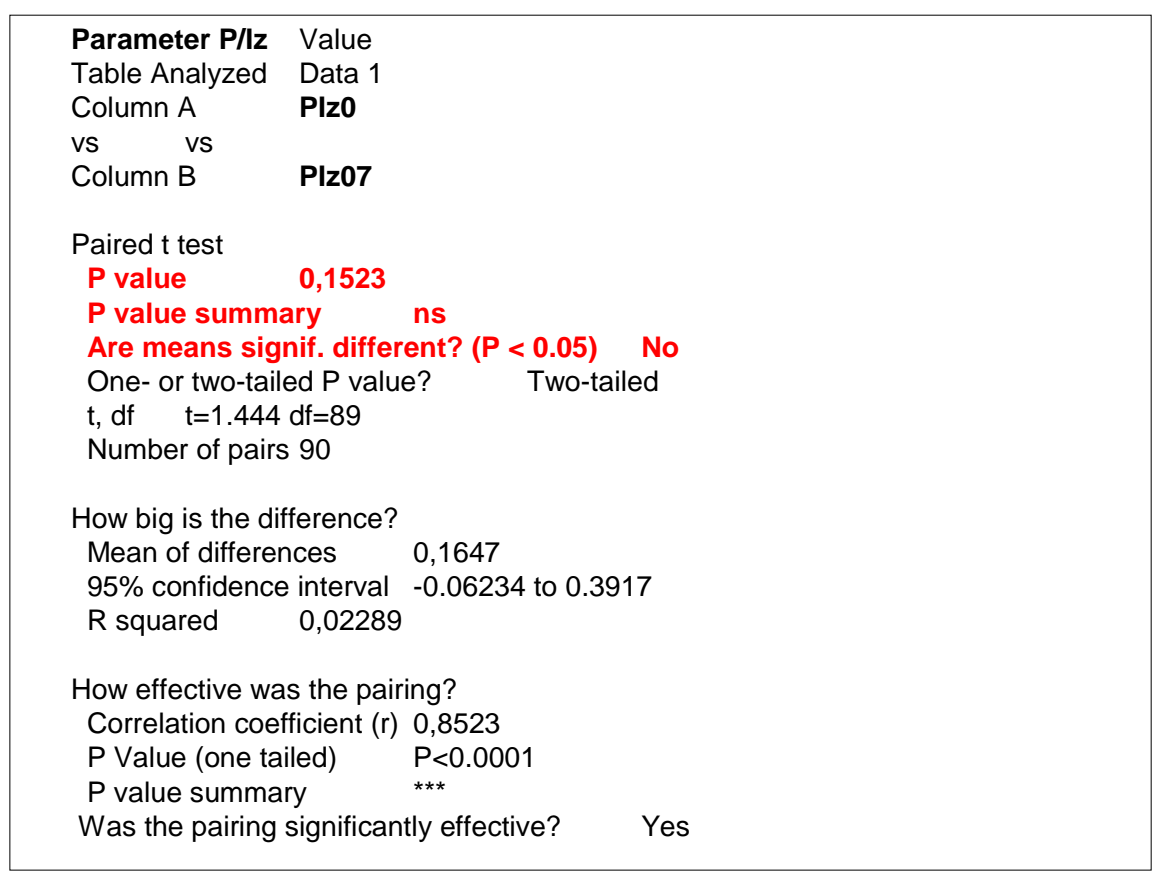




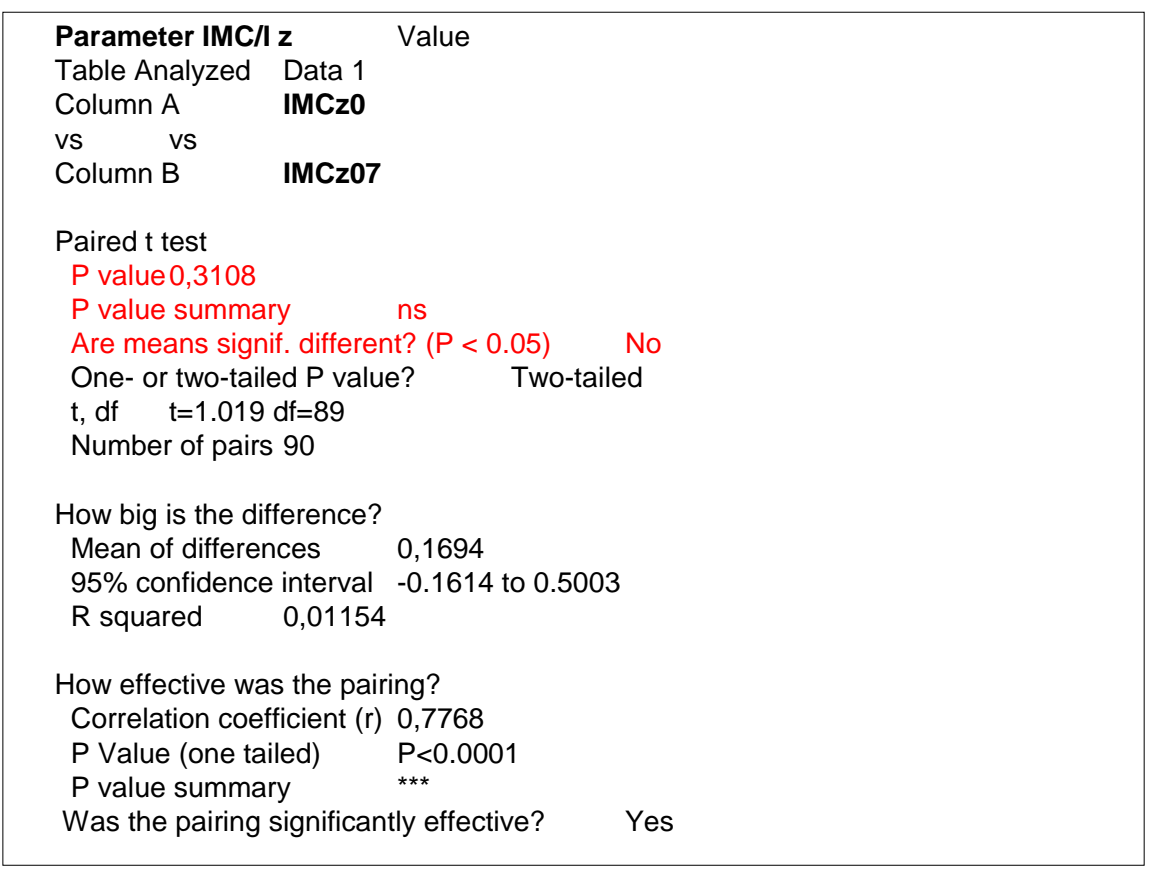

\begin{tabular}{|c|c|c|}
\hline \multicolumn{2}{|c|}{ Parameter CB/Ez } & Value \\
\hline $\begin{array}{l}\text { Table Analyzed } \\
\text { Column A }\end{array}$ & \multicolumn{2}{|c|}{$\begin{array}{l}\text { Data } 1 \\
\text { CBEz0 }\end{array}$} \\
\hline vs vs & & \\
\hline Column B & \multicolumn{2}{|l|}{ CBEz07 } \\
\hline \multicolumn{3}{|l|}{ Paired t test } \\
\hline$P$ value & \multicolumn{2}{|c|}{$P<0.0001$} \\
\hline \multirow{2}{*}{\multicolumn{3}{|c|}{$\begin{array}{l}P \text { value summary } \quad * \star * \\
\text { Are means sianif, different? }(P<0.05) \quad \text { Yes }\end{array}$}} \\
\hline & & \\
\hline $\begin{array}{l}\text { One- or two-tail } \\
t, d f \quad t=4.612 \\
\text { Number of pairs }\end{array}$ & $\begin{array}{l}\text { ed } P \text { value } \\
d f=67 \\
68\end{array}$ & e? Two-tailed \\
\hline \multicolumn{3}{|c|}{ How big is the difference? } \\
\hline \multicolumn{2}{|c|}{ Mean of differences } & 0,5225 \\
\hline \multicolumn{2}{|c|}{$95 \%$ confidence interval } & 0.2962 to 0.7488 \\
\hline $\mathrm{R}$ squared & 0,2410 & \\
\hline \multicolumn{3}{|c|}{ How effective was the pairing? } \\
\hline \multicolumn{3}{|c|}{ Correlation coefficient $(r) \quad 0,8938$} \\
\hline \multirow{2}{*}{\multicolumn{2}{|c|}{$\begin{array}{l}P \text { Value (one tailed) } \\
P \text { value summary }\end{array}$}} & $P<0.0001$ \\
\hline & & *** \\
\hline \multicolumn{3}{|c|}{ Was the pairing significantly effective? } \\
\hline
\end{tabular}


DCT

$22 / 7 / 2008 \quad 11: 23$

Page 1

Wilcoxon matched-pairs signed-ranks test

Does the median of the differences between PCT 0 and PCT 7

differ signficantly from zero?

The two-tailed $\mathrm{P}$ value is < 0.0001 , considered extremely significant.

(The $P$ value is an estimate based on a normal approximation.)

Calculation details

Sum of all signed ranks $(W)=1779.0$

Sum of positive ranks $(\mathrm{T}+)=2469.5$

Sum of negative ranks $(\mathrm{T}-)=-690.50$

Number of pairs $=79$

Note: 12 pairs were excluded from calculations because both

values were equal.

Assumption test: Was the pairing effective?

Nonparametric Spearman correlation coefficient $(r)=0.8752$

The one-tailed $P$ value is $<0.0001$, considered extremely significant.

Effective pairing results in a significant correlation between the

columns. With these data, the pairing (or matching) appears

to be effective.

Summary of Data

$\begin{array}{rrrr}\text { Parameter: } & \text { PCT O } & \text { PCT } 7 & \text { Difference } \\ \text { Mean: } & 9.226 & 8.016 & 1.210 \\ \text { \# of points: } & 91 & 91 & 91 \\ \text { Std deviation: } & 6.148 & 5.186 & 2.395 \\ \text { Std error: } & 0.6445 & 0.5436 & 0.2511 \\ \text { Minimum: } & 2.000 & 1.500 & -4.000 \\ \text { Maximum: } & 38.000 & 32.000 & 9.000 \\ \text { Median: } & 8.000 & 7.500 & 1.000 \\ \text { Lower 958 CI: } & 7.944 & 6.935 & 0.7102 \\ \text { Upper 958 CI: } & 10.509 & 9.098 & 1.710\end{array}$


AMB

$22 / 7 / 200811: 46$

Page 1

Paired t test

Does the mean of the differences between IMB 0 and AMB 7

differ significantly from zero?

$\underline{P}$ value

The two-tailed $P$ value is 0.3529 , considered not significant.

$t=0.9339$ with 90 degrees of freedom.

$95 \%$ confidence interval

Mean difference $=0.2527$ (Mean of paired differences)

The $95 \%$ confidence interval of the difference: -0.2849 to 0.7904

Assumption test: Was the pairing effective?

Correlation coefficient $(r)=0.9335$

The one-tailed $\mathrm{P}$ value is $<0.0001$, considered extremely significant.

Effective pairing results in a significant correlation between the columns.

with these data, the pairing (or matching) appears to be effective.

Assumption test: Are the differences sampled from a Gaussian distribution?

The paired t test assumes that the differences are sampled from a

Gaussian distribution. This assumption is tested using the

method of Kolmogorov and Smirnov:

The Kolmogorov-Smirnov distance (KS) is 0.15

The $P$ value is 0.0406

The data failed the normality test with $\mathrm{P}<0.05$.

Consider using a nonparametric test or transforming the data

(i.e. converting to logarithms or reciprocals).

Summary of Data

\begin{tabular}{rrrr}
\hline \multicolumn{4}{c}{ Summary of Data } \\
Parameter: & AMB 0 & AMB 7 & Difference \\
Mean: & 13.279 & 13.027 & 0.2527 \\
\# of points: & 91 & 91 & 91 \\
Std deviation: & 7.061 & 7.098 & 2.582 \\
Std error: & 0.7401 & 0.7441 & 0.2706 \\
Minimum: & 3.800 & 3.200 & -11.100 \\
Maximum: & 41.000 & 40.000 & 10.700 \\
Median: & 12.000 & 10.900 & 0.4000 \\
Lower 95\% CI: & 11.807 & 11.546 & -0.2858 \\
Upper 95\% CI: & 14.752 & 14.507 & 0.7913
\end{tabular}




\section{CMB}

Does the mean of the differences between CMB 0 and CMB 7

differ significantly from zero?

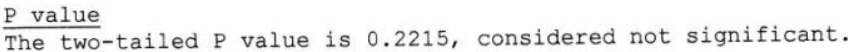

$t=1.231$ with 90 degrees of freedom.

$95 \%$ confidence interval

Mean difference $=0.1412$ (Mean of paired differences)

The $95 \%$ difference: -0.08667 to 0.3691

Assumption test: Was the pairing effective?

Correlation coefficient $(r)=0.9430$

The one-tailed $P$ value is $<0.0001$, considered extremely significant.

Effective pairing results in a significant correlation between the columns.

With these data, the pairing (or matching) appears to be effective.

Assumption test: Are the differences sampled from a Gaussian distribution?

The paired t test assumes that the differences are sampled from a

Gaussian distribution. This assumption is tested using the

method of Kolmogorov and Smirnov:

The Kolmogorov-Smirnov distance (KS) is 0.09

The $\mathrm{P}$ value is $>0.10$ The data passed the normality test with $\mathrm{P}>0.05$.

Summary of Data

\begin{tabular}{rrrr}
\multicolumn{4}{c}{ Summary of Data } \\
\hline Parameter: & CMB 0 & CMB 7 & Difference \\
Mean: & 12.515 & 12.374 & 0.1412 \\
\# of points: & 91 & 91 & 91 \\
Std deviation: & 3.231 & 3.250 & 1.094 \\
Std error: & 0.3387 & 0.3407 & 0.1147 \\
Minimum: & 6.900 & 6.300 & -3.400 \\
Maximum: & 22.700 & 22.400 & 3.200 \\
Median: & 12.300 & 11.700 & 0.2900 \\
Lower 958 CI: & 11.841 & 11.696 & -0.08706 \\
Upper 95\% CI: & 13.189 & 13.052 & 0.3695
\end{tabular}




\section{REFERÊNCIAS}


Agus MS, Jaksic T. Nutritional support of the critically ill child. Curr Opin Pediatr. 2002;14:470-81.

Alievi PT, Carvalho PR, Trotta EA, Mombelli Filho R. The impact of admission to a pediatric intensive care unit assessed by means of global and cognitive performance scales. J Pediatr. 2007;83:488-90.

Alves JGB, Britto LMA, Melo MAS, Oliveira VA. Morbimortalidade no desnutrido grave hospitalizado. $J$ Pediatr. 1988;64:60-1.

Baudouin SV, Evans TW. Nutritional support in critical care. Clin Chest Med. 2003;24:633-44.

Becerra M, Ibáñez S, Castillo C. Nutritional evaluation in hospitalized infants. Rev Chil Pediatr. 1986;57:237-40.

Benedini JM, Zamberlan P. Avaliação e recomendações nutricionais da criança normal. In: Cardoso AL, Delgado AF, Zamberlan P (eds). Nutrologia básica e avançada. São Paulo: Manole; 2009 [no prelo]. 
Berberoglu M. Evaluation of the correlation between serum tumor necrosis factor-alpha and relative body mass index (RBMI) in childhood. $J$ Pediatr Endocrinol Metab. 2001;14:543-7.

Bettler J, Roberts KE. Nutrition assessment of the critically ill child. AACN Clin Issues. 2000;11:498-506.

Briassoulis G, Venkataraman S, Thompson AE. Energy expenditure in critically ill children. Crit Care Med. 2000;28:1166-72.

Briassoulis G, Zavras N, Hatzis T. Malnutrition, nutritional índices, and early enteral feeding in critically ill children. Nutrition. 2001;17:548-57.

Bruun LI, Bosaeus I, Bergstad I, Nygaard K. Prevalence of malnutrition in surgical patients: evaluation of nutritional support and documentation. Clin Nutr. 1999;18:141-7.

Cartwright MM. The metabolic response to stress: a case of complex nutrition support management. Crit Care Nurs Clin N Am. 2004;16:467-87.

Chioléro R, Revelly JP, Tappy L. Energy metabolism in sepsis and injury. Nutrition. 1997;13:45S-51S.

Chumlea WC, Guo SS, Steinbaugh ML. Prediction of stature from knee height for black and white adults and children with application to mobilityimpaired or handicapped persons. J Am Diet Assoc. 1994;94:1385-91. 
Chwals WJ. Overfeeding the critically ill child: fact or fantasy? New Horiz. 1994;2:147-55.

Chwals WJ. Terapia nutricional na criança e no recém-nascido em estresse metabólico. In: Telles Jr M, Leite HP. Terapia nutricional no paciente pediátrico grave. São Paulo: Atheneu; 2005. p.11-40.

Collins S. Using middle upper arm circumference to assess severe adult malnutrition during famine. JAMA. 1996;276:391-5.

Colpan A, Akinci E, Erbay A, Balaban N, Bodur H. Evaluation of risk factors for mortality in intensive care units: a prospective study from a referral hospital in Turkey. Am J Infect Control. 2005;33:42-7.

Correia MI, Waitzberg DL. The impact of malnutrition on morbidity, mortality, length of hospital stay and costs evaluated through a multivariate model analysis. Clin Nutr. 2003;22:235-9.

Correia MITD. Avaliação nutricional de pacientes cirúrgicos. In: Campos ACL. Nutrição em cirurgia. São Paulo: Atheneu; 2001. p.1-13.

Correia MITD. Repercussões da desnutrição sobre a morbi-mortalidade e custos, em pacientes hospitalizados no Brasil [tese]. São Paulo: Faculdade de Medicina, Universidade de São Paulo; 2000. 
Coss-Bu JA, Jefferson LS, Walding D, David Y, Smith EO, Klish WJ. Resting energy expenditure and nitrogen balance in critically ill pediatric patients on mechanical ventilation. Nutrition. 1998;14:649-52.

Coss-Bu JA, Klish WJ, Walding D, Stein F, Smith EOB, Jefferson LS. Energy metabolism, nitrogen balance, and substrate utilization in critically ill children. Am J Clin Nutr. 2001;74:664-9.

Curley MA, Castillo L. Nutrition and shock in pediatric patients. New Horiz. 1998;6:212-25.

Cuthbertson D, Tilstone WJ. Metabolism during the postinjury period. Adv Clin Chem.1969;12:1-55.

de Lorenzo AG, Grau T, Montejo JC, Leyba CO, Santana SR; SENPEBaxter. III Working Meeting SENPE-Baxter: complementary parenteral nutrition in the critically ill patient. Nutr Hosp. 2008;23:203-5.

Delgado AF, Barbieri CP. Avaliação nutricional e metabólica. In: Telles Jr M, Leite HP. Terapia nutricional no paciente pediátrico grave. São Paulo: Atheneu; 2005. p.41-7.

Delgado AF, Kimura HM, Cardoso AL, Uehara D, Carrazza FR. Nutritional follow-up of critically ill infants receiving short term parenteral nutrition. Rev Hosp Clin Fac Med São Paulo. 2000;55:3-8. 
Delgado AF, Okay TS, Leone C, Nichols B, Del-Negro GM, Costa-Vaz FA. Hospital malnutrition and inflammatory response in critically ill children and adolescents admitted to a tertiary intensive care unit. Clinics. 2008;63:35762.

Delgado AF. Avaliação das concentrações de citocinas e suas relações com o estado metabólico e nutricional na criança gravemente doente [tese]. São Paulo: Faculdade de Medicina, Universidade de São Paulo; 2005.

Dimand RJ, Kallas HJ. Metabolic and nutritional support of the critically ill infants and children. In: Mohan OE, Fineman JR (eds). Current concepts in pediatric critical care. California: Society of Critical Care Medicine; 1999. p.38-56.

Earle M Jr, Martinez Natera O, Zaslavsky A, Quinones E, Carrillo H, Garcia Gonzalez E, Torres A, Marquez MP, Garcia-Montes J, Zavala I, GarciaDavila R, Todres ID. Outcome of pediatric intensive care at six centers in Mexico and Ecuador. Crit Care Med. 1997;25:1462-7.

Feferbaum R, Delgado AF, Zamberlan P, Leone C. Challenges of nutritional assessment in pediatric ICU. Curr Opin Clin Nutr Metab Care. 2009;12:24550.

Feferbaum R. Estudo do gasto energético no recém-nascido e lactente com sepse [tese livre-docência]. São Paulo: Faculdade de Medicina, Universidade de São Paulo; 2001. 
Ferreira HS, França AOS. Evolution of nutritional status in hospitalized children. J Pediatr. 2002;78:491-6.

Fonte JCM, Ribeiro P, Rocha RGA. Associação de Medicina Intensiva Brasileira. Terapia nutricional no paciente grave - TENUTI. Rio de Janeiro: Revinter; 2001.

Frisancho AR. Anthropometric standards for the assesment of growth and nutritional status. USA: University Michigan Press, 1999.

Frisancho AR. Triceps skin fold and upper arm muscle size norms for assessment of nutritional status. Am J Clin Nutr. 1974;27:1052-8.

Gemke RJ, van Vught J. Scoring systems in pediatric intensive care: PRISM III versus PIM. Intensive Care Med. 2002;28:204-7.

Giner M, Alessandro L, Meguid M, Gleason J. A correlation between malnutrition and poor outcome in critically ill patients still exist. Nutrition. 1996;12:26-9.

Gómez F. Desnutrition. Bol Med Hosp Infant Mex. 1946;3:543-51.

Hankard R, Bloch J, Martin P, Randrianasolo H, Bannier MF, Machinot S, Cézard JP. Nutritional status and risk in hospitalized children. Arch Pediatr. $2001 ; 8: 1203-8$. 
Hasenboehler E, Williams A, Leinhase I, Morgan SJ, Smith WR, Moore EE, Stahel PF. Metabolic changes after polytrauma: an imperative for early nutritional support. World J Emerg Surg. 2006;4:1-29.

Heidegger CP, Darmon P, Pichard C. Enteral vs. parenteral nutrition for the critically ill patient: a combined support should be preferred. Curr Opin Crit Care. 2008;14:408-14.

Heidegger CP, Romand JA, Treggiari MM, Pichard C. Is it now time to promote mixed enteral and parenteral nutrition for the critically ill patient? Intensive Care Med. 2007;33:963-9.

Hendricks KM, Duggan C, Gallagher L, Carlin AC, Richardson DS, Collier SB, Simpson W, Lo C. Malnutrition in hospitalized pediatric patients. Current prevalence. Arch Pediatr Adolesc Med. 1995;149:1118-22.

Heyward VH, Stolarczyk LM. Avaliação da composição corporal aplicada. São Paulo: Manole; 2000.

Huang YC, Yen CE, Cheng $\mathrm{CH}$, Jih KS, Kan MN. Nutritional status of mechanically ventilated critically ill patients: comparison of different types of nutritional support. Clin Nutr. 2000;19:101-7.

Hulst J, Joosten K, Zimmermann L, Hop W, Van Buuren S, Buller H, Tibboel D, Van Goudoever J. Malnutrition in critically ill children: from admission to 6 months after discharge. Clin Nutr. 2004;23:223-32. 
Israëls T, Chirambo C, Caron HN, Molyneux EM. Nutritional status at admission of children with cancer in Malawi. Pediatr Blood Cancer. $2008 ; 51: 626-8$

Ista E, Joosten K. Nutritional assessment and enteral support of critically ill children. Crit Care Nurs Clin N Am. 2005;17:385-93.

Jellife DB. The assessment of the nutritional status of the community (with special reference to field surveys in developing regions of the world). Monogr Ser World Health Organ. 1966;53:3-271.

Jones GD, Thorburn K, Tigg A, Murdoch IA. Preliminary data: PIM vs PRISM in infants and children post cardiac surgery in a UK PICU. Intensive Care Med. 2000;26:145.

Joosten KF, Hulst JM. Prevalence of malnutrition in pediatric hospital patients. Curr Opin Pediatr. 2008;20:590-6.

Joosten KF, Verhoeven JJ, Hazelzet JA. Energy expenditure and substrate utilization in mechanically ventilated children. Nutrition. 1999;15:444-8.

Kac G, Camacho-Dias P, Silva-Coutinho D, Silveira-Lopes R, Marins VV, Pinheiro $A B$. Length of stay is associated with incidence of in-hospital malnutrition in a group of low-income Brazilian children. Salud Publica Mex. $2000 ; 42: 407-12$. 
Kan MN, Chang HH, Sheu WF, Cheng CH, Lee BJ, Huang YC. Estimation of energy requirements for mechanically ventilated, critically ill patients using nutritional status. Crit Care. 2003;7:108-15.

Keusch GT. The history of nutrition: malnutrition, infection and immunity. $J$ Nutr. 2003;133:336S-40S.

Koletzko B, Goulet O, Hunt J, Krohn K, Shamir R; Parenteral Nutrition Guidelines Working Group; European Society for Clinical Nutrition and Metabolism; European Society of Paediatric Gastroenterology, Hepatology and Nutrition (ESPGHAN); European Society of Paediatric Research (ESPR). 1. Guidelines on Paediatric Parenteral Nutrition of the European Society of Paediatric Gastroenterology, Hepatology and Nutrition (ESPGHAN) and the European Society for Clinical Nutrition and Metabolism (ESPEN), Supported by the European Society of Paediatric Research (ESPR). J Pediatr Gastroenterol Nutr. 2005;41(Suppl2):1-87.

Koletzko B. Pediatric nutrition in practice. Basel: Karger; 2008.

Lavery GG, Glover P. The metabolic and nutritional response to critical illness. Curr Opin Crit Care. 2000;6:233-8.

Lee SY, Gallagher D. Assessment methods in human body composition. Curr Opin Clin Nutr Metab Care. 2008;11:566-572. 
Leite HP, Isatugo MK, Sawaki L, Fisberg M. Anthropometric nutritional assessment of critically ill hospitalized children. Rev Paul Med. 1993;111:309-13.

Leleiko NS, Luder E, Fridman M, Fersei J, Benkov K. Nutritional assessment of pediatric admitted to na acute-care pediatric service utilizing anthropometric measurements. JPEN J Parenter Enteral Nutr. 1986;10:166-8.

Leone C. Avaliação da condição nutricional. In: Nóbrega FJ. Distúrbios da nutrição. Rio de Janeiro: Revinter; 1998. p.65-9.

Long CL, Schaffel N, Geiger JW, Schiller WR, Blakemore WS. Metabolic response to injury and illness: estimation of energy and protein needs from indirect calorimetry and nitrogen balance. JPEN J Parenter Enteral Nutr. $1979 ; 3: 452-6$

Luengas J, Fajardo A, Limón MS, Esquivel S. Evaluación somatométrica de lactentes hospitalizados por algunos procesos infecciosos. Rev Mex Pediatr. 1983;50:385-501.

Marcondes E. Conceito e Nomenclatura. Classificação. Etiopatogenia. In: Marcondes E, Monteiro DM, Barbieri D, Quarentei G, Yunes J, Campos JVM. Desnutrição. São Paulo: Sarvier; 1976. p.3-28. 
Martin CM, Doig GS, Heyland DK, Morrison T, Sibbald WJ; Southwestern Ontario Critical Care Research Network. Multicentre, cluster-randomized clinical trial of algorithms for critical-care enteral and parenteral therapy (ACCEPT). CMAJ. 2004;170:197-204.

Mascarenhas MR, Zemel B, Stallings VA. Nutritional assessment in pediatrics. Nutrition. 1998;14:105-15.

Melgar MG, Huerta SF, Santillán JP, Camarena D, López U. Valoración nutricional antropométrica del paciente hospitalizado. Bol Med Hosp Infant Mex. 1986;4:233-6.

Merrit RJ, Suskind RM. Nutritional survey of hospitalized pediatric patients. Am J Clin Nutr. 1979;32:1320-5.

Monte CMG. Desnutrição: um desafio secular à nutrição infantil. J Pediatr. 2000;76:285-97S.

Mota EM, Garcia PCR, Piva JP, Fritscher CC. A influência da desnutrição na utilização da ventilação mecânica em crianças admitidas em UTI pediátrica. J Pediatr. 2002;78:146-52.

Moura EFA. Estado nutricional de crianças hospitalizadas. J Pediatr. 1990;66:243-6. 
Nandi J, Meguid MM, Inui A, Xu Y, Makarenko IG, Tada T, Chen C. Central mechanisms involved with catabolism. Curr Opin Clin Nutr Metab Care. 2002;5:407-18.

NCHS (National Center for Health Statistic). Growth curves children birth-18. Washington. DC: National Center for Health Statistic; 2000.

Onis M, Frongillo EA, Blössner M. Is malnutrition declining? An analysis of change in levels of child malnutrition since 1980. Bull World Health Organ. 2000;78:1222-33.

Onis M, Yip R, Mei Z. The development of MUAC-for-age reference data recommended by a WHO Expert Committee. Bull World Health Organ. $1997 ; 75: 11-8$

Pawellek I, Dokoupil K, Koletzko B. Prevalence of malnutrition in paediatric hospital patients. Nutrition. 2008;27:72-6.

Pelletier D, Frongillo Jr A, Habicht JP. Epidemiologic evidence for a potentiating effect of malnutrition on child mortality. Am J Public Health. 1993;83:1130-3.

Pichard C, Kyle UG, Morabia A, Perrier A, Vermeulen B, Unger P. Nutritional assessment: lean body mass depletion at hospital admission is associated with an increased length of stay. Am J Clin Nutr. 2004;79:613-8. 
Plank LD, Hill GL. Energy balance in critical illness. Proc Nutr Soc. $2003 ; 62: 545-52$.

Pollack M. Escore de risco de mortalidade pediátrica. In: Piva J, Carvalho PR, Garcia PC (eds). Terapia intensiva em pediatria. Rio de Janeiro: Editora Medsi; 1992. p.689-702.

Pollack MM, Ruttimann UE, Wiley JS. Nutritional depletions in critically ill children: associations with physiologic instability and increased quantity of care. JPEN J Parenter Enteral Nutr. 1985;9:309-13.

Pollack MM, Wiley JS, Holbrook PR. Early nutritional depletion in critically ill children. Crit Care Med. 1981;9:580-3.

Pollack MM, Wiley JS, Kanter R, Holbrook PR. Malnutrition in critically ill infants and children. JPEN J Parenter Enteral Nutr. 1982;6:20-4.

Ravasco P, Camilo ME, Gouveia-Oliveira A, Adam S, Brum G. A critical approach to nutritional assessment in critically ill patients. Clin Nutr. $2002 ; 21: 73-7$.

Rocker G, Cook D, Sjokvist P, Weaver B, Finfer S, McDonald E, Marshall J, Kirby A, Levy M, Dodek P, Heyland D, Guyatt G; Level of Care Study Investigators; Canadian Critical Care Trials Group. Clinician predictions of intensive care unit mortality. Crit Care Med. 2004;32:1149-54. 
Romaldini CC, Margarido MT, Bueno L, Tanikawa CE, Cardoso AL, Carrazza FR. Avaliação do estado nutricional de crianças hospitalizadas. Rev Paul Pediatr. 1996;14:149-52.

Schofield C, Ashworth A. Why have mortality rates for severe malnutrition remained so high? Bull World Health Organ. 1996;74:223-9.

Seltzer MH, Fletcher HS, Slocum BA, Engler PE. Instant nutritional assessment. JPEN J Parenter Enteral Nutr. 1979;3:157-9.

Shann F, Pearson G, Slater A, Wilkinson K. Paediatric index of mortality (PIM): a mortality prediction model for children in intensive care. Intensive Care Med. 1997;23:201-7.

Shew SB, Jacsik T. The metabolic needs of critically ill children and neonates. Semin Pediatr Surg. 1999;8:131-9.

Silveira CRM, Mello ED, Carvalho PRA. Evolution of nutritional status of pediatric in patients of a tertiary care general hospital in Brazil. Nutr Hosp. 2008;23:599-606.

Skillman HE, Wischmeyer PE. Nutrition therapy in critically ill infants and children. JPEN J Parenter Enteral Nutr. 2008;32:520-34.

Slater A. Monitoring outcome in paediatric intensive care. Paediatr Anaesth. $2004 ; 14: 113-6$. 
Slone DS. Nutritional support of the critically ill and injured patient. Crit Care Clin. 2004;20:135-57.

Soler-Cataluña JJ, Sánchez-Sánchez L, Martínez-García MA, Sánchez PR, Salcedo E, Navarro M. Mid-arm muscle area is a better predictor of mortality than body mass index in COPD. Chest. 2005;128:2108-15.

Stratton RJ, Elia M. Who benefits from nutritional support: what is the evidence? Eur J Gastroenterol Hepatol. 2007;19:353-8.

Sungurtekin $\mathrm{H}$, Sugurtekin $\mathrm{U}$, Oner $\mathrm{O}$, Okke $\mathrm{D}$. Nutrition assessment in critically ill patients. Nutr Clin Pract. 2008;23:635-41.

Tibby SM, Taylor D, Festa M, Hanna S, Hatherill M, Jones G, Habibi P, Durward A, Murdoch IA. A comparison of three scoring systems for mortality risk among retrieved intensive care patients. Arch Dis Child. 2002;87:421-5.

Turi RA, Petros AJ, Eaton S, Fasoli L, Powis M, Basu R, Spitz L, Pierro A. Energy metabolism of infants and children with systemic inflammatory response syndrome and sepsis. Ann Surg. 2001;233:581-7.

Vasquez-Garibay EM, Sandoval-Galindo DM, Kumazawa-Ichikawa MR, Romero-Velarde E, Nápoles-Rodrígues F. The nutritional status of the child entering the Nuevo Hospital Civil de Guadalajara. Bol Med Hosp Infant Mex. 1993;50:383-93. 
Vella V, Tomkins A, Borghesi A, Migliori GB, Ndiku J, Adriko BC. Anthropometry and childhood mortality in northwest and southwest Uganda. Am J Public Health. 1993;83:1616-8.

Waitzberg DL, Caiaffa WT, Correia MITD. Hospital malnutrition: the Brazilian national survey (IBRANUTRI): a study of 4000 patients. Nutrition. 2001;17:573-80.

Waitzberg DL, Rodrigues JG, Correia MITD. Desnutrição hospitalar no Brasil. In: Waitzberg DL. Nutrição oral, enteral e parenteral na prática clínica. 3a ed. São Paulo: Atheneu; 2000. p.385-98.

Waterlow JC. Classification and definition of protein calorie malnutrition. Brit Med J. 1972;3:566-9.

Waterlow JC. Protein-energy malnutrition: the nature and extent of the problem. Clin Nutr. 1997;16(Suppl):3-9.

Weinsier RL, Hunker EM, Krumdieck CL, Butterworth CE Jr. Hospital malnutrition. A prospective evaluation of general medical patients during the course of hospitalization. Am J Clin Nutr. 1979;32:418-26.

Wells JC, Fewtrell MS. Is body composition important for paediatricians? Arch Dis Child. 2008;93:168-72.

Wolfe RR. Sepsis as a modulator of adaptation to low and high carbohydrate and low and high fat intakes. Eur J Clin Nutr. 1999;53:136S-42S. 
World Health Organization. Multicentre Growth Reference Study Group. WHO Child Growth Standards based on length/height, weight and age. Acta Paediatr. 2006;450:76-85S.

World Health Organization. Physical status: the use and interpretation of anthropometry. Report of a WHO Expert Commitee. Geneva: World Health Organization; 1995. (WHO Technical Report Series 854).

Yeong LS, Dympna G. Assessment methods in human body composition. Curr Opin Clin Nutr Metab Care. 2008;11:566-72.

Zemel BS, Riley EM, Stallings VA. Evaluation of methodology for nutritional assessment in children: anthropometry, body composition, and energy expenditure. Annu Rev Nutr. 1997;17:211-35. 